Florida International University FIU Digital Commons

\title{
An Assessment of The Role of Crime Prevention Through Environmental Design (CPTED) in Campus Safety
}

Auzeen Shariati

Florida International University, ashar028@fiu.edu

DOI: 10.25148 /etd.FIDC001947

Follow this and additional works at: https://digitalcommons.fiu.edu/etd

Part of the Public Affairs, Public Policy and Public Administration Commons

\section{Recommended Citation}

Shariati, Auzeen, "An Assessment of The Role of Crime Prevention Through Environmental Design (CPTED) in Campus Safety" (2017). FIU Electronic Theses and Dissertations. 3391.

https://digitalcommons.fiu.edu/etd/3391 


\section{FLORIDA INTERNATIONAL UNIVERSITY}

Miami, Florida

AN ASSESSMENT OF THE ROLE OF CRIME PREVENTION THROUGH ENVIRONMENTAL DESIGN (CPTED) IN CAMPUS SAFETY

A dissertation submitted in partial fulfillment of the

requirements for the degree of

DOCTOR OF PHILOSOPHY

in

PUBLIC AFFAIRS

by

Auzeen Shariati

2017 
To: Dean John F. Stack, Jr.

Steven J. Green School of International and Public Affairs

This dissertation, written by Auzeen Shariati, and entitled An Assessment of the Role of Crime Prevention through Environmental Design (CPTED) in Campus Safety, having been approved in respect to style and intellectual content, is referred to you for judgment.

We have read this dissertation and recommend that it be approved.

Nadja Schreiber-Compo

Sukumar Ganapati

Hai Guo

N. Emel Ganapati, Co-Major Professor

Rob T. Guerette, Co-Major Professor

Date of Defense: June 26, 2017

The dissertation of Auzeen Shariati is approved.

Dean John F. Stack, Jr. Steven J. Green School of International and Public Affairs

Andrés G. Gil

Vice President for Research and Economic Development and Dean of the University Graduate School

Florida International University, 2017 


\section{DEDICATION}

This dissertation is gratefully dedicated to my family, Shanaz, Kamal, and Pooya Shariati, for their endless support, patience, encouragement, and most of all love. I could not have survived this journey without them. 


\section{ACKNOWLEDGMENT}

I wish to thank the members of my dissertation committee-Dr. Hai Guo, Dr. Sukumar Ganapati, and Dr. Nadja Schreiber-Compo-for their time, guidance and support throughout the process. I would also like to thank my co-advisor, Dr. N. Emel Ganapati, for her kindness, patience, and enthusiasm, which helped me discover my passion and strive to achieve it. Finally, I would like to express special gratitude to my chair and mentor, Dr. Rob Guerette, for his unwavering support, insightful advice, and generous help, which enabled me to pursue my academic goals. Thank you all for everything.

I wish to acknowledge the financial support of the FIU Dissertation Evidence Acquisition (DEA) Fellowship and Dissertation Year Fellowship (DYF), which allowed me to focus on my dissertation for three consecutive semesters. I would also like to recognize the financial support of the Morris and Anita Broad Research Award (FIU), which contributed to my data collection efforts and facilitated the completion of this endeavor.

Lastly, I thank Florida International University and the Departments of Public Administration and Criminal Justice for providing assistance and resources, which were instrumental in the completion of this work. 


\section{ABSTRACT OF THE DISSERTATION \\ AN ASSESSMENT OF THE ROLE OF CRIME PREVENTION THROUGH \\ ENVIRONMENTAL DESIGN (CPTED) IN CAMPUS SAFETY}

by

Auzeen Shariati

Florida International University, 2017

Miami, Florida

\section{Professor Rob T. Guerette, Co-Major Professor \\ Professor N. Emel Ganapati, Co-Major Professor}

The use of crime prevention initiatives on American college campuses has rapidly increased in the past three decades as high profile crime incidents continue to erode the public's perception of universities as sanctuaries - isolated from criminal activity. Crime Prevention Through Environmental Design (CPTED) is an environmental approach to crime prevention that refers to strategies that focus on reducing crime opportunities by manipulating the physical and social qualities of the environment. Although empirical research on CPTED is growing, little is known about the impact of this method on educational settings. The main argument of the present study is that CPTED has the potential to foster campus safety by reducing crime and increasing the perception of safety. Based on findings from previous studies, it is expected that universities with higher level of CPTED are more likely to have lower crime rates, and students residing in high CPTED campus facilities are more likely to have higher perception of safety.

To test the hypothesized effect, a content analysis of the annual safety reports of 100 postsecondary institutions in the United States was conducted. In addition, the 
residents of two dormitories of a university were surveyed to assess their safety perceptions. Furthermore, a case study was conducted in a college campus with a systematic deployment of the CPTED approach. In-depth interviews, one focus group, insite observations, and analysis of secondary data were performed to contextualize the study findings.

Although the quantitative analysis of the national review of the annual safety reports did not provide evidence in support of the hypothesized effect, it uncovered a reverse relationship between crime rate and use of environmental crime prevention measures. The results of the survey of students' perception of safety, on the other hand, revealed evidence in support of the second hypothesis of the dissertation. Furthermore, the qualitative case study analysis provided insight into the implementation procedures, strengths, and challenges of the systematic CPTED program. The main findings show how CPTED works in the academic context and what alterations are needed to advance the program. 


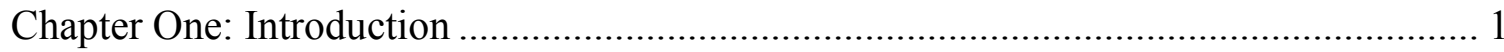

Background of the Problem................................................................................ 2

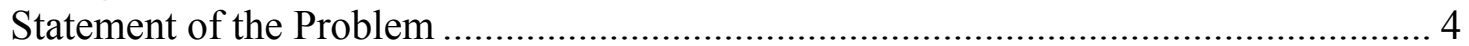

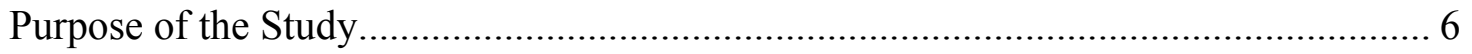

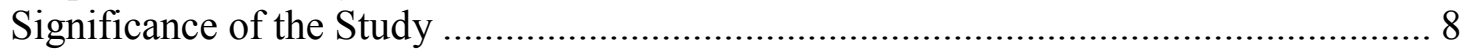

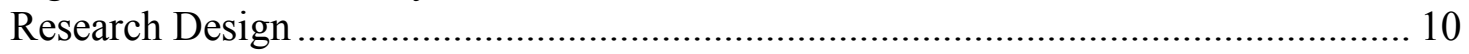

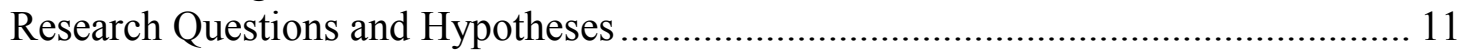

Conceptual Framework ……………………………………………………... 12

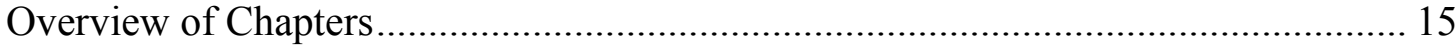

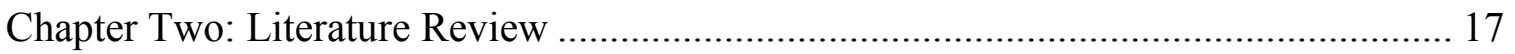

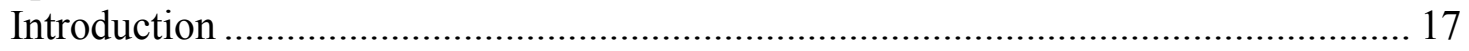

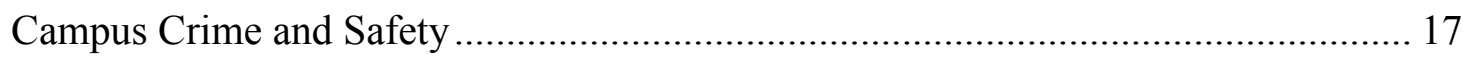

Historical Evolution of CPTED ........................................................................ 19

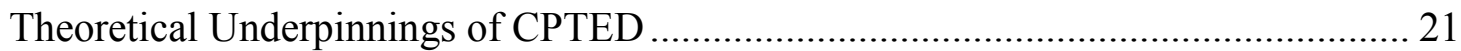

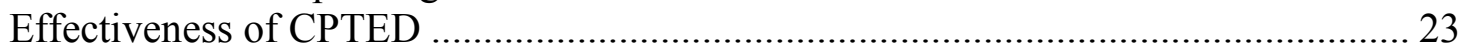

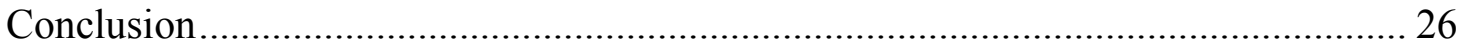

Chapter Three: National Assessment of the Role of CPTED in Campus Safety ............. 28

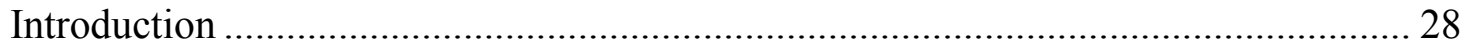

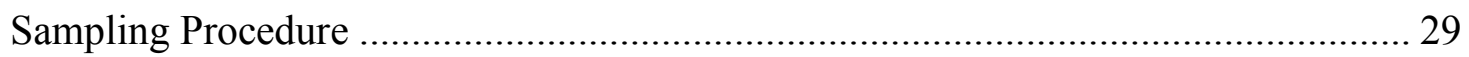

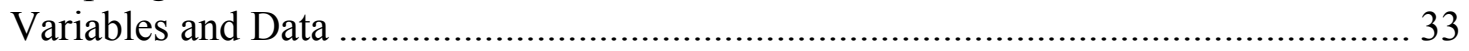

Operationalization of the CPTED Variables ............................................................. 36

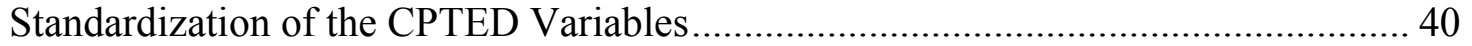

Operationalization of Non-CPTED Control Variables ……………………………..... 41

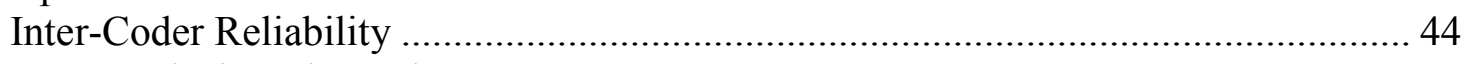

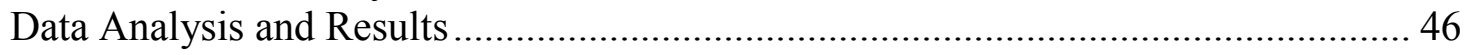

Discussion and Conclusion .................................................................................... 54

Chapter Four: An Analysis of the Relation Between CPTED and Perception of Safety . 57

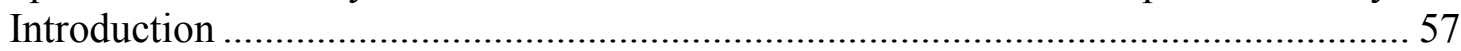

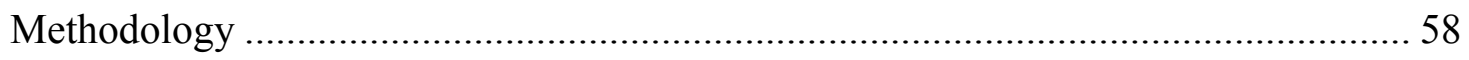

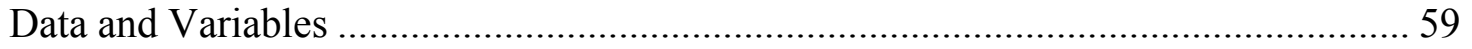

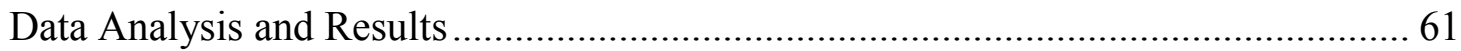

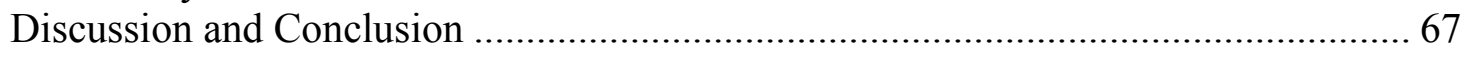

Chapter Five: A Case Study on the Application of CPTED in a College Campus .......... 70

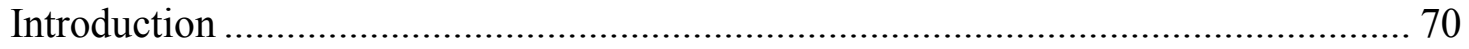

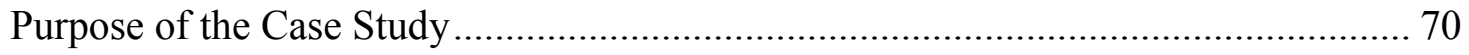

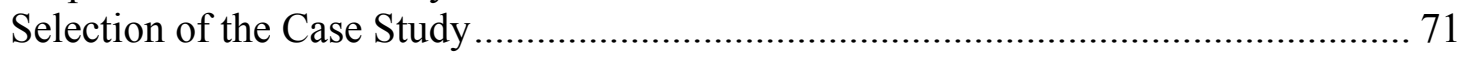


Data Collection ......................................................................................... 73

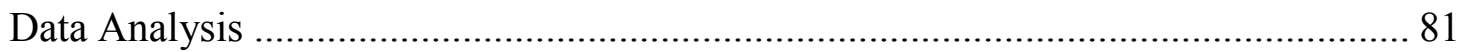

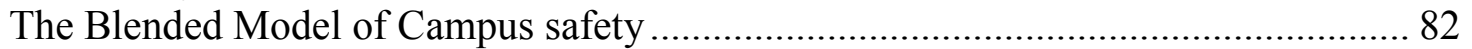

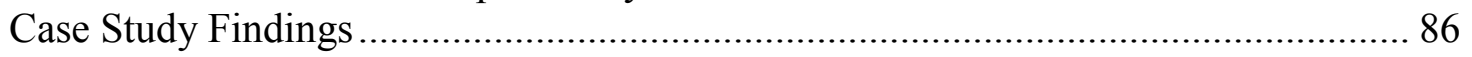

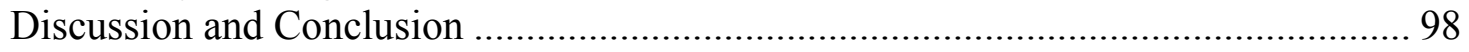

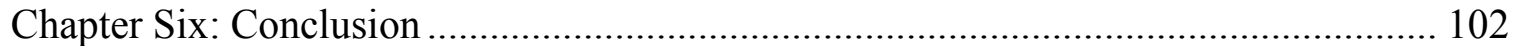

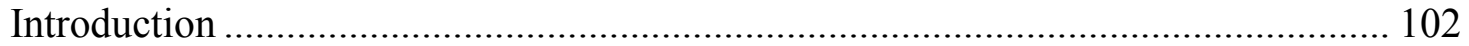

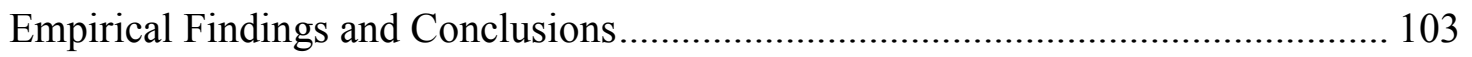

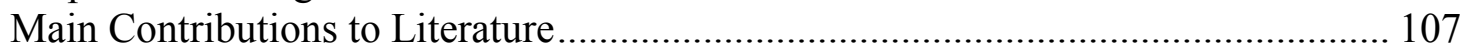

Strengths, Limitations and Opportunities for Future Research ............................. 108

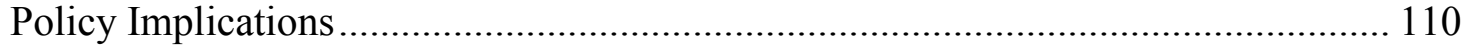

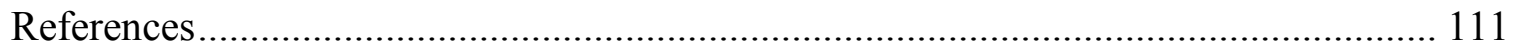

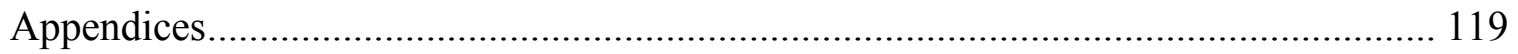

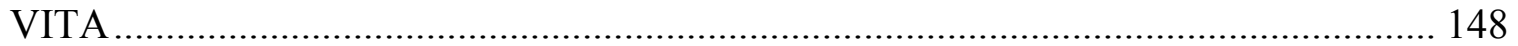




\section{LIST OF TABLES}

TABLE

PAGE

Table 1: Sampling: Justification of Number of Sampled Schools within the Strata ........ 31

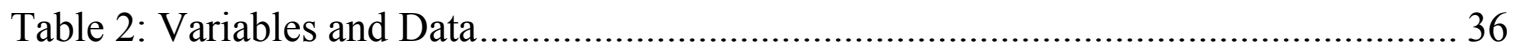

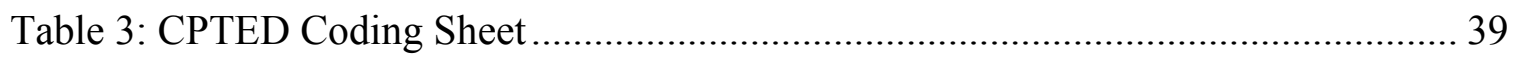

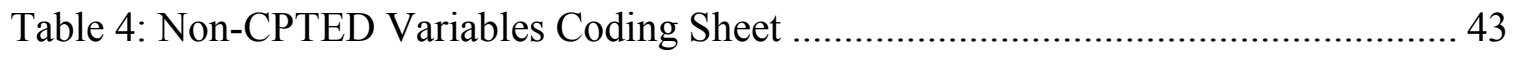

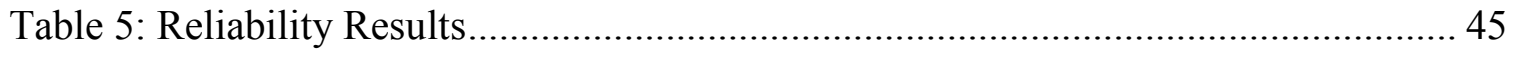

Table 6: Descriptive Statistics of Variables Used in the Analyses ............................... 48

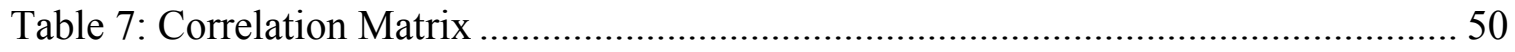

Table 8: Regression Models Explaining Campus Crime …....................................... 52

Table 9: Regression Models Explaining CPTED Application ..................................... 53

Table 10: Descriptive Statistics of the Variables Used in the Analyses ......................... 62

Table 11: Regression Models Explaining Perception of Safety ................................... 64

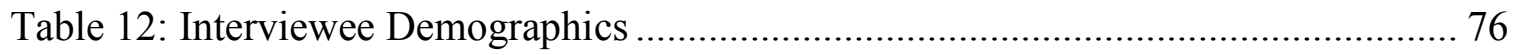

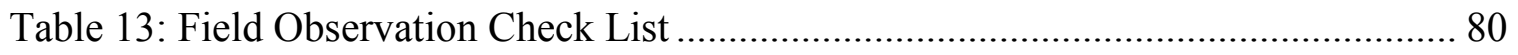




\section{LIST OF FIGURES}

FIGURE

PAGE

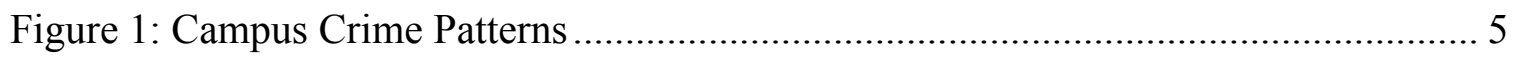

Figure 2: Conceptual Framework for CPTED Strategies .......................................... 15

Figure 3: Census Regions and Divisions of the United Sates...................................... 29

Figure 4: Distribution of Sampled Universities Across the U.S................................. 33

Figure 5: Level of CPTED Application Across Sampled Universities........................... 47

Figure 6: Variability of CPTED Strategies Across the Sample .................................... 49

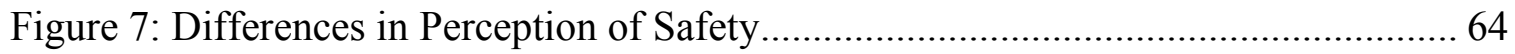

Figure 8: Blended Model of Campus Safety....................................................... 83

Figure 9: Colorado College CPTED Program ............................................................ 86 


\section{LIST OF ABBREVAITIONS AND ACRONYMS}

$\begin{array}{ll}\text { BJS } & \text { Bureau of Justice Statistics } \\ \text { CC } & \text { Colorado College } \\ \text { CPT } & \text { Crime Pattern Theory } \\ \text { CPTED } & \text { Crime Prevention through Environmental Design } \\ \text { DOE } & \text { Department of Education } \\ \text { DOJ } & \text { Department of Justice } \\ \text { FBI } & \text { Federal Bureau of Investigation } \\ \text { FIU } & \text { Florida International University } \\ \text { NCS } & \text { National Crime Survey } \\ \text { NCVS } & \text { National Crime Victimization Survey } \\ \text { RAA } & \text { Routine Activity Approach } \\ \text { RCP } & \text { Rational Choice Perspective } \\ \text { SCP } & \text { Situational Crime Prevention } \\ \text { UA } & \text { University Apartments } \\ \text { UCR } & \text { Uniform Crime Reports } \\ \text { UT } & \text { University Towers }\end{array}$




\section{Chapter One: Introduction}

The issues of crime and violence on American college campuses have existed since the first institutions of higher learning were established in the United States; however, they had not been raised as a social concern until the late 1980s. Several fatal incidents that resulted in criminal proceedings shattered the historical image of universities as being sanctuaries and led to a new standard of legal responsibility, which held schools liable when appropriate protection measures were lacking for campus communities (Smith, 1989). Thus, campus crime is no longer considered a private problem solely related to victims and individual institutions. Researchers, advocacy groups, student victims, and their families have fought a long battle to bring this issue to the attention of legislators, policy-makers, and the general public (Sloan \& Fisher, 2011; Tewksbury, 2013).

Although universities are expected to provide safe learning environments that facilitate students' success, they are susceptible to crime and violence due to several reasons. The population structure of universities is mainly composed of young individuals, and this can be associated with higher risk of exposure to—or engagement in —unlawful activities. The stressful situations that students might face during their academic life can also aggravate these circumstances, particularly if the students are away from their families. Additionally, most college campuses are designed to be open to the public, which may entice intruders to prey on students (Heilbrun, Dvoskin, \& Heilbrun, 2009).

Victimization research has shown that crime victims are likely to experience lower quality of life due to impaired social, occupational, and interpersonal functioning (Hanson, Sawyer, Begle, \& Hubel, 2010). In educational settings, the findings of well-established 
research suggest that on-campus victimization results in physical and mental disorders such as chronic pain and anxiety, as well as malfunction in the social, family, and work realms (Jordan, Combs, \& Smith, 2014). Furthermore, campus victimization gives rise to indirect consequences on the broader campus community, including victims' circles of acquaintances, crime witnesses, and interventionists (Pezza \& Bellotti, 1995).

The traumatic nature of on-campus victimization, particularly in the case of highprofile massacres, intensifies reactions to this issue. In spite of their relatively low base rate, college mass-killings continue to spark intense debates on the importance of campus safety, highlighting the need for effective strategies to reduce tragedies of this kind (Heilbrun et al., 2009). A study on the Virginia Tech (2007) and Northern Illinois University (2008) mass-shootings revealed that fear of crime at another university has significantly increased following these incidents (Kaminski, Koons-Witt, Thompson, \& Weiss, 2010). To address these concerns, various task forces have been organized to provide recommendations for proactive strategies to prevent college campus violence (Fox \& Savage, 2009).

\section{Background of the Problem}

In the late 1980s, the heinous murder of a 19-year-old student at Lehigh University, in Pennsylvania, led to national campaigns demanding transparency on campus crime and security (Janosik \& Gregory, 2003). In 1986, Jeanne Clery, who was a college freshman at the time, was attacked, raped, and killed by another student while she was sleeping in her residential dormitory. The Clery family soon realized that the risk of violence and victimization was foreseeable due to evident failures in the security features of the campus. 
Resultantly, Lehigh University was held liable in a lawsuit brought by the Clerys, laying the foundation for enactment of laws on campus safety (Fisher \& Sloan, 2013).

This tragic event has been a defining moment in the history of campus safety initiatives. The Jeanne Clery Disclosure of Campus Security Policy and Campus Crime Statistics Act, also known as "Clery Act," was passed in 1990. This Federal law requires all institutions of higher education that participate in Federal financial aid programs, referred to as Title IV universities, to report their campus crime statistics in annual safety reports (herein referred to as Clery Reports) and to devise crime prevention programs to protect campus communities.

Prior to the passage of this law, only a few empirical studies had investigated campus crime and its predictors. Pioneering case studies by Kirkpatrick and Kanin (1957) and Kanin $(1967,1970,1977)$ were the initial efforts to examine college campus victimization (Fisher \& Sloan, 2013). These early case studies examined sexual violence perpetrated by male college students against female students. In the Pre-Clery era, another seminal research study by Koss, Gidycz, and Wisniewski (1987) assessed the prevalence of sexual violence and victimization in a national sample of university students. This study revealed that sexual victimization on college campuses was excessively underreported in the National Crime Survey (NCS) of 1984. Accordingly, Koss et al. (1987) questioned the methodology of sexual victimization surveys of the time.

Following the enactment of the Clery Act, a substantial proportion of universities across the nation started to report their crime statistics. The availability of a new source of data as well as the developments following the Clery incident—which had attracted the attention of the general public - increased researchers' capacity to investigate campus 
safety. Moreover, in the 1990s, several large-scale studies were funded by the U.S. Department of Justice (DOJ), focusing on the correlates of college students' victimization —including demographic characteristics, lifestyle, and routine activities. The Bureau of Justice Statistics (BJS) also contributed to the development of campus safety research by adding a question to the National Crime Victimization Survey (NCVS), which asked if the respondent was a college student (Fisher \& Sloan, 2013).

\section{Statement of the Problem}

Based on the statistics reported by the U.S. Department of Education (DOE), there are 6700 Title IV postsecondary institutions (DOE, 2015a) offering higher education programs to 20.6 million students across the United States (DOE, 2015b). In 2015, a total of 36,225 criminal offenses occurred in U.S. Title IV institutions. These crimes included 49 murders, 3 negligent manslaughters, 13,880 burglaries, 9,295 sex offenses, 5,284 motor vehicle thefts, 2,984 robberies, 4,053 aggravated assaults, and 677 arsons (DOE, 2016a). The most common type of crime, burglary, constitutes $38 \%$ of all criminal incidents of 2015. Other frequently reported crimes were sex offenses (25\%), motor vehicle theft (14\%), aggravated assault (11\%), and robbery $(8 \%)$.

Figure 1 indicates the patterns of campus crime over time. The overall campus crime rate per 100,000 student population increased from 176.5 in 2014 to 178.5 in 2015. This differed from the downward trend in the overall crime rates reported between 2007 to 2014. In addition, crimes against persons and crimes involving property have undergone changes in opposite directions from 2007 to 2015 . While violent crimes have continually increased since 2010, crimes against property have significantly dropped from 2007-2015. 
Figure 1: Campus Crime Patterns

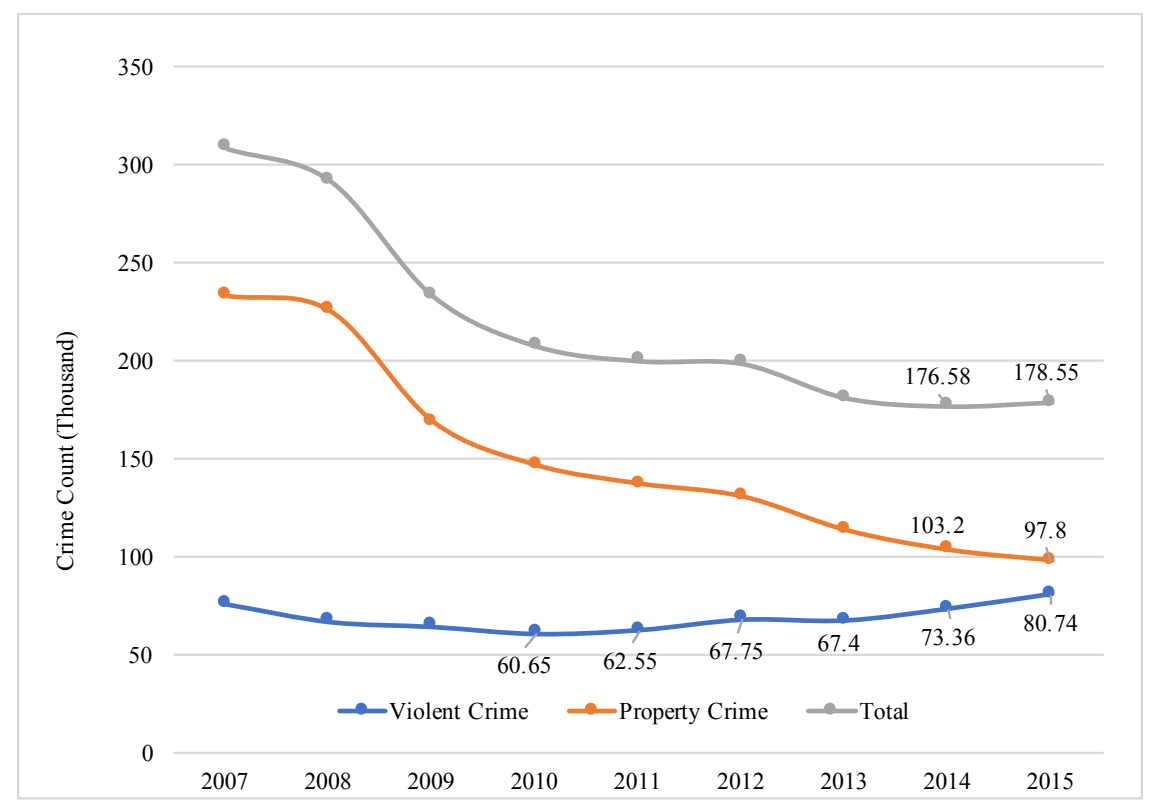

Source: U.S. Department of Education

Since 2009, compared to other violent crimes (i.e., murder, negligent manslaughter, robbery, and aggravated assault), reports of sexual offenses increased the most. Moreover, they constituted $25 \%$ of all criminal incidents on U.S. campuses in 2015. Burglary, on the other hand, has shown a substantial reduction compared to other crimes involving property. Despite this downward trend, burglary continues to be the most prevalent crimeaccounting for $38 \%$ of all campus crimes in 2015 .

Identifying frequencies and temporal variations in campus crime helps legislators and government authorities set priorities and manage resources to address safety issues. Knowing these priorities also highlights the need for empirical research to understand factors contributing to these patterns and offers implications for preventive actions by adopting strategies tailored to the critical security problems. Given the priorities recognized 
based on the above variations, proper preventive measures should be devised to control major campus crimes.

There are two general approaches to crime control: proactive and reactive. The proactive approach aims to prevent crime by identifying risk factors and applying proper interventions. This approach includes three major strategies. First, developmental perspective aims to reduce crime using early-in-life interventions, such as family and school-based programs. Second, a community-based approach maintains that crime is caused by economic, cultural, and social problems within the communities. Thus, every initiative to prevent crime must target these root causes of deviant behavior (Welsh \& Farrington, 2012). Third, situational crime prevention focuses on the circumstances that give rise to criminal conduct. These situations are "the closest in time to the crime event and may be more amenable to being changed" (Smith \& Clarke, 2012, p. 291).

The reactive approach, on the other hand, mainly focuses on taking action after criminal acts occur without considering the root causes. This approach includes "traditional deterrent, incapacitative, and rehabilitative strategies operated by law enforcement and criminal justice system agencies" (Welsh \& Farrington, 2010, p. 4).

\section{Purpose of the Study}

This dissertation examines the application of a proactive crime control perspective in college campuses. This approach is called Crime Prevention Through Environmental Design (CPTED) and focuses on manipulating the environment as a means to increase safety. It postulates that the modification of certain design features reduces crime opportunities and encourages legitimate use of the environment (McCormick, 2011). 
The CPTED approach differs from other crime prevention perspectives in two respects. First, it examines how crime can be facilitated by place rather than individual propensities. Then, it puts the burden of crime control not only on criminal justice officials but also on planners, landscape designers, architects, and public development agencies (Armitage, 2014).

In urban planning literature, CPTED is regarded as "a useful planning tool for assisting in the creation of more efficient, sustainable and livable urban design" (Cozens, 2008, p. 272). CPTED comprises inexpensive and simple design tactics that lead to longlasting deterrent outcomes (McCormick, 2011). In the present study, it is argued that CPTED strategies can be used on college campuses to decrease the vulnerability of school structures to criminal incidents and ensure that students experience less fear of crime. The CPTED method can be an appropriate preventive tool for college campuses, because it will produce long-term savings on policing. Moreover, the proactive nature of CPTED is better suited to learning and research environments-compared to reactive and coercive strategies.

Though CPTED has shown promise in reducing crime in different settings, such as commercial and residential areas (Casteel \& Peek-Asa, 2000; Casteel, Peek-Asa, Howard, \& Kraus, 2004; Cozens, Saville, \& Hillier, 2005; McCormick, 2011), research has not yet assessed the effectiveness of this approach in an educational context. Previous research has not empirically examined the extent to which CPTED principles have already been implemented on school campuses. Resultantly, the appropriateness of CPTED in academic settings has not been evaluated yet. The present study sought to narrow this gap in the research literature by conducting an assessment of the ongoing implementation of CPTED 
in American universities. The relationship between the application of this method and campus crime was analyzed.

Another area that has received little attention in the literature involves the perception of safety within campus communities, specifically as it relates to the deployment of CPTED. While some research has assessed the nature of fear of crime among university communities generally, no studies have examined the influence of CPTED on students' perceptions of safety. To address this gap, a comparative analysis of two residential facilities: one with high CPTED and one with low CPTED was conducted. The differences between the physical design of the two facilities and the safety perceptions of residents were examined.

Moreover, the research literature lacks a qualitative case study investigating the use of CPTED in university campuses. The present study sought to fill this gap by conducting a case study in a college campus that regularly and systematically applies CPTED strategies. The qualitative research design helped provide insight into the use and perceptions of CPTED and served to augment the quantitative analyses performed in the study.

\section{Significance of the Study}

This study is significant for three reasons. First, it narrows a crucial gap in the existing literature on the link between environmental crime prevention approaches and campus safety using an interdisciplinary perspective that includes quantitative and qualitative analysis. There is a dearth of research on the topic area investigated in the present study —in two respects. (1) Much of the extant research on campus safety are either descriptive studies, providing estimations of campus crime (Fisher, Cullen, \& Turner, 2000; Kilpatrick, Resnick, Ruggiero, Conoscenti, \& McCauley, 2007; Stewart \& Fisher, 
2013; Belknap \& Erez, 2013) or explanatory research examining the factors that contribute to campus crime occurrence (Siegel \& Raymond, 1992; Fisher \& Nasar, 1992; Nasar \& Fisher, 1993; Wolkvein, Szelest \& Lizotte, 1995; Fisher, Sloan, Cullen \& Lu, 1998; Henson \& Stone, 1999; Mustaine \& Tewksbury, 2002; Sloan, Lanier, \& Beer, 2000; Dowdall, 2013; Mustaine \& Tewksbury, 2013). The existing body of research is lacking an evaluation perspective focusing on the effectiveness of policies and programs designed for campus safety. (2) Among the studies that empirically evaluated the use of CPTED, most have focused on commercial and residential settings (Casteel \& Peek-Asa, 2000; Casteel et al., 2004; Minnery \& Lim, 2005; Marzbali, Abdullah, Razak, \& Maghsoodi Tilaki, 2012a, 2012b). An examination of the role CPTED standards in an educational context has been disregarded in previous research. Distinct from the existing literature, this dissertation adopted an evaluation perspective to assess the role of CPTED in campus safety. It sought to provide insight into the extent to which American universities have adopted strategies consistent with CPTED. This study also aimed to advance scientific knowledge on how the use of this method can impact campus crime and security. Additionally, it attempted to identify the strengths and challenges of applying this approach in academic settings.

Second, this study is significant because it offers benefits for practice and policy efforts. The study aimed to be of practical value to the university community by suggesting effective solutions for campus safety issues. The potential guidelines that can be developed based on the principles of CPTED for academic settings can benefit university communities - educating them on how to contribute to their own safety. Campus safety officials can also benefit from this study by using it as a model of CPTED in the college context. In terms of policy-making, this study may generate the information needed to 
determine how to create a safe educational environment on college campuses. It can also define standard operation measurement tools to help college administrators and planners while they engage in design or construction processes.

Third, the present study is significant because it addresses a gap in the research literature - in terms of qualitative research on the application of CPTED, particularly in academic settings. Thus, this study adopted a mixed methods approach. The quantitative methodology offers insight into the extent and impact of CPTED in an educational context; to complement the quantitative component, qualitative analysis was conducted in a case study on the actual implementation of CPTED measures in a college campus. Using qualitative methods, the strengths and shortcomings of the CPTED approach were analyzed to offer practical solutions to address its weaknesses.

\section{Research Design}

The main objective of this dissertation was to understand how the use of CPTED strategies affects campus safety. The study adopted a mixed methods approach, and it was conducted in the following three phases:

In the first phase, a national sample of one hundred Title IV institutions was drawn, and their Clery Reports were reviewed to evaluate level of consistency with CPTED standards and determine if this level of consistency was associated with campus crime rate. After conducting a content analysis of the Clery Reports of the sampled universities, the level of CPTED application at each university was measured.

The second phase was a comparative assessment of the relationship between students' perception of safety and the application of CPTED in a university campus. The data were collected by administering survey questionnaires and conducting in-site 
observations. This phase was carried out at two residential facilities of Florida International University - the two facilities differed in terms of compatibility with CPTED.

In the third phase, a case study was crafted at Colorado College, as this institution had already adopted CPTED-related policies, systematically. Qualitative methods were utilized to identify the strengths and challenges of applying CPTED approach in the university context and to determine what modifications are needed to increase its effectiveness in academic settings.

\section{Research Questions and Hypotheses}

This study sought to advance scientific research on the impact of CPTED on campus safety, to identify potential strengths and challenges of its utilization in the university context, and to offer policy recommendations for a better deployment. To achieve these goals, this study addressed three research questions.

Q1: Is there a relationship between the use of CPTED strategies and campus crime rate?

Q2: Is the use of CPTED principles correlated with students' perception of safety in college campuses?

Q3: What are the strengths and challenges of using CPTED techniques in the college context?

Quantitative methods were used to address the first two research questions of the dissertation. First, the relationship between CPTED and campus crime rate was assessed. Then, the connection between CPTED and perception of safety of campus resident students was measured. Finally, qualitative methods were used to explore the strengths and 
challenges of applying CPTED in an educational setting. Below, the hypotheses for the first two research questions are presented.

Hp1: Yes, campuses with higher level of application of CPTED will have lower crime rates.

Hp2: Yes, there will be a positive relationship between resident students' perception of safety and the extent to which their facilities have adopted the CPTED standards.

\section{Conceptual Framework}

This study is informed by the "Defensible Space" theory, developed by Oscar Newman in 1972. This is the "dominant theoretical framework put forward to explain the unique contribution that environmental design and layout play in creating opportunities for crime" (Reynald \& Elffers, 2009, p. 26). The theory establishes a link between environmental conditions and crime, and emphasizes the role of residents in defending their space and reducing crime opportunities (Newman, 1996). Newman's theory soon became a standard of urban design and planning for crime prevention in the United States and constituted a baseline for the CPTED theory (Crowe \& Zahm, 1994).

Newman's framework originally consisted of three components: natural surveillance, territoriality, and image. He argued that vulnerability to crime increases for places that fail to meet these qualifications. Despite ample popularity within the policy arena, the theory was severely criticized by criminologists due to its excessive focus on physical elements and failure to consider social factors. This critique was later acknowledged by Newman and reflected in his newer versions of the theory (Reynald \& Elffers, 2009). The conceptual framework of the present study is composed of the five 
principles of CPTED, which are defined in light of the defensible space theory. The five components of CPTED are discussed below.

\section{Natural Surveillance:}

The first principle of CPTED is natural surveillance, which refers to the capacity of environment to provide opportunities for people to watch over one another (Johnson, Gibson, \& McCabe, 2014). Fostering natural surveillance encourages the use of areas by authorized people and creates a sense of responsibility in residents toward their space. This, in turn, increases the inherent risk and difficulty of crime and dissuades rational would-becriminals from committing unlawful behavior.

\section{Access Control:}

Access control is the second component of CPTED; it is based on the presumption that by restricting entry and exit of visitors, we can reduce the possibility that intruders will access certain areas. According to Zahm (2007), the environment must include features that suggest: who is authorized to be in a given site, who is not allowed to be there, and what activities are permissible. This can be accomplished with locks, gates, doors, and so forth.

\section{Maintenance:}

The third element of CPTED, maintenance, focuses on maintaining a pleasant image for an area to protect ownership and improve quality of life. The appealing image of a well-kept area enables residents to develop attachments to their neighborhood and strive for its safety (Johnson et al., 2014). On the other hand, poor protection and maintenance (e.g., presence of graffiti, litter, and broken fixtures), could attract potential criminals to the area, and alienate responsible residents (Fritz, 2009). 


\section{Territoriality:}

The fourth principle of CPTED, territoriality, allows owners to define and control their property and to restrict intruders' access. This can be accomplished using physical barriers (e.g., fences and hedges) or symbolic barriers (e.g., signage, planting, and landscaping). This strategy conveys the message that the area has restricted access and is monitored by authorized individuals (Reynald \& Elffers, 2009). Through territorial reinforcement, motivated offenders will presumably be discouraged and shift their focus to other potential targets.

\section{Activity Support:}

The fifth CPTED principle is activity support, which aims to increase community interaction using a variety of passive or active strategies. The use of design elements that attract legitimate users (e.g., proper landscaping, gathering areas) is referred to as passive activity support. Active examples, on the other hand, involve strategies such as holding cultural events, which increase the presence of people-making the area less desirable for motivated offenders (Fritz, 2009).

Figure 2 illustrates how CPTED strategies can work together to reduce crime and increase perception of safety. 
Figure 2: Conceptual Framework for CPTED Strategies

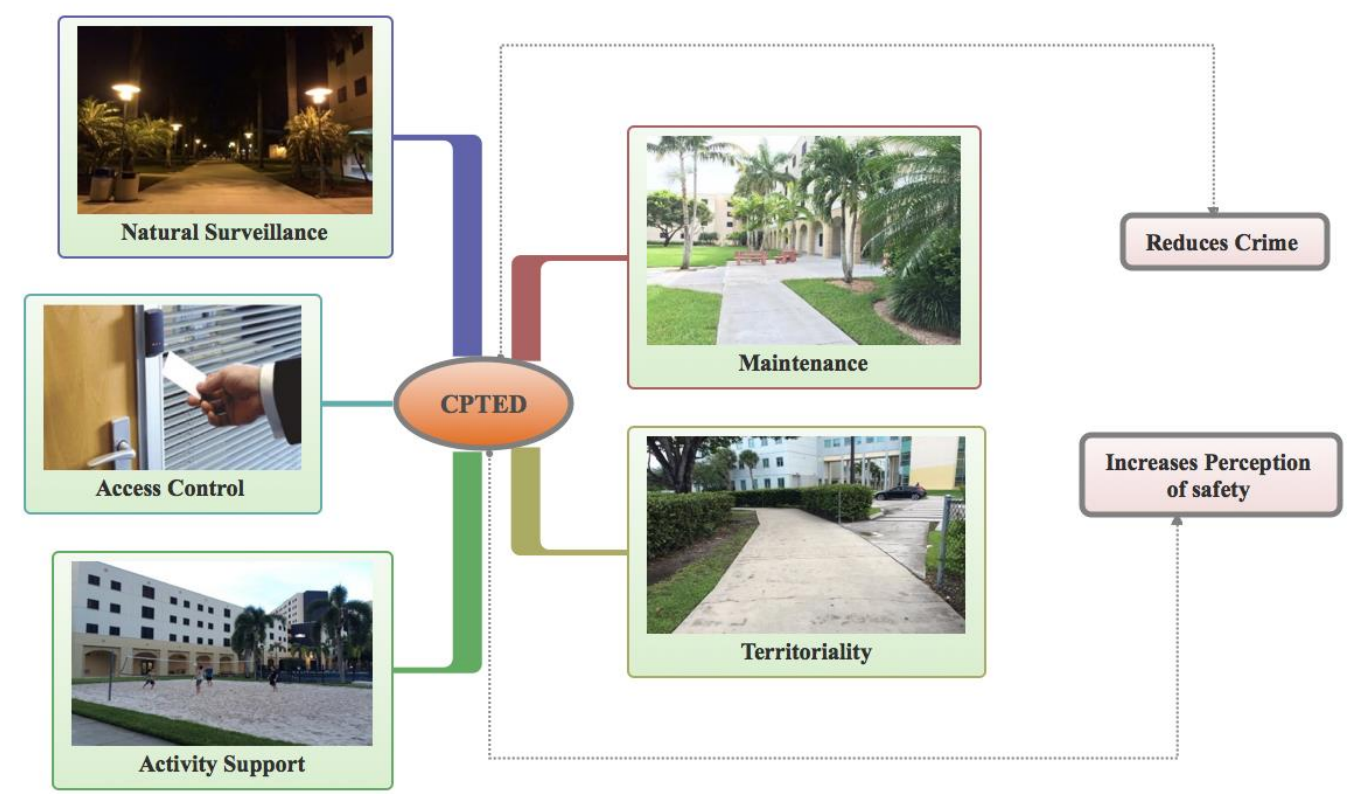

\section{Overview of Chapters}

This dissertation is organized as follows. Chapter 2 reviews the literature on the topic examined in this dissertation. This chapter analyzes in detail the existing knowledge on campus crime and safety. This will be followed by a review of the historical evolution of CPTED, its theoretical foundations, and evidence of effectiveness. After the literature review of both campus safety and CPTED, the gap in the research literature is identified. Subsequently, Chapter 3 presents a national assessment of the application of CPTED in a representative sample of Title IV institutions in the United States. The relationship between the use of CPTED strategies and campus crime rates are also discussed in Chapter 3. Then, the unit of analysis - University in the United States-, the sampling procedures, and the study variables are presented. The chapter continues with a detailed description of the operationalization of the study variables, and the inter-coder reliability technique that was 
used. The results of the correlation and regression analyses are then presented. A discussion of the findings, conclusions, and limitations close this chapter.

Chapter 4 presents an analysis of the association between the level of CPTED compliance and residents' perception of safety. This is a quantitative analysis comparing a high CPTED residential facility and a low CPTED residential facility at Florida International University. The chapter describes the purpose of the study and the variables included in the analysis. Then, the survey instrument and observation techniques used to collect data are explained. The chapter reviews the analytical approach, and discusses the results, conclusions, and limitations. Chapter 5 presents the qualitative case study conducted at the Colorado College campus. It commences by explaining the purpose of the case study and the selection criteria for the case study site. The methods of investigation and sampling techniques are then outlined. The findings of the interviews, focus group, observations, and secondary sources are then presented. Lastly, a discussion of the key findings, conclusions, and limitations complete the chapter.

The last chapter concludes the dissertation. This chapter discusses the results of all three phases of the study. The aim is to ground the results into the existing literature. The chapter also provides policy implications to practitioners. In particular, the discussion focuses on how to foster the strengths and address the limitations of CPTED in academic settings. It also sets the groundwork for future development of the use of CPTED in the university context. 


\section{Chapter Two: Literature Review}

\section{Introduction}

This dissertation builds on the Defensible Space Framework (Newman, 1972) to contribute to the literature on campus safety. The two bodies of research that informed this study are examined here. First, the literature on campus safety research is reviewedidentifying a critical gap in the literature: evaluation of campus safety initiatives. Then, the chapter focuses attention on previous studies investigating CPTED. Following a review of the historical evolution of CPTED, the theoretical perspectives that gave rise to environmental approaches for crime prevention are discussed. In the final section, the existing research related to the effectiveness of the CPTED approach is reviewed and analyzed. The goal of this chapter is to explain the link between established theories of environmental criminology and campus safety research.

\section{Campus Crime and Safety}

To more clearly present the relevant literature, the taxonomy developed by Fisher and Sloan (2013) in their book "Campus Crime: Legal, Social, and Policy Perspectives" is used. This classification identifies three categories: (1) descriptive studies examining the extent and nature of campus crime; (2) explanatory research examining the predictors of campus crime, which can be categorized as student and institutional factors; and, (3) evaluation studies focusing on the effectiveness of policies and programs for campus safety.

Descriptive studies focus on the type and prevalence of on-campus victimization. The issues of sexual assault and stalking on college campuses continue to influence thematic development in the descriptive body of research - suggesting that a substantial 
portion of the population of female students repeatedly experience some form of sexual assault during college (Fisher et al., 2000; Kilpatrick et al., 2007; Stewart \& Fisher, 2013; Belknap \& Erez, 2013). These findings have attracted public attention to the issue of sexual violence against college students and have led to institutional (Title IX of Higher Education Act Enforcement, 2011) and legislative responses (Violence against Women Act Renewal, 2013) (Fisher \& Sloan, 2013).

Explanatory studies are informed by existing theories to examine the predictors of on-campus victimization. Students' lifestyle and routine activities have been extensively examined as the correlates of campus crime in previous literature. These studies have revealed that students' characteristics and lifestyles, such as their relationship behaviors and alcohol drinking habits, are important determinants of their victimization (Siegel \& Raymond, 1992; Wolkvein et al., 1995; Fisher et al., 1998; Henson \& Stone, 1999; Mustaine \& Tewksbury, 2002; Sloan et al., 2000; Dowdall, 2013; Mustaine \& Tewksbury, 2013).

The second group of factors examined by explanatory studies are institutional characteristics. A major theme that is relevant to the focus of this dissertation attributes campus crime to the physical design of campus. Fisher and Nasar (1992) and Nasar and Fisher (1993) are among the early empirical researchers that examined three correlates of crime and fear: prospect, refuge, and escape. Their findings demonstrated that higher levels of fear of crime on campus is associated with locations' poor visibility, victims' lower chance of escape, and areas offering more hiding places for offenders. A large-scale study by Siegel and Raymond (1992) conducted in four hundred U.S. institutions revealed that ecological features of campus, together with students' characteristics, are correlated with 
campus violent crime. In a single case study at Louisiana State University, Fernandez (2005) surveyed a random sample of students to explore their perceptions of safe and unsafe exterior sites on campus. The study's findings were consistent with CPTED theory, suggesting that visibility, clean and well-kept areas, and proper landscaping increase students' perception of safety.

The third body of scholarly research on campus safety comprises studies that evaluate the effectiveness of programs and policies addressing campus crime. Despite nearly three decades of legislative and institutional efforts to support the implementation of crime prevention programs in postsecondary institutions, evaluation literature on the effectiveness of prevention programs is scarce. Two relatively recent studies sought to address this gap - focusing on the implementation of bystander intervention programs (i.e., training bystanders to intervene when observing criminal acts in progress) on college campuses. Banyard Moynihan, and Plante (2007) and Coker et al. (2011) evaluated the impact of bystander trainings on the desired outcome of the program: increases in bystander behaviors to halt crimes in progress. Both studies suggested that bystander intervention programs hold promise in promoting a community-based approach to crime prevention.

\section{Historical Evolution of CPTED}

The catalyst of this approach to crime prevention through environmental design (CPTED) dates back to 1961, when the director of the Chicago Housing Authority, Elizabeth Woods, proposed to improve public housing safety by increasing visibility in area (Nichols, 2012). In the same year, the seminal work of Jane Jacobs, "The Death and Life of Great American Cities," discussed the role of environmental factors in crime and 
disorder. She emphasized the impact of visibility, demarcation of public and private spaces, and diverse use of environment on crime prevention (Cullen \& Wilcox, 2010).

The term "crime prevention through environmental design" was coined by Ray Jeffery in his book with the same title in 1971. Jeffrey (1971) noted the importance of preventing future crime rather than taking a reactive approach. He argued that spatial factors play a critical role in crime occurrence. Thus, manipulating those conditions can be an effective way to reduce crime (Cullen \& Wilcox, 2010). The most frequently cited definition of the term was presented by Tim Crowe (2000). He defined CPTED as "the proper design and effective use of the built environment [that] can lead to a reduction in the fear and incidence of crime, and an improvement of the quality of life" (Crowe, 2000, p. 46).

The theory of CPTED had, initially, focused on the physical aspects of environment-assuming that crime opportunities would decrease by modifying the physical design of a given area. This perspective, known as first generation CPTED, entails strategies to manipulate physical design to decrease opportunities for criminal behavior (WAPC, 2006). The basic strategies of first generation CPTED are: providing adequate visibility, specifying the boundaries, maintaining a pleasant image of the neighborhood, and limiting intruders' opportunities to gain access to the area.

A second generation of CPTED was developed after first generation CPTED approaches drew two main criticisms: (1) generating crime displacement rather than reducing it, and (2) devising preventive strategies solely for hypothetical rational offenders. The second generation is regarded as a complementary addition to the first generation CPTED, as it focuses on social and cultural dynamics of environment rather than physical 
aspects (Atlas, 2008). "It is not a replacement for first generation CPTED. Instead, it is intended to augment physical environmental design through the addition of socially cohesive stratagem" (Letch, McGlinn, Bell, Downing, \& Cook, 2011, p.40). While firstgeneration CPTED concerns design strategies to prevent criminals from entering an area, second-generation CPTED concerns preventing crime from increasing in an area (Saville \& Cleveland, 1999). Thus, the second-generation theoretical framework of CPTED included a fifth component: activity support. The newly added element of CPTED involves two types of tactics: active efforts (e.g., organizing events to attract more legitimate users to an area) and passive strategies (e.g., integrating aesthetically pleasing design features into the environment to attract people accordingly) (Fritz, 2009).

\section{Theoretical Underpinnings of CPTED}

To understand how the CPTED approach fits in the context of criminological theories, it can be regarded within the larger framework of Situational Crime Prevention (SCP). Situational crime prevention, "a more recent term that originated in the U.K., subsumes CPTED and is much broader in scope. It refers to any opportunity reducing measure, whether of design, management or even policing, intended to increase the difficulties or risks of offending" (Clarke, 1989, p. 13). SCP entails a process of problemsolving using a standard methodology. Through analysis of the crime problem, the situations that facilitate crime are identified. Appropriate interventions are then developed to discourage potential criminals from offending, based on the underlying factors. The next step is an evaluation of how the implemented strategies impacted the crime issue; lastly, results are disseminated (Clarke, 1997). SCP and CPTED are both informed by three criminological theories, including Rational Choice Perspective (RCP), Routine Activity 
Approach (RAA), and Crime Pattern Theory (CPT). These theories, which help explain the rationales of SCP and CPTED approaches to crime prevention, are described below.

The Rational Choice Perspective (RCP), by Clarke and Cornish (1985), suggests that motivated offenders assess the potential costs and benefits of a given crime opportunity before deciding to pursue it. If the hazards outweigh the perceived rewards, they will not place themselves at risk by committing the crime. Thus, manipulating the circumstances that give rise to criminal opportunities can reduce the willingness of would-be-offenders to engage in criminal activities (Smith \& Clarke, 2012). After identifying potential risk factors of crime among victims, offenders, and/or places, the RCP approach enables the development of appropriate interventions to alter the suitability of crime. For instance, improving the visibility of secluded areas in a college campus is a CPTED technique that is informed by RCP. This technique aims to dissuade motivated offenders by increasing the risk of arrest and punishment.

Routine Activity Approach (RAA), proposed by Cohen and Felson (1979), is another theory that helps explain why crime occurs and provides implications for prevention. Based on this theory, three factors are critical for crime to occur: a motivated offender, a suitable target, and absence of a capable guardian. Elimination of any one of these components serves as a crime prevention technique. Thus, any efforts to strengthen potential crime targets by providing effective guardianship helps to avert motivated criminals from their targets (Clarke, 1997). For example, controlling access to the residential facilities of college campuses with mechanical keys or electronic key cards is a CPTED strategy designed to protect campus residents from crime. 
The last theoretical perspective that informs SCP and CPTED is Crime Pattern Theory (CPT) (Brantingham, Brantingham, \& Taylor, 2005). This theory links rational choice perspective and routine activity approach to understand why some places generate or facilitate crime (Eck \& Weisburd, 2015). CPT examines concentrations of crime among targets, offenders, and/or guardians to explain spatial crime patterns. This theory "enables crime prevention policy makers and practitioners to identify locations which are in need of preventive interventions and also helps them find tailored preventive methods for each area" (Shariati \& Guerette, 2017, p. 263).

\section{Effectiveness of CPTED}

This section reviews previously conducted evaluation research on CPTED. The goal is to provide insight into the implementation of CPTED and its effectiveness. In general, evaluation of crime prevention is defined as "investigating the impact of a prevention technique or intervention on the level of subsequent crime, fear, or other intended outcome" (Lab, 2014, p. 34). To achieve this goal, findings from a series of experimental projects conducted in the 1970s and 1980s is reviewed. Then, several, more-recent CPTED evaluation studies are presented.

\section{Early Experimental Projects}

A decade after CPTED was introduced as a method to address the issue of crime, a series of nation-wide initiatives were started in the United States to empirically evaluate the efficacy of this approach in achieving the desired goals. Randomized control trials (e.g., experimental design), were used to evaluate the CPTED programs' interventions. "The experimental design addresses the various threats to internal validity - that is, factors that could cause the results other than the measures that were implemented" (Lab, 2014, p. 42). 
Westinghouse CPTED Program (1974-1976) was one of the well-known projects of this generation designed to implement CPTED and assess its effectiveness in reducing crime. It included three smaller projects in different settings: school, commercial, and residential (Kaplan et al., 1978). The school demonstration of this project was executed in four high schools in Broward County, Florida. The City of Portland, Oregon provided the commercial setting for the project. And, a residential demonstration was developed in the Willard-Homewood neighborhood in Minneapolis, Minnesota (Kaplan et al., 1978: Wallis \& Ford, 1981a, 1981b; Kushmuk \& Whittemore, 1981). The analysis of the program demonstrations did not lead to identical conclusions on the effectiveness of CPTED strategies in different contexts. "The Portland commercial demonstration was relatively successful. The schools in the demonstration achieved a reduction in crime and fear, but the results were more modest than those achieved in Portland. Finally, the residential demonstration failed to achieve its anticipated effect" (Wallis \& Ford, 1981a, P.4).

Another experimental project of this kind was the Hartford Neighborhood Crime Prevention Program, launched in 1973. This program devised a crime prevention strategy utilizing police resources, citizen participation, and physical design characteristics to reduce residential burglary, street robbery, and fear of these crimes. It was implemented in two residential neighborhoods in Hartford, Connecticut. The project designed a number of manipulations to the physical environment (e.g., highlighting neighborhoods' boundaries and reducing the traffic into and within residential areas) (Hollander, Hartmann, Brown, \& Wiles, 1979). Following a three-year implementation, the project "showed a clear and significant reduction in burglary and a probable reduction (at least a reversal in the 
increasing trend) in street crime. Measurements also showed corresponding reductions in fear of these crimes" (Gardiner, 1978, p.67).

\section{CPTED Evaluation Studies}

The relative success of these early experimental projects led to the development of numerous programs to implement and assess CPTED strategies. Consequently, several large-scale reviews of these programs were conducted during the 1990s and 2000s. Poyner (1993) reviewed 122 crime prevention projects. The programs included in Poyner's review are classified into six groups, which included a category for environmental design and improvement. Among the projects categorized as environmental, over half (24 out of 45) were found to be effective for all crime types. Eck (2000) reviewed 99 crime prevention programs that entailed place-based opportunity blocking techniques. The results showed that over $90 \%$ of these interventions had been effective. Despite these promising findings, the evaluations are weak in terms of scientific rigor, which is due to the lack of control for places and/or time periods.

A systematic review of 28 studies focusing on CPTED's impact on reducing robberies showed evidence of robbery reduction (Casteel \& Peek-Asa, 2000). Two groups of studies were included in the review: (1) studies with high scientific rigor (i.e., compared period/population, measured a clear outcome, analyzed sufficient data) and (2) studies that merely reported some statistical evaluation of CPTED. Both primary and secondary studies showed evidence of robbery reduction. The effects were greater for interventions such as basic store design, cash control, and training components.

Cozens et al. (2005) conducted a narrative review of numerous studies on CPTED. Despite acknowledging the limitations of this approach (e.g., inability to address irrational 
offenders, possibility of detrimental influence of socio-economic and demographic factors, and displacement issues), the Cozens et al. study concluded that CPTED has shown promise in reducing crime and fear of crime and in increasing properties' value and investment capacity of neighborhoods.

Additionally, a number of evaluation studies have been conducted as single CPTED case studies - focusing on certain outcomes, such as fear of crime. Two case studies in Penang, Malaysia investigated the interrelations between fear, victimization, and CPTED (Marzbali et al., 2012a, 2012b). Both studies came to similar conclusions, suggesting a negative indirect relationship between CPTED and fear of crime through victimization (Marzbali et al., 2012a) and a significant reduction in burglary victimization associated with CPTED (Marzbali et al., 2012b).

In another experimental study, Casteel et al. (2004) measured the impact of CPTED in reducing crime in liquor stores located in Santa Monica, California. An intervention plan was designed and used for nine liquor stores, and thirteen other stores were assigned to the comparison group. The findings indicated a significant reduction in crime in the experimental group. However, a case study by Minnery and Lim (2005) in two residential areas of Queensland, Australia, indicated that CPTED measures had some impact on actual victimization, but no relationship was found between CPTED and fear of victimization.

\section{Conclusion}

This chapter synthesized the relevant research on campus safety and CPTED. The chapter started by reviewing three groups of campus safety studies. The review identified an important gap in the literature linking evaluation research and campus safety initiatives. Traditionally, campus safety research has focused on providing descriptions of the nature 
of campus crime or explanations of its predictors. Thus, this dissertation sought to narrow this gap by assessing the role of a crime prevention method - CPTED—in campus safety.

Then, the review of CPTED research reinforced the present study's theoretical argument for a relationship between the environment and crime. CPTED project reports and program evaluations supported the effectiveness of this approach in reducing crime and fear in residential and commercial settings. Nonetheless, a clear gap was found in the previous research literature focusing on the influence of CPTED in addressing crime in educational settings. Although a connection may exist between proper environmental design and lower crime in college campuses, few empirical research studies have investigated this relationship. In an effort to fill this gap, the present study has examined the extent and influence of the use of CPTED strategies in the university context. 


\section{Chapter Three: National Assessment of the Role of CPTED in Campus Safety}

\section{Introduction}

The aim of this chapter is to present the research methods, analytical approach, and findings of the first phase of this dissertation - in which the impact of CPTED on campus crime rate was investigated. The unit of analysis was a university campus in the United States, and quantitative methods were used to answer the first research question of the study (i.e., is there a relationship between the use of CPTED strategies and campus crime rate?).

Annual safety reports (i.e., Clery Reports) were used to collect data on campus crime and campus safety programs. All institutions of higher education that participate in federal student financial aid programs are subject to the Title IV of Higher Education Act of 1965. As Title IV institutions, these schools are required to publish annual Clery Reports to provide transparency on campus crime and security.

A national sample of one hundred Title IV institutions was drawn. Then, a content analysis of the Clery Reports of the sampled universities was conducted to gather information on the institutions' level of CPTED and other crime prevention programs. Content analysis is "a systematic, replicable technique for compressing many words of text into fewer content categories based on explicit rules of coding” (Stemler, 2001, p.1).

In the following sections, the procedures used to draw the representative sample of U.S. universities is presented. Then, the variables included in the analysis, data collection methods, and operationalization techniques will be discussed. The next section describes the inter-coder reliability technique that was used to examine the validity of coding of the 
variables. Finally, the chapter concludes with a discussion of results, policy implications, and directions for future research.

\section{Sampling Procedure}

Using a proportionate stratified sampling technique, a national sample of U.S. universities was drawn. This sample includes 100 higher education institutions located across nine divisions within four regions of the country: West, Midwest, Northeast, and South. U.S. Census taxonomy for the regions and divisions of the United States was adopted for the purpose of sampling.

Figure 3 illustrates the U.S. Census classification.

Figure 3: Census Regions and Divisions of the United Sates

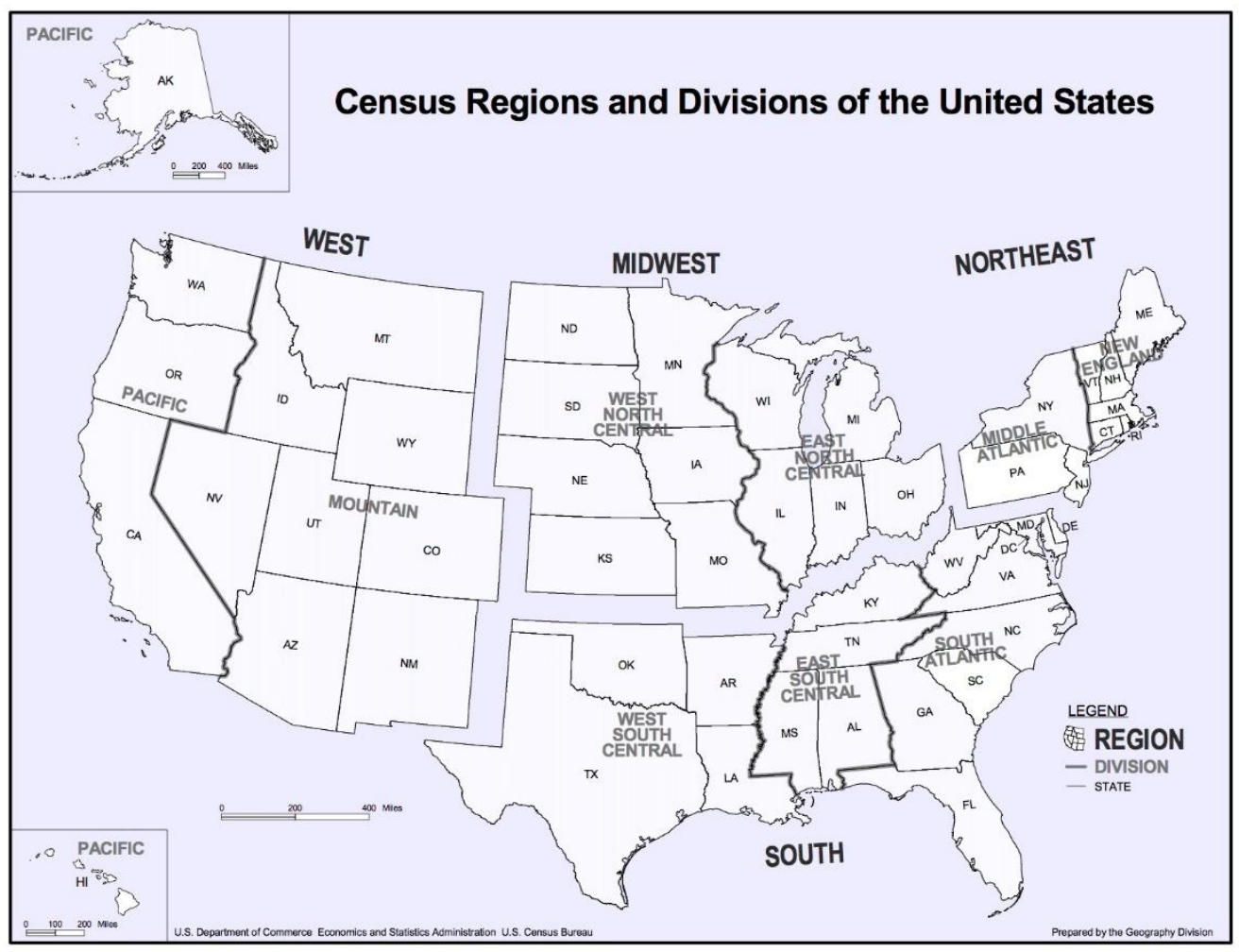

Adopted from U.S. Census Bureau 
The office of Federal Student Aid of the U.S. Department of Education publishes a list of the Title IV institutions on its website every academic year. This list provides certain information for all the listed schools, including school code, school name, address, city, state, ZIP code, region, and division. This list was obtained for the academic year 2015-16, which included 6,708 institutions. 137 institutions - of the total of 6,708 listed schoolswere located in unincorporated territories of the United States such as American Samoa, Puerto Rico, Guam, and the U.S. Virgin Islands. To comply with the geographic classification adopted from the U.S. Census, those 137 schools were removed from the baseline data.

Then, to draw a sample of 100 schools from the total population of institutions, a proportionate stratified sampling technique was used. The list of institutions indicated how many schools existed in each region, division, and state. First, the stratification was done for the nine divisions of the United States and a proportionate number for each stratum (division) was obtained. Then, the same method of stratification was used for the states and a proportionate number for each state was calculated. Finally, a systematic sampling with a random start was used to pick the schools within each state.

After drawing the sample, the next step was to search for the Clery Reports of the sampled universities. These reports are published online and can be found on the official websites of the institutions. However, for several schools in the sample, the researcher's attempts to obtain their Clery Reports were not successful. These institutions either lacked an official website or did not publish reports on campus safety on their websites; these institutions included beauty schools, career institutes, massage therapy centers, art and photography institutes, and language academies. 
Although these schools were listed by the Federal Aid Program as Title IV institutes, they had not produced Clery Reports or they did not upload reports to a public website. To address this issue, the entire list of schools was cleaned and the sample was drawn again. All of the institutes without obtainable Clery Reports (976 schools) were removed from the total list. The final list of schools from which the sample was redrawn included 5,595 higher education institutions. Table 1 illustrates the sampling procedure and the final number of schools for each stratum.

Table 1: Sampling: Justification of Number of Sampled Schools within the Strata

\begin{tabular}{|c|c|c|c|c|}
\hline Stratum (Division) & State & $\begin{array}{c}\text { Institutions } \\
\text { within States }\end{array}$ & $\begin{array}{c}\text { Total } \\
\text { Institutions }\end{array}$ & $\begin{array}{c}\text { Sample } \\
\text { Size }\end{array}$ \\
\hline \multirow[t]{5}{*}{ West Pacific } & $\mathrm{AK}$ & 10 & \multirow[t]{5}{*}{754} & \multirow[t]{5}{*}{14} \\
\hline & WA & 91 & & \\
\hline & OR & 66 & & \\
\hline & $\mathrm{CA}$ & 567 & & \\
\hline & $\mathrm{HI}$ & 20 & & \\
\hline \multirow[t]{8}{*}{ West Mountain } & MT & 22 & \multirow[t]{8}{*}{346} & \multirow[t]{8}{*}{6} \\
\hline & ID & 21 & & \\
\hline & WY & 10 & & \\
\hline & $\mathrm{NV}$ & 27 & & \\
\hline & UT & 47 & & \\
\hline & $\mathrm{CO}$ & 95 & & \\
\hline & $\mathrm{AZ}$ & 90 & & \\
\hline & NM & 34 & & \\
\hline \multirow[t]{7}{*}{ West North Central } & ND & 24 & \multirow[t]{7}{*}{508} & \multirow[t]{7}{*}{9} \\
\hline & SD & 28 & & \\
\hline & $\mathrm{NE}$ & 41 & & \\
\hline & $\mathrm{KS}$ & 73 & & \\
\hline & $\mathrm{MN}$ & 104 & & \\
\hline & IA & 79 & & \\
\hline & MO & 159 & & \\
\hline \multirow[t]{5}{*}{ East North Central } & WI & 96 & \multirow[t]{5}{*}{843} & \multirow[t]{5}{*}{15} \\
\hline & IL & 224 & & \\
\hline & IN & 102 & & \\
\hline & $\mathrm{OH}$ & 263 & & \\
\hline & MI & 158 & & \\
\hline \multirow[t]{2}{*}{ Middle Atlantic } & NY & 420 & \multirow[t]{2}{*}{861} & \multirow[t]{2}{*}{15} \\
\hline & NJ & 131 & & \\
\hline
\end{tabular}




\begin{tabular}{|c|c|c|c|c|}
\hline Stratum (Division) & State & $\begin{array}{c}\text { Institutions } \\
\text { within States }\end{array}$ & $\begin{array}{c}\text { Total } \\
\text { Institutions }\end{array}$ & $\begin{array}{c}\text { Sample } \\
\text { Size }\end{array}$ \\
\hline & PA & 310 & & \\
\hline New England & VT & 25 & 354 & 6 \\
& NH & 27 & & \\
& ME & 37 & & \\
& MA & 172 & & \\
& CT & 75 & & \\
& RI & 18 & & 19 \\
\hline South Atlantic & DE & 14 & 1025 & \\
& MD & 78 & & \\
\cline { 2 - 4 } & DC & 31 & & \\
& WV & 66 & & \\
& VA & 134 & & \\
& NC & 168 & & \\
& SC & 79 & & \\
& GA & 139 & & \\
& FL & 316 & & \\
\hline East South Central & KY & 90 & 350 & 6 \\
& TN & 140 & & \\
& MS & 45 & & \\
& AL & 75 & & \\
\hline West South Central & AR & 55 & 554 & 10 \\
& LA & 90 & & \\
& OK & 97 & & \\
& TX & 312 & & \\
\hline Total Number of Institutions & & 5595 & 5595 & 100 \\
\hline
\end{tabular}

Despite the use of stratified sampling technique, which increases the representation from all the different divisions and states, the final list shows that several states do not have a representative institution. Eight states (Montana, Wyoming, New Mexico, South Dakota, Rhode Island, New Hampshire, Alaska, and Hawaii) and District of Columbia are not represented in the final sample. This is because a sample of 100 institutions is relatively small to capture schools from every state. Figure 4 shows the distribution of sampled universities across the United States; the figure illustrates the lack of representation for the District of Colombia and the eight states listed above. 
Figure 4: Distribution of Sampled Universities Across the U.S.

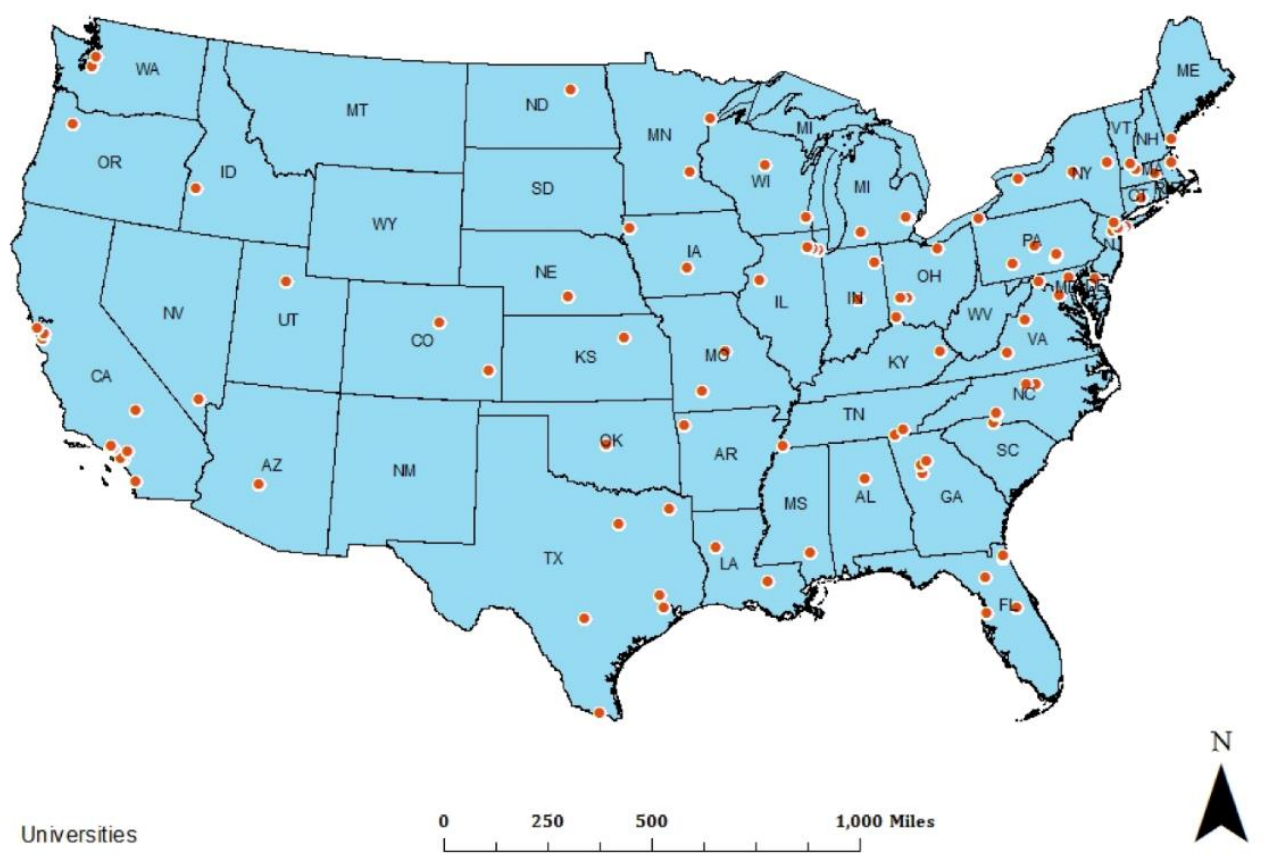

\section{Variables and Data}

Campus crime rate is the dependent variable of the study, which in turn, includes four types of crime. The five principles of CPTED are the main independent variables of the analysis. In addition, several control variables are included in the model. The variables used in the analysis, their descriptions, and data sources are described below.

\section{Dependent Variables}

Four categories of campus crime - including violent crime, property crime, violence against women (VAWA), and other violations - are examined as the study dependent variables. Each group includes several types of crime. Violent crime entails criminal homicide, aggravated assault, robbery, and sex offenses. Property crime comprises burglary, motor vehicle theft, and arson. Violence against women (VAWA) comprises 
dating violence, domestic violence, and stalking. Lastly, other violations include drug law violations, liquor law violations, and illegal carrying of or possession of weapons. These crime statistics were obtained from the latest Clery Reports of the sampled institutions. Then, campus crime rates were calculated per 1,000 student enrollment population.

The Handbook for Campus Safety and Security Reporting, published by the U.S. Department of Education, provides the definitions of each of these crime types. All Title IV institutions must comply with this document's definitions for the purpose of counting and reporting criminal offenses (U.S. DOE, 2016b). According to the latest published handbook:

the definitions for Murder, Rape, Robbery, Aggravated Assault, Burglary, Motor Vehicle Theft, Arson, Weapons Carrying, Possessing, Etc., Law Violations, Drug Abuse Violations, and Liquor Law Violations are from the Summary Reporting System (SRS) User Manual from the FBI's UCR Program. (U.S. DOE, 2016b, p.

The list of crime definitions is provided in the Appendix.

\section{Independent Variables}

The main independent variables of the study are the five principles of CPTED, which are estimated using two data sources: universities' Clery Reports and campus maps. The first three CPTED techniques-natural surveillance, access control, and maintenance - are typically discussed in each institution's Clery Report. In addition to reporting campus crime statistics, Clery Reports describe universities' crime prevention efforts. One aspect of prevention is campus physical design and environmental practices that have been implemented by each institution. Visibility within the campus, the level and 
methods of access control, and the maintenance services provided for the institutions are mostly reflected in the Clery Reports.

In the present study, a set of indicators for each CPTED strategy was developed. The Clery Reports of the sampled universities were then reviewed and each campus was scored for CPTED techniques based on those indicators. However, the last two principles of CPTED, territoriality and activity support, are not reflected in the Clery Reports. Thus, campus maps were used to measure the level of the application of these two strategies. Hence, using several indicators for these two CPTED components, the institutions' maps were examined and each campus was scored for the level of territoriality and activity support measures.

\section{Control Variables}

Three groups of control variables are accounted for in the regression model. The first group comprises non-CPTED crime prevention strategies, which include measures that are designed to prevent crime but are not considered to be environmental design techniques (e.g., educational programs, patrolling, surveillance cameras, etc.). These factors are also measured using the Clery Reports. The second group of variables that are controlled for in the model are school characteristics, which include public vs. private, graduate vs. undergraduate, size of the school, and urban vs. rural. These data were gathered from Carnegie Foundation and U.S. Census Bureau websites. The last group of control variables includes city crime rates (e.g., city violent crime rate and city property crime rate), which were obtained from Federal Bureau of Investigation (FBI), Uniform Crime Reports (UCR) Data. City crime rates are calculated per 100,000 populations. Table 2 lists all the study variables, the data sources, and the years for which the data were collected. 
Table 2: Variables and Data

\begin{tabular}{|c|c|c|c|}
\hline & Variables & Sources & Year \\
\hline DV: Campus Crime & $\begin{array}{l}\text { Violent Crime } \\
\text { Property Crime } \\
\text { Violence against Women } \\
\text { Crime } \\
\text { Other Violations }\end{array}$ & Clery Reports & 2014 \\
\hline IV: CPTED & $\begin{array}{l}\text { Natural Surveillance } \\
\text { Access Control } \\
\text { Maintenance } \\
\text { Territoriality } \\
\text { Activity Support } \\
\end{array}$ & $\begin{array}{l}\text { Clery Reports } \\
\text { Campus Maps }\end{array}$ & 2014 \\
\hline $\begin{array}{l}\text { IV: Non-CPTED } \\
\text { Crime Prevention }\end{array}$ & $\begin{array}{l}\text { Awareness Programs } \\
\text { Patrol } \\
\text { CCTV } \\
\text { Emergency Callbox } \\
\text { Community-oriented Programs } \\
\text { Campus Escort }\end{array}$ & Clery Reports & 2014 \\
\hline IV: School Characteristics & $\begin{array}{l}\text { Graduate vs. Undergraduate } \\
\text { Public vs. Private } \\
\text { Size } \\
\text { Urban vs. Rural }\end{array}$ & $\begin{array}{l}\text { Carnegie } \\
\text { Foundation } \\
\text { U.S. Census }\end{array}$ & $\begin{array}{r}2014 \\
2010 \\
\end{array}$ \\
\hline IV: City Crime & $\begin{array}{l}\text { City Violent Crime } \\
\text { City Property Crime }\end{array}$ & UCR & 2012 \\
\hline
\end{tabular}

\section{Operationalization of the CPTED Variables}

To measure the CPTED principles, composite measures (scales) were developed for each concept, based on their definitions and the existing research literature. Three subvariables were defined for each CPTED variable; then, for each sub-variable, three indicators were developed. The CPTED principles were scored based on the presence of these indicators in each school's Clery Report/campus map. Following the review of Clery Reports, a CPTED score was assigned to each institution.

Similar procedures have been used in urban planning research to grade urban design qualities. By developing operational definitions, physical features can be measured and 
then statistical relationships between these features can be analyzed (Ewing, Handy, Brownson, Clemente, \& Winston, 2006).

\section{Natural Surveillance}

Natural surveillance is an abstract concept that refers to an area's status in terms of appropriate visibility (e.g., sufficient lighting, lack of hidden or obscured areas). Proper visibility causes legitimate users to feel safe in an area and discourages motivated offenders from committing crime. This concept was operationalized by developing three subvariables: campus visibility status, buildings' visibility status, and regular control of lighting failures. Then, each of the sub-variables was divided into three indicators. The total score for each of these three sub-variables ranges from 0-3. The total score for natural surveillance, which comprises the three scores, ranges from 0-9.

\section{Access Control}

Access control is defined as ruling and restricting the entry/access to a given place by the owners. This mechanism reduces the chance of intruders gaining access to the area to commit crime. For the context of a college campus, this concept was operationalized by defining three sub-variables: main entrance control, restricted access to residential buildings, and restricted access to academic and administrative buildings. Then, for each sub-variable, three indicators were developed. The total score for each of these three subvariables ranges from $0-3$. The sum of all three scores results in a total score for access control, which ranges from 0-9.

\section{Maintenance}

Maintenance is another principle of CPTED suggesting that a well-kept area creates higher perception of safety and reduces the opportunity for unlawful acts in a given 
environment. This concept was operationalized by defining three sub-variables: landscaping, grounds-keeping, and regular control of security/hardware failures. The total possible score for each of these three factors ranges from 0-3; the total score for maintenance ranges from 0-9.

\section{Territoriality}

The fourth principle of CPTED, territoriality, refers to specifying the boundaries of property to decrease the chance of victimization. To operationalize this concept in the school setting, three sub-variables were developed: defining campus boundaries, demarcating boundaries of individual buildings, and defining boundaries between residential and non-residential areas. The total score for each of these three elements ranges from $0-3$ and the total possible score for territoriality ranges from 0-9.

\section{Activity Support}

The last CPTED concept, activity support, refers to the design mechanisms that are used in an area to support its legitimate use and discourage the presence of unauthorized users. In the university context, three sub-variables were defined to operationalize this concept: holding on-campus events, providing recreational opportunities, and existence of student gathering areas. The total score for each of these three sub-variables ranges from 03 , and the sum of all the three scores comprise the total score for activity support-ranging from $0-9$.

Table 3 presents the measurement criteria used to operationalize CPTED concepts. The list includes the indicators of each CPTED principle. The total CPTED score for each institution ranges from $0-45$ and the total possible value of each CPTED strategy ranges from $0-9$. 
Table 3: CPTED Coding Sheet

\begin{tabular}{|c|c|c|}
\hline $\begin{array}{l}\text { CPTED } \\
\text { Concepts }\end{array}$ & Sub-Variables & Indicators \\
\hline \multirow{3}{*}{$\begin{array}{l}\text { Natural } \\
\text { Surveillance } \\
\quad(0-9)\end{array}$} & $\begin{array}{l}\text { Campus Visibility } \\
\text { Status }(0-3)\end{array}$ & $\begin{array}{l}\text { Proper lighting in common areas } \\
\text { Placement of physical features providing better } \\
\text { visibility (e.g., big windows) } \\
\text { Removing obstructions (e.g., potential hiding spots) }\end{array}$ \\
\hline & $\begin{array}{c}\text { Buildings' } \\
\text { Visibility Status } \\
(0-3)\end{array}$ & $\begin{array}{l}\text { Illuminated building exteriors } \\
\text { Well-lighted building surroundings } \\
\text { Buildings' proper interior visibility }\end{array}$ \\
\hline & $\begin{array}{l}\text { Regular Control of } \\
\text { Lighting }(0-3)\end{array}$ & $\begin{array}{l}\text { Encourage people to report lighting failures } \\
\text { Perform regular inspections } \\
\text { Conduct lighting surveys }\end{array}$ \\
\hline \multirow{3}{*}{$\begin{array}{l}\text { Access } \\
\text { Control } \\
(0-9)\end{array}$} & $\begin{array}{l}\text { Main Entrance } \\
\text { Control (0-3) }\end{array}$ & $\begin{array}{l}\text { Vehicle traffic control } \\
\text { ID check } \\
\text { Visitors sign up/Wear badges }\end{array}$ \\
\hline & $\begin{array}{l}\text { Restricted Access } \\
\text { to Residential } \\
\text { Buildings }(0-3)\end{array}$ & $\begin{array}{l}\text { Locked 24/7 } \\
\text { Front desk control } \\
\text { Presence of patrol }\end{array}$ \\
\hline & $\begin{array}{l}\text { Restricted Access } \\
\text { to Non-Residential } \\
\text { Buildings }(0-3)\end{array}$ & $\begin{array}{l}\text { Locked after business hours } \\
\text { Certain labs/rooms only accessible by those } \\
\text { authorized } \\
\text { Additional security measures applied during } \\
\text { extended breaks }\end{array}$ \\
\hline \multirow{3}{*}{$\begin{array}{l}\text { Territoriality } \\
\qquad(0-9)\end{array}$} & $\begin{array}{l}\text { Defining Campus } \\
\text { Boundaries }(0-3)\end{array}$ & $\begin{array}{l}\text { Physical barricades separating campus from } \\
\text { surroundings } \\
\text { Features defining entry/exit of campus area } \\
\text { Signage to direct traffic }\end{array}$ \\
\hline & $\begin{array}{l}\text { Defining Individual } \\
\text { Buildings' } \\
\text { Boundaries }(0-3)\end{array}$ & $\begin{array}{l}\text { Physical barricades around individual buildings } \\
\text { Features defining entry/exit to individual offices } \\
\text { Signage to direct traffic unto individual buildings }\end{array}$ \\
\hline & $\begin{array}{l}\text { Defining } \\
\text { Boundaries } \\
\text { between } \\
\text { Residential and } \\
\text { Non-Residential } \\
\text { Areas }(0-3)\end{array}$ & $\begin{array}{l}\text { Physical barricades around residential areas } \\
\text { Features defining entry/exit to residential areas } \\
\text { Signage indicating the area is residential }\end{array}$ \\
\hline Maintenance & Landscaping (0-3) & Planting and vegetation care \\
\hline
\end{tabular}




\begin{tabular}{|c|c|c|}
\hline \multirow[t]{3}{*}{$(0-9)$} & & $\begin{array}{l}\text { Ground cover/turf maintenance } \\
\text { Sidewalk/road/bike path care }\end{array}$ \\
\hline & $\begin{array}{l}\text { Grounds Keeping } \\
\qquad(0-3)\end{array}$ & $\begin{array}{l}\text { Trash and recycling collection } \\
\text { Landscape pest control } \\
\text { Special occasion services; snow removal }\end{array}$ \\
\hline & $\begin{array}{l}\text { Regular control of } \\
\text { broken fixtures } \\
(0-3)\end{array}$ & $\begin{array}{l}\text { Encourage people to report broken fixtures } \\
\text { Perform regular inspections } \\
\text { Conduct surveys about failures }\end{array}$ \\
\hline \multirow{3}{*}{$\begin{array}{l}\text { Activity } \\
\text { Support } \\
(0-9)\end{array}$} & $\begin{array}{l}\text { Holding Events } \\
\qquad(0-3)\end{array}$ & $\begin{array}{l}\text { Holding on-campus alcohol-free social events } \\
\text { Holding academic seminars/conferences } \\
\text { Holding entertainment events }\end{array}$ \\
\hline & $\begin{array}{l}\text { Existence of } \\
\text { Recreational } \\
\text { facilities }(0-3)\end{array}$ & $\begin{array}{l}\text { Existence of indoor recreational facilities } \\
\text { Existence of outdoor recreational facilities } \\
\text { Existence of student organizations/clubs }\end{array}$ \\
\hline & $\begin{array}{l}\text { Existence of } \\
\text { Gathering Areas } \\
(0-3)\end{array}$ & $\begin{array}{l}\text { Existence of picnic tables, benches, etc. } \\
\text { Existence of cafes, food courts, student lounges } \\
\text { Existence of shops and supermarkets }\end{array}$ \\
\hline $\begin{array}{c}\text { Total } \\
\text { CPTED } \\
(0-45)\end{array}$ & & Sum of all the above variables \\
\hline
\end{tabular}

\section{Standardization of the CPTED Variables}

Fifty-one of the total 100 sampled universities did not have any student residential facilities. Thus, one indicator of access control (i.e., restricted access to residential buildings) and one indicator of territoriality (i.e., defining boundaries between residential and non-residential areas) were not applicable in those cases. Thus, the total possible score of access control and territoriality for these institutions ranged from 0-6 rather than 0-9. This could have created inconsistency in the variables' weights. To address this limitation, the values assigned to all the CPTED sub-variables were standardized by calculating a proportionate value for each quantity. Following standardization, each CPTED sub-variable ranged from 0-3, and the indicators of each sub-variable ranged from 0-1. 


\section{Operationalization of Non-CPTED Control Variables}

Non-CPTED control variables were included in the model. These are nonenvironmental strategies that are employed on college campuses to prevent crime. The nonCPTED variables that were taken into account in the model include educational and awareness programs, presence of patrol officers, surveillance cameras [closed-circuit television (CCTV)], emergency callboxes, community-oriented programs, and campus escort. The operationalization of these variables is discussed below.

\section{Educational and Awareness Programs}

Universities typically offer educational programs for campus safety. These programs can include lectures, seminars, workshops, and trainings. Through these programs, institutions may provide general security tips for students, staff, and faculty. They may also go beyond that generic approach and target particularly vulnerable groupseducating them on specific safety hazards. Some schools offer these educational programs only to newcomers during the orientation period, while others hold regular and ongoing awareness and prevention campaigns. The education and awareness activities at some schools were minimal (e.g., security tips in their official websites and newspapers; Clery Reports).

These criteria above were used to operationalize this variable. Three indicators were developed: providing basic security tips, providing primary awareness programs (for newcomers), and holding ongoing awareness events. So, the total possible score for this variable ranges from $0-3$. If a university offers only one of these three services, the assigned score is 1 . If two are offered, the score is 2; if all three are offered, the score is 3 . 
A 0 score is assigned to schools that do not perform any of these tasks. Thus, this variable was coded as an ordinal variable, based on the universities' Clery Reports.

\section{Presence of Patrol}

The model also controls for the presence of patrol officers on campus. These officers can be either campus safety officers - who are non-sworn and unarmed — or sworn police officers who are authorized to carry firearms and make arrests. This variable was coded as a binary variable, where 0 indicates lack of patrol officers, and 1 indicates their presence on campus. The presence or lack of patrol officers was based on the institutions' Clery Reports.

\section{Surveillance Cameras (CCTV)}

The use of CCTV on school campuses was also controlled for in the study. So, the application of formal surveillance through the use of CCTV was coded as a binary variable. The schools that have camera systems in place were coded as 1, and institutions without CCTV were coded as 0 . The utilization of surveillance cameras was also reported on institutions' Clery Reports.

\section{Emergency Callboxes (Blue Light Phones)}

Blue light phones or emergency callboxes are usually located throughout campuses to facilitate communication with campus security offices, in case of a security hazard. By pressing a button, it connects to the dispatcher for immediate assistance. The study model controlled for the presence of these emergency phones on school campuses. Thus, institutions with this security feature were coded as 1 , and institutions without this element were coded as 0 . This variable was also coded based on schools' Clery Reports. 


\section{Community-Oriented Programs}

The other factor that was controlled for in the model is community-oriented prevention programs. In the context of universities, these strategies refer to the involvement of campus community in crime prevention. Neighborhood watch and bystander intervention programs are two common community-oriented strategies that are used on college campuses. This was coded as a binary variable, where 1 represents use of this type of program, and 0 indicates lack of such program. This variable was coded according to schools' Clery Reports.

\section{Campus Escort}

Campus escort is the last non-CPTED control variable that is accounted for in the model. This service provides safe transit - from one location on campus to another-at night for students, faculty, and staff upon request. Institutions that offer this service were coded as 1 ; they were coded as 0 if the service is not offered.

Table 4 lists the operationalization criteria used for the non-CPTED crime prevention techniques. The total possible scores for each variable is shown in the table.

Table 4: Non-CPTED Variables Coding Sheet

\begin{tabular}{|l|c|c|}
\hline Non-CPTED Variables & \multicolumn{1}{|c|}{ Indicators } & Range \\
\hline $\begin{array}{l}\text { Educational and Awareness } \\
\text { Programs }\end{array}$ & $\begin{array}{l}\text { Provide security tips (0/1) } \\
\text { Hold primary awareness programs (0/1) } \\
\text { Hold regular awareness campaigns (0/1) }\end{array}$ & $0-3$ \\
\hline Presence of Patrol & Yes/No & $0-1$ \\
\hline Surveillance Cameras (CCTV) & Yes/No & $0-1$ \\
\hline $\begin{array}{l}\text { Emergency Callbox or Blue Light } \\
\text { Phones }\end{array}$ & Yes/No & $0-1$ \\
\hline Community-oriented Programs & Yes/No & $0-1$ \\
\hline Campus Escort & Yes/No & $0-1$ \\
\hline
\end{tabular}




\section{Inter-Coder Reliability}

Using the above operationalization technique, the Clery Reports and the campus maps of the sampled institutions were reviewed. All CPTED principles and non-CPTED control variables were coded for each institution. Then, to improve the reliability of selfcoded data and reduce the possibility of any bias, an inter-coder reliability technique was used. "Inter-coder reliability is an indispensable validity criterion for studies that employ content analysis" (Freelon, 2010, p.20). "The ultimate aim of testing reliability is to ensure that unreliabilities are negligible so as to justify continuing the coding or starting an analysis of the data toward answering research questions" (Krippendorff, 2004, p. 241). To ensure inter-coder reliability, four conditions must be met: using multiple independent coders, having a proper operationalization technique, setting a threshold for agreement, and reporting reliability scores (Berke \& Godschalk, 2009).

Two graduate students were recruited to measure the same variables: CPTED and non-CPTED concepts. Each student reviewed one-half of the Clery Reports and campus maps (i.e., 50 schools each student) and coded them using the same operationalization criteria. Two sets of data, one coded by the researcher and one coded by the recruited students, were compared to check the reliability of coding. To assess the level of agreement between the two datasets, the Reliability Calculator OIR (Freelon, 2013) was used. This is an inter-coder reliability web-service. ${ }^{1}$ It can calculate reliability coefficients for ordinal, interval, and ratio data coded by two or more individuals.

Inter-coder reliability for nominal-level data is calculated by dividing the number of agreements between two independent coders by the total number of the unit of analysis.

\footnotetext{
${ }^{1}$ http://dfreelon.org/utils/recalfront/recal-oir/
} 
However, the nominal method cannot be applied for variables at the other three levels of measurement: ordinal, interval, and ratio (Freelon, 2010, 2013). To address this limitation, Hayes and Krippendorff (2007) explain how the Krippendorff reliability coefficient can be used for all four levels of measurement (Freelon, 2013). "The result is a suite of four mathematically distinct Krippendorff's alpha formulae, each calibrated to fit the contours of one of the measurement levels" (Freelon, 2013, p. 11). The Reliability Calculator OIR (ReCal OIR) web-service has added a new function to the original two nominal-only ReCal modules (Freelon, 2010), which operates with all four levels of measurement (Freelon, 2013).

The next step was to select a threshold for an acceptable level of agreement between coders. The Krippendorff's standard, which relies on variables with reliabilities above .80, was adopted (Krippendorff, 2004). In Table 5, agreement coefficients among the two datasets of the study variables are reported.

Table 5: Reliability Results

\begin{tabular}{|l|c|}
\hline Variables & Compliance Coefficients \\
\hline CPTED Principles & \\
Natural Surveillance & .95 \\
Access Control & .86 \\
Territoriality & .89 \\
Maintenance & .93 \\
Activity Support & .88 \\
\hline Non-CPTED Crime Prevention & \\
Educational Programs & .95 \\
Patrol & .90 \\
CCTV & .91 \\
Emergency Callbox & .88 \\
Community-Oriented Programs & .83 \\
Campus Escort & .89 \\
\hline
\end{tabular}




\section{Data Analysis and Results}

Earlier in this chapter, the quantitative research design and methods used to test the first hypothesis of this study were presented. Below, results of the quantitative analyses performed in the first phase of the dissertation are discussed. This section proceeds as follows. First, a map is provided to visually illustrate the distribution of CPTED across the United States. Second, descriptive statistics of the sample are briefly reviewed. Then, the correlation matrix of the variables adopted in the analysis is provided. Finally, results of the regression analysis for several equation models are discussed.

Figure 5 displays the level of CPTED use within the sampled institutions across the U.S. states. The dots represent universities and the colors represent level of CPTED application. No clear pattern is observed here; however, in the northeastern part of the country and the South Atlantic region, there is a lower application of CPTED; moving toward the mid-west and southcentral areas, higher level of CPTED is observed. 
Figure 5: Level of CPTED Application Across Sampled Universities

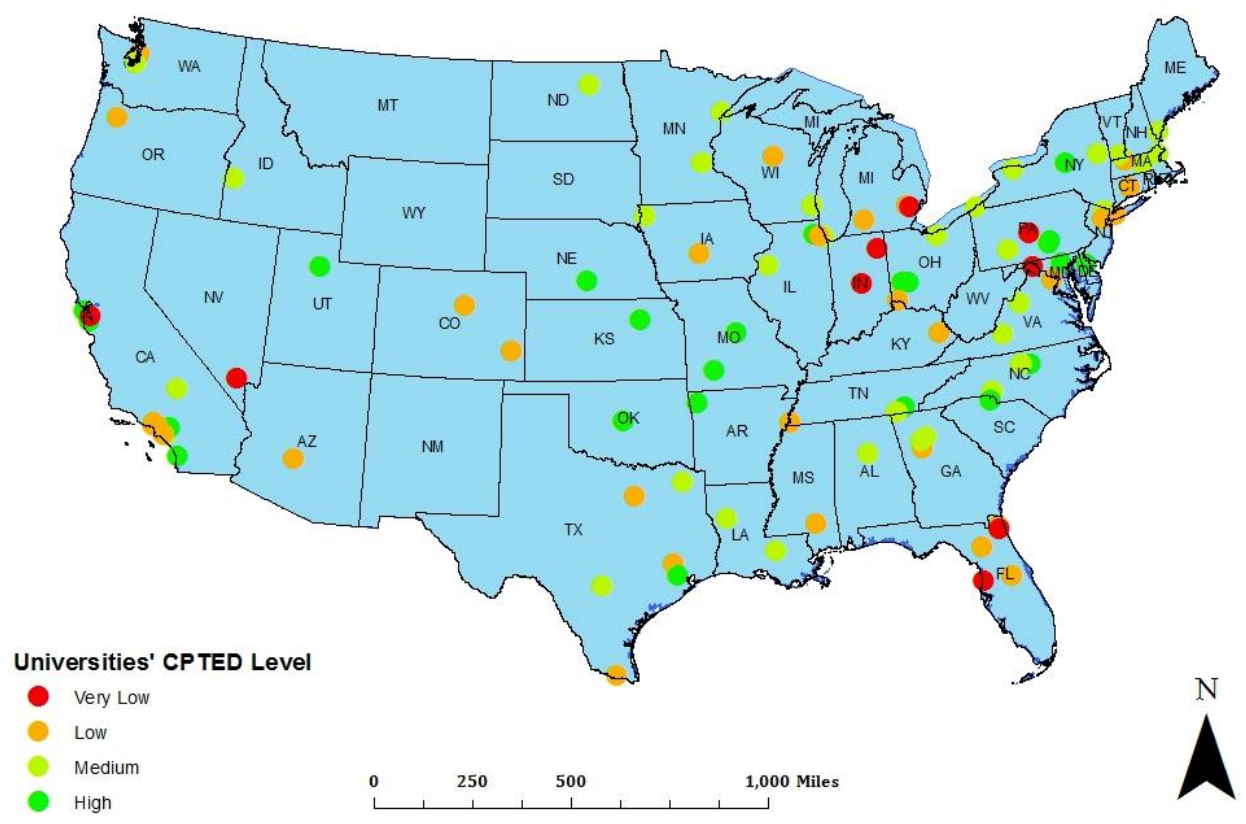

\section{Descriptive Statistics}

Table 6 presents descriptive statistics for the variables used in the analysis; the table presents several important findings. First, violent crime and property crime were committed at about the same rate in the sampled school campuses, $M=3.01$ and $M=3.02$, respectively, whereas violence against women (VAWA) and other violations differed significantly from violent crime and property crime in terms of frequency (VAWA crime $M=1.32$ vs. other violations $M=15.87$ ). Second, standard deviation of the mean for other violations is higher than the other three crime types, suggesting that the other violations' data are more spread out from the mean (other violations $S D=33.66$ vs. violent crime $S D=10.73$, property crime $S D=6.52$, VAWA crime $S D=5.77$ ). This might be due to the wide range of violations that fall within this crime category (i.e., violations of drug, liquor, and weapons laws). Third, 
among the CPTED strategies, access control and activity support are more common across the sampled universities (access control $M=.29$, activity support $M=.28$ ), whereas the other three CPTED measures are not as visible (natural surveillance $M=.14$, maintenance $M=.13$, territoriality $M=.12$ ).

Table 6: Descriptive Statistics of Variables Used in the Analysis

\begin{tabular}{|c|c|c|c|c|c|c|c|}
\hline Variable & Description & Min & Max & Mean & Std. Dev. & Range & $\mathbf{N}$ \\
\hline \multicolumn{8}{|l|}{ Dependent Variables } \\
\hline Campus Crime Total & Rate Per 1000 & 0 & 209.85 & 23.23 & 41.62 & & 100 \\
\hline Violent Crime & Rate Per 1000 & 0 & 80.9 & 3.01 & 10.73 & & 100 \\
\hline Property Crime & Rate Per 1000 & 0 & 42.31 & 3.02 & 6.52 & & 100 \\
\hline VAWA & Rate Per 1000 & 0 & 43.47 & 1.32 & 5.77 & & 100 \\
\hline Other Violations & Rate Per 1000 & 0 & 188.9 & 15.87 & 33.66 & & 100 \\
\hline \multicolumn{8}{|l|}{ Independent Variables } \\
\hline \multicolumn{8}{|l|}{ CPTED Principles } \\
\hline Natural Surveillance & & 0 & .55 & .14 & .145 & $0-1$ & 100 \\
\hline Access Control & & 0 & .77 & .29 & .173 & $0-1$ & 100 \\
\hline Maintenance & & 0 & .44 & .13 & .132 & $0-1$ & 100 \\
\hline Territoriality & & 0 & .66 & .12 & .121 & $0-1$ & 100 \\
\hline Activity Support & & 0 & 1 & .28 & .266 & $0-1$ & 100 \\
\hline Total CPTED Score & & 0 & 2.48 & .95 & .591 & $0-5$ & 100 \\
\hline \multicolumn{8}{|l|}{ Non-CPTED } \\
\hline Awareness Programs & & 0 & 3 & 1.68 & 1.014 & $0-3$ & 100 \\
\hline Patrol & $1=$ Yes & 0 & 1 & .61 & .490 & $0-1$ & 100 \\
\hline CCTV & $1=$ Yes & 0 & 1 & .39 & .490 & $0-1$ & 100 \\
\hline Emergency Call Box & $1=$ Yes & 0 & 1 & .37 & .485 & $0-1$ & 100 \\
\hline Community-Oriented & $1=$ Yes & 0 & 1 & .47 & .502 & $0-1$ & 100 \\
\hline Campus Escort & $1=$ Yes & 0 & 1 & .48 & .502 & $0-1$ & 100 \\
\hline \multicolumn{8}{|l|}{ School Characteristics } \\
\hline Undergraduate & $1=$ Yes & 0 & 1 & .51 & .502 & $0-1$ & 100 \\
\hline Large & $1=$ Yes & 0 & 1 & .22 & .416 & $0-1$ & 100 \\
\hline Public & $1=$ Yes & 0 & 1 & .36 & .482 & $0-1$ & 100 \\
\hline Urban & $1=$ Yes & 0 & 1 & .57 & .498 & $0-1$ & 100 \\
\hline \multicolumn{8}{|l|}{ City Crime Rate } \\
\hline City Overall Crime & $\begin{array}{l}\text { Rate Per } \\
100,000\end{array}$ & 943 & 16712.3 & 4620.5 & 2326.81 & & 100 \\
\hline City Violent Crime & $\begin{array}{l}\text { Rate Per } \\
100,000\end{array}$ & 10.4 & 1750.3 & 570.5 & 370.8 & & 100 \\
\hline City Property Crime & $\begin{array}{l}\text { Rate Per } \\
100,000\end{array}$ & 887.8 & 16194.4 & 4049.9 & 2111.2 & & 100 \\
\hline
\end{tabular}


Figure 6: Variability of CPTED Strategies Across the Sample

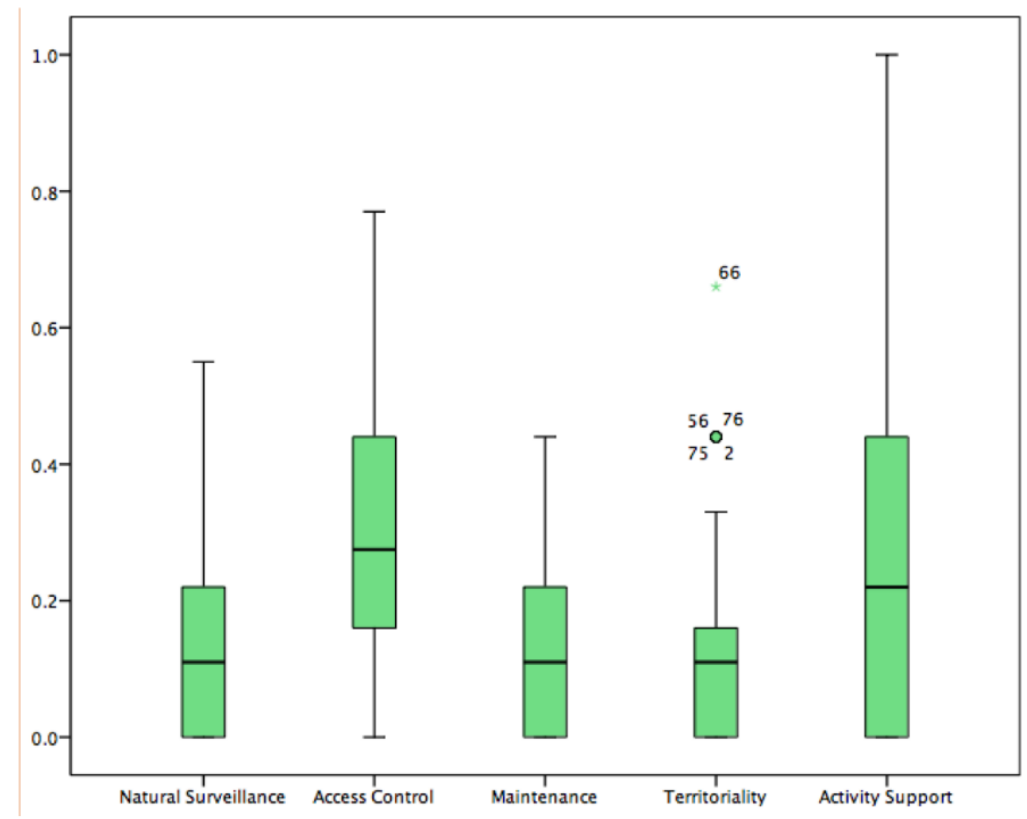

Boxplots further illustrate the variability of the five CPTED strategies across the sample, as presented in Figure 6. Fourth, among non-CPTED prevention measures, patrol $(M=.61)$, awareness programs $(M=.56)$, and campus escort $(M=.48)$ are more commonly used. In addition, Table 6 reveals the institutional characteristics of the sampled schools. Fifty-seven percent of the schools are located in an urban area. Fifty-one percent are predominantly undergraduate. Thirty-six percent are public institutions and $22 \%$ are categorized as large schools. Finally, the table reports on city crime rates, suggesting that the mean of city's property crimes is significantly higher than the average city's violent crimes.

\section{Correlation and Regression Findings}

To further analyze the study variables, correlations were run to determine any significant relationships. The variables were not normally distributed. Thus, Spearman's 
correlations were conducted to statistically test the relationships. As reported in Table 7, Spearman's correlations identified significant positive correlations between CPTED variables and campus crime rates, which was an unexpected finding. Total CPTED Score is correlated with all types of campus crime in a positive direction.

Table 7: Correlation Matrix

\begin{tabular}{llllll}
\hline Independent variables & $\begin{array}{l}\text { Violent } \\
\text { Crime }\end{array}$ & $\begin{array}{l}\text { Property } \\
\text { Crime }\end{array}$ & $\begin{array}{l}\text { VAWA } \\
\text { Crime }\end{array}$ & $\begin{array}{l}\text { Other } \\
\text { Violations }\end{array}$ & $\begin{array}{l}\text { Overall } \\
\text { Crime }\end{array}$ \\
\hline CPTED Principles & & & & & \\
\hline Natural Surveillance & .185 & .132 & $.375^{* * *}$ & .157 & .157 \\
Access Control & $.249^{* *}$ & $.228^{* *}$ & $.225^{* *}$ & $.262^{* * *}$ & $.383^{* * *}$ \\
Maintenance & $.309^{* * *}$ & $.204^{* *}$ & $.430^{* * *}$ & $.313^{* * *}$ & $.274^{* * *}$ \\
Territoriality & .092 & .100 & $.411^{* * *}$ & $.283^{* * *}$ & .166 \\
Activity Support & $.269^{* * *}$ & $.251^{* *}$ & $.497^{* * *}$ & $.541^{* * *}$ & $.356^{* * *}$ \\
Total CPTED Score & $.327^{* * *}$ & $.288^{* * *}$ & $.574^{* * *}$ & $.502^{* * *}$ & $.420^{* * *}$ \\
\hline Non-CPTED Prevention & & & & & \\
\hline Awareness programs & $.259^{* * *}$ & $.219^{* *}$ & $.305^{* * *}$ & $.310^{* * *}$ & $.302^{* * *}$ \\
Patrol & .094 & .131 & $.492^{* * *}$ & $.369^{* * *}$ & $.229^{* *}$ \\
CCTV & .028 & .055 & .114 & .106 & .118 \\
Emergency Callbox & $.280^{* * *}$ & $.198^{* *}$ & $.449^{* * *}$ & $.298^{* * *}$ & $.262^{* * *}$ \\
Community-oriented programs & .164 & .051 & $.352^{* * *}$ & $.313^{* * *}$ & .186 \\
Campus Escort & $.263^{* * *}$ & .151 & $.384^{* * *}$ & $.261^{* * *}$ & .195 \\
\hline
\end{tabular}

$* \mathrm{p}<.1 * * \mathrm{p}<.05 * * * \mathrm{p}<.01$

This unexpected positive correlation also exists between campus crime and nonCPTED crime prevention strategies, as presented in

Table 7. Awareness programs and emergency callbox are significantly correlated with all types of crime. Presence of patrol and community-oriented programs are significantly correlated with VAWA crime and other violations. Campus escort is correlated with violent Crime, VAWA, and other violations.

Given this significant correlation, it appears that universities that have higher rates of crime are more likely to use CPTED and other crime prevention strategies. In other words, universities that are experiencing crime issues seem to be implementing crime 
prevention measures that are aligned with CPTED and non-CPTED techniques. The analysis has not controlled for the time element. Thus, it is not clear when these crime prevention strategies were implemented. Therefore, no causal conclusion can be made asserting that CPTED/non-CPTED measures are creating the crime issue, because it is not known which factor comes first.

To further test this proposition, a series of nested regression models were used. Two sets of regression equations were run to estimate the inter-relationships between campus crime and CPTED techniques - using Ordinary Least Square (OLS) approach. The first set of regression equations included four models. In the first model, only CPTED strategies were included. The second model considered non-CPTED measures in addition to the CPTED variables. Then, school characteristics were introduced into the third model. Finally, city crime rates were added to the last model.

Below, the equation for the final model is presented. It consists of one dependent variable (campus overall crime rate), five main independent variables (CPTED components), and several control variables. This model has the following regression equation:

$$
C C=C+\beta_{1} X_{1}+\beta_{2} X_{2}+\beta_{3} X_{3}+\beta_{4} X_{4}+\beta_{5} X_{5}+\beta_{6} X_{6}+\beta_{7} X_{7}+\beta_{8} X_{8}
$$

Where $C C$ is Campus Crime, $X_{1}$ through $X_{5}$ represent five principles of CPTED (i.e., natural surveillance, access control, territoriality, maintenance, and activity support) as the explanatory variables. Three groups of control variables are also considered in the model, including non-CPTED prevention measures, school features, and city crime rates, shown as $X_{6}, X_{7}$, and $X_{8}$, respectively. 
Table 8 provides the results of the four models explaining campus crime rates. In Model 1, access control and activity support are significant at the .01 level, and they remain significant through the fourth model. However, none of the control variables are found to be significant. R-Square has slightly increased through the last model. While the study hypothesis is not supported here, this significant positive association aligns with the correlation results discussed earlier. The reverse relationship between two CPTED measures (i.e., access control and activity support) and campus crime reinforces the argument that time is playing a role in the model. In other words, universities with crime issues tend to implement higher level of access control and activity support.

Table 8: Regression Models Explaining Campus Crime

\begin{tabular}{|c|c|c|c|c|}
\hline & Model 1 & Model 2 & Model 3 & Model 4 \\
\hline \multicolumn{5}{|l|}{ CPTED Strategies } \\
\hline Natural Surveillance & -.984 & -.721 & -.724 & -.723 \\
\hline Access Control & $1.309 * * *$ & $1.276 * * *$ & $1.220 * * *$ & $1.189 * * *$ \\
\hline Maintenance & .978 & .902 & 1.023 & 1.089 \\
\hline Territoriality & -.804 & -.856 & -.867 & -.835 \\
\hline Activity Support & $1.041 * * *$ & $1.227 * * *$ & $1.338 * * *$ & $1.326^{* * *}$ \\
\hline \multicolumn{5}{|l|}{ Non-CPTED Strategies } \\
\hline Awareness Program & & .090 & .098 & .105 \\
\hline Patrol & & -.330 & -.311 & -.329 \\
\hline CCTV & & .58 & .036 & .040 \\
\hline Emergency Callbox & & .143 & .130 & .130 \\
\hline Community-oriented & & .053 & .074 & .061 \\
\hline Campus Escort & & -.114 & -.100 & -.090 \\
\hline \multicolumn{5}{|l|}{ School Features } \\
\hline Undergraduate & & & .042 & .048 \\
\hline Public & & & -.098 & -.079 \\
\hline Large & & & -.103 & -.101 \\
\hline Urban & & & -.007 & -.012 \\
\hline \multicolumn{5}{|l|}{ City Crime Rate } \\
\hline City Violent Crime & & & & .105 \\
\hline City Property Crime & & & & .044 \\
\hline $\mathrm{R}^{2}$ & .229 & .264 & .272 & .275 \\
\hline
\end{tabular}


Considering the above results, another set of regression analyses were run to explore the possible influence of campus crime rates on the use of CPTED. Hence, in the second set of equations, CPTED is the dependent variable and campus crime is the independent variable. School characteristics and city crime rates are also included in the analysis as control variables.

Table 9: Regression Models Explaining CPTED Application

\begin{tabular}{llll}
\hline & Model 1 & Model 2 & Model 3 \\
\hline Campus Crime Rate & & & \\
Campus Violent Crime & .011 & .034 & .037 \\
Campus Property Crime & -.038 & -.029 & -.033 \\
Campus VAWA Crime & $.099^{*}$ & .057 & .061 \\
Campus Other Violations & $.066^{* * *}$ & $.051^{* * *}$ & $.051^{* *}$ \\
University Characteristics & & & \\
Undergraduate & & $-.066^{* * *}$ & $-.070^{* * *}$ \\
Large & & $.060^{*}$ & $.060^{*}$ \\
Public & & $.052^{*}$ & .049 \\
Urban & & .008 & .013 \\
City Crime Rate & & & \\
City Violent Crime & & & -.039 \\
City Property Crime & & & .062 \\
$\mathrm{R}^{2}$ & & .399 & .407 \\
\hline${ }^{*} \mathrm{p}<.1 . * * \mathrm{p}<.05 . * * \mathrm{p}<.01$ & & &
\end{tabular}

Table 9 presents the results of the second set of regression equations. Model 1 examines campus crime rates as the independent variables. There are several important findings here. Most important and in support of the reverse relationship argument, two types of campus crime are associated with higher use of CPTED. Other violationsviolations of liquor, drug, and weapons laws - are significantly and positively related to the 
use of CPTED. On-campus violence against women is also associated with higher application of CPTED measures.

In the second model, violence against women no longer influences the use of CPTED strategies on campus - however, other violations remained significant through the third model. Additionally, Model 2 controls for institutional characteristics, suggesting that universities that are predominantly undergraduate use less CPTED. This model further reveals that large universities tend to apply CPTED strategies more than smaller institutions. Lastly, Model 2 identifies significant positive relationship between being a public school and higher CPTED application. Following the inclusion of city crime rates in Model 3, being a public school no longer influences the use of CPTED, whereas city crimes were not found to be significant. In the final model, three variables remain influential on CPTED utilization: other violations and being a large institution-in a positive direction - and being a predominantly undergraduate institution in a negative direction.

\section{Discussion and Conclusion}

The phase one of this dissertation explored the inter-relationships between CPTED and campus crime. Correlation and regression analyses were performed to test the first hypothesis of the study. The hypothesis stated that universities with higher level of CPTED application are more likely to have lower crime rates - compared to low-CPTED campuses. Although the results of the analyses did not support the hypothesis due to the lack of control for the time factor, they revealed several important findings, which are discussed in this section. 
First, this phase contributes to the research literature by assessing the extent of CPTED application at university campuses in the United States. A systematic content analysis of the Clery Reports of a representative sample of American universities offered insight into the deployment of CPTED strategies in U.S. institutions of higher education. The descriptive findings, when taken as a whole, suggest that the CPTED approach is being utilized at U.S. universities, with some spatial variations. The analyses also examined the variability of the use of CPTED strategies across the sampled universities, indicating that access control and activity support strategies are the most commonly used CPTED methods.

Second, the highly significant correlations between campus crime rates and use of CPTED provided insight into the possible influence of universities' crime issues on the use of crime prevention measures. To explore this, a second set of regression analyses were run to measure the impact of crime on the use of CPTED. The analyses supported the reverse relationship argument and uncovered the effect of campus crime on the use of CPTED strategies. The regression findings indicated that institutions with higher crime rates tend to apply more environmental crime prevention techniques.

This study had several noteworthy limitations. The time factor was not controlled for in the analyses because the data on crime rates and CPTED strategies were collected from the latest Clery Reports of the sampled intuitions - published in the 2014-2015 academic year. Controlling for the time factor was not possible due to the complexities involved in the data collection process. Because of the tedious process of content analysis of Clery Reports, it was not feasible to review multiple years of reports for each institution. Collecting time-series data of CPTED application and crime rates in future studies can 
provide further understanding of temporal variations in the use of CPTED and its influence on campus safety over time.

The second limitation relates to potential inconsistencies between what is reflected in Clery Reports and what is actually in practice, CPTED-wise. Although the Clery Reports should clearly detail the universities' safety policies and practices, discrepancies can create bias in the study results. This dissertation was not able to verify the accuracy of the reports because of time concerns; however, future studies can address this issue by including a survey component targeting personnel from the institutions' safety departments, or conducting qualitative research to investigate the actual status of CPTED utilization.

Moreover, inconsistencies did exist across institutions in terms of how they report on available security services and crime prevention procedures. Universities differed considerably in terms of the content and the narration style that they used in the Clery Reports to describe their safety and prevention programs. This might have affected the coding of CPTED components throughout the documents.

To address this issue, an inter-coder reliability analysis was conducted, using multiple coders and an operationalization protocol to verify the reliability of self-coded data. Furthermore, to complement the analyses performed in this phase, two other study phases were designed, which are discussed in the following chapters: (Phase 2) an analysis of campus residents' perception of safety, which aimed to assess the effect of CPTED on community's feelings of safety aside from official crime rates; and (Phase 3) a qualitative case study in a campus setting with a systematic CPTED program in place, which sought to advance knowledge on the use of environmental crime prevention approaches in academic settings. 


\section{Chapter Four: An Analysis of the Relation Between CPTED and Perception of Safety}

\section{Introduction}

The second phase of this study focuses on students' safety perception as another dimension of campus security. This phase sought to investigate the effect of the application of CPTED on students' perception of safety; the aim was to obtain a more tangible understanding of the impact of CPTED-beyond what could be obtained from an examination of official campus crime rates. The literature review chapter indicated that previous research has not empirically examined the extent to which the principles of CPTED have been applied in university campuses. Although CPTED has shown promise in reducing crime opportunities, research has only begun to empirically assess whether environmental design is associated with residents' perception of safety. Moreover, researchers in this area have not yet determined if the campus housing facilities' compatibility with CPTED standards affects the residents' perception of safety.

This phase of the dissertation aimed to narrow this gap in the literature by comparing the perception of safety at two different campus residential facilities. This phase was carried out in a university with two structures that varied significantly in terms of environmental design. The reason for this selection was to control for other determinants of crime, including urban/rural setting, community characteristics, and the university's macrolevel security policies. In other words, several other factors that contribute to criminal offending were held constant by examining two different parts of the same university. Thus, one high-CPTED facility and one low-CPTED facility were identified and the perceptions of safety of their inhabitants were compared. 
This phase of the dissertation sought to address the second research question of the study: is the use of CPTED principles correlated with students' perception of safety in college campuses? Below, the methods used to answer the second research question are described. Then, the variables included in the analysis and their operationalization criteria are explained. Following a description of the study's analytical approach, the t-tests and regression results are presented. A discussion of results, limitations, and conclusions complete the chapter.

\section{Methodology}

The gap in the research literature gave rise to the following question: are residents of dormitories with design features that are consistent with CPTED principles more likely to have higher perception of safety compared to residents in facilities with lower level of CPTED? To answer this research question, this phase examined: (1) whether there was a significant difference between the perceptions of safety of students residing in the two facilities and (2) whether their safety perceptions were influenced by the location of their residence.

Resident students were selected as study participants, as previous research has shown that they spend a considerable amount of time at or near their campus residences (Robinson, 1999). Therefore, they have a good assessment of the area-compared to other frequent users or commuters to campus. Thus, their perception of safety is, to a great extent, affected by the social and environmental characteristics of their living quarters on campus.

Two housing facilities of Florida International University (FIU), located in Miami, Florida, were selected for this study: a newly built facility—which was more likely to meet 
CPTED criteria - and an old facility, appeared less compatible with CPTED standards. University Apartments (UA) comprises a series of two story buildings in a courtyard style located in the eastern part of campus and University Towers (UT) is a complex of apartment buildings situated in the center of the campus as a part of a residential quad. UA was built in 1986 in a traditional architectural style while UT was constructed in 2000 with a more modern design and landscaping. UA accommodates 537 individuals and UT accommodates 481 students. Residents of both halls are mostly upper-classmen (junior/senior students). At first glance, sizeable differences exist between these two structures in terms of environmental design and landscaping.

\section{Data and Variables}

The data for this phase came from two sources: (1) individual-level data from a survey of students residing in the two facilities administered during a three-week period from May $3^{\text {rd }}$ to $28^{\text {th }} 2015$ and (2) systematic observations of the buildings' environmental features during a two-week period from July $15^{\text {th }}$ to $28^{\text {th }} 2015$.

Through the administration of a survey questionnaire, the perceptions of safety of students residing in each facility were estimated and in-site observations were conducted to determine how consistent each facility was with CPTED. T-test was used to compare the average perception of safety of the residents of the two sites; then, a multivariate regression analysis was conducted to determine if their safety perception was correlated with their place of residence. The survey questionnaire is attached in the Appendix.

Survey respondents were selected using a convenience sampling techniqueapplied while walking around each facility and asking passersby to participate. The final sample consisted of 100 respondents: 50 students residing in UA and 50 students residing 
in UT. Although several individuals refused to participate, the response rate was $91 \%$. Participants' verbal consent was obtained at the start of each conversation following an explanation of the purpose of research, and a description of the potential risks and benefits of participation.

In addition, a series of in-site observations were conducted. Using a check-list of CPTED components and their indicators, the level of CPTED for each dormitory was determined. The CPTED elements were measured using the operationalization techniques described in the first phase. See Table 3 for the complete list of CPTED principles' measurement criteria and indicators. Through active looking, informal conversation, and field notes, the indicators of CPTED principles were identified and each dormitory was scored.

\section{Dependent Variable}

The perception of safety of on-campus residents is the dependent variable of the study, which stems from respondents' self-reports. This variable was measured by asking five survey questions: (1) How safe do you feel in your individual rooms? (2) How safe do you feel about the safety of your personal belongings in the rooms? (3) How safe do you feel in the dormitory halls, (4) How safe do you feel while walking in surrounding areas at night, and (5) How safe do you feel overall in their dorm residence. The dependent variable was estimated at an ordinal level of measurement, ranging from 1 (very unsafe) to 10 (very safe).

\section{Independent Variables}

The main explanatory variable of this phase is the dormitory of residence. To measure the impact of location, a dichotomous variable was developed: residing in UT was 
coded as 1 and residing in UA was coded as 0 . In addition, a group of resident-related variables were controlled for in the model. These variables include: age, gender, race, educational level, duration of stay in dormitory, and victimization experience. Gender and race were measured at the nominal level, age and duration of stay at the ratio level, and educational status at the ordinal level. Victimization experience was measured as a dichotomous variable. Respondents were asked whether they had ever been victimized in/around their dormitory or if they know of someone who had such experience. Their responses were coded as $0=$ "No Victimization Experience" and $1=$ "Having 1 or more Victimization Experience either of themselves or others."

\section{Data Analysis and Results}

To answer the first part of the research question, a one-tailed t-test was used to determine whether the average safety perceptions of each site's residents were equivalent or different. The null hypothesis in this approach is that there is no statistically significant difference between the two group means; $\mathrm{H}_{0}: U T=U A$, which suggests that differences between two facilities - in terms of environmental design — do not significantly affect the perception of safety of residents.

To address the second part of the research question, a series of nested regression models were used. Three models were estimated to examine the correlations between students' perception of safety and their residential facilities. Model 1 assessed the influence of residing in one of the two sites on the residents' perception of safety. Model 2 considered the effect of participants' demographic characteristics. Thus, age, gender, educational standing, and race/ethnicity were added to the model. Lastly, Model 3 added previous victimization experience and duration of stay in residential facilities to the 
equation to examine a full model of location, demographics, and past victimization experience.

\section{Descriptive Statistics}

Table 10 summarizes the descriptive statistics of the study variables. The table presents several central findings. First, the residents of UT, on average, reported an overall perception of safety of 7.12, while UA residents, on average, showed a lower perception of safety: 5.34. Second, the respondents from both residences were approximately the same age on average (UT, $M=23$ vs. $U A, M=22$ ), the number of male and female participants was intentionally kept equal, and the average duration of stay of UT and UA residents was also approximately the same (UT, $M=1.7$ years vs. UA, $M=1.4$ years).

However, the proportions of freshmen and non-Americans in the population differed according to residence: Freshmen UT, N=11 (22\%) vs. UA, N=19 (38\%); NonAmericans UT, $\mathrm{N}=6(12 \%)$ vs. UA, $\mathrm{N}=12(24 \%)$. This difference indicates a possible impact on the average safety perception of UA residents from more newcomers or foreign students. Third, UT participants had a higher rate of past victimization compared to UA respondents [UT (14\%) vs. UA (10\%)], although they showed a higher level of safety perception. This was an interesting finding-suggesting that better environmental design can compensate for the influence of past victimization experience on perception of safety.

Table 10: Descriptive Statistics for the Variables Used in the Analyses

\begin{tabular}{cllll}
\hline & Mean & Std. Dev & Range & Number \\
\hline & \multicolumn{4}{l}{ University } \\
\hline & & & \\
\hline Dependent Variables & 5.85 & 1.31 & $3-10$ & 50 \\
Perception of Safety & 5.44 & 1.83 & $2-9$ & 50 \\
Individual Rooms & 5.24 & 1.94 & $2-10$ & 50 \\
Personal Belongings & 5.29 & 1.95 & $3-10$ & 50 \\
Safety in Halls & 5.32 & 1.69 & $2-8$ & 50
\end{tabular}




\begin{tabular}{lllll} 
Independent Variables & & & \\
Age & 22 & .48 & $19-29$ & 50 \\
Male & .5 & .51 & $0-1$ & 25 \\
Freshman & .38 & .3 & $0-1$ & 9 \\
Non-American & .24 & .5 & $0-1$ & 12 \\
Duration of Stay & 1.4 & .8 & $>1-4<$ & 50 \\
Victimization Experience & .1 & .4 & $0-1$ & 5 \\
\hline & University Towers (UT) & & \\
\hline Dependent Variables & & & & \\
Perception of Safety & 6.24 & .96 & $3-10$ & 50 \\
Individual Rooms & 6.8 & 1.68 & $2-10$ & 50 \\
$\quad$ Personal Belongings & 5.72 & 1.71 & $3-10$ & 50 \\
$\quad$ Safety in Halls & 6.08 & 1.38 & $1-10$ & 50 \\
$\quad$ Walking at Night & 5.92 & 1.55 & $2-10$ & 50 \\
& & & & \\
Independent Variables & & & & \\
Age & 23 & .43 & $18-27$ & 50 \\
Male & .5 & .53 & $0-1$ & 25 \\
Freshman & .22 & .27 & $0-1$ & 11 \\
Non-American & .12 & .39 & $0-1$ & 6 \\
Duration of Stay & 1.7 & .91 & $>1-4<$ & 50 \\
Victimization Experience & .14 & .18 & $0-1$ & 7 \\
& & & & \\
\hline
\end{tabular}

\section{T-test Results}

The descriptive statistics clearly indicate higher average safety perception for UT residents. Additionally, t-tests were used to determine if there were statistically significant differences between the group means of safety perceptions of residents of each facility. The average perception of safety of UT residents was significantly higher than that of UA inhabitants: $t(99)=2.99, p<.01$. The $t$-test results indicated a statistically significant difference at the .05 significance level between the group means of UA and UT residences, rejecting the null hypothesis of the study and suggesting that the two groups were significantly different in their perceptions of safety. Figure 7 contains a boxplot to further illustrate the differences revealed in the means tests. 
Figure 7: Differences in Perception of Safety

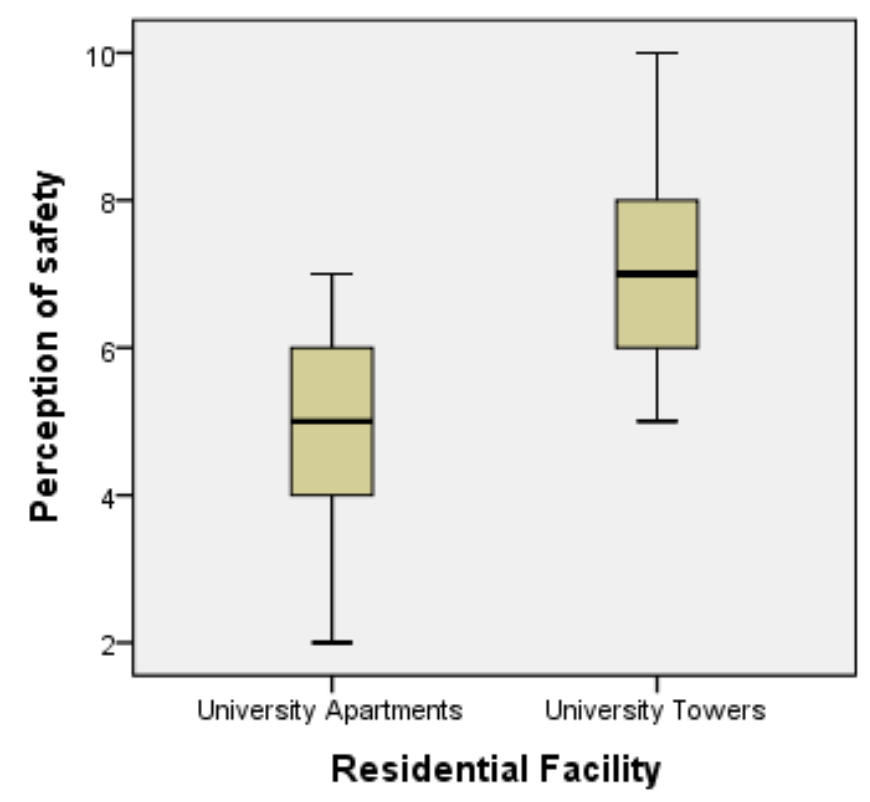

Table 11: Regression Models Explaining Perception of Safety

\begin{tabular}{|c|c|c|c|c|c|c|}
\hline \multirow{2}{*}{$\begin{array}{l}\text { Independent } \\
\text { Variables }\end{array}$} & \multicolumn{2}{|c|}{ Model 1} & \multicolumn{2}{|c|}{ Model 2} & \multicolumn{2}{|l|}{ Model 3} \\
\hline & $\beta$ coefficient & $\mathrm{SE}$ & $\beta$ coefficient & SE & $\beta$ coefficient & $\mathrm{SE}$ \\
\hline UT & $.41^{* *}$ & .448 & $.38^{*}$ & .356 & $.33^{*}$ & .342 \\
\hline $\begin{array}{l}\text { Age } \\
\text { Male } \\
\text { Freshman } \\
\text { Non-American }\end{array}$ & & & $\begin{array}{c}1.09 \\
.5 \\
-.08^{*} \\
-.61^{*}\end{array}$ & $\begin{array}{l}.843 \\
.768 \\
.678 \\
.817\end{array}$ & $\begin{array}{c}.98 \\
.66 \\
-.06^{*} \\
-.57^{*}\end{array}$ & $\begin{array}{l}.653 \\
.732 \\
.923 \\
.745\end{array}$ \\
\hline $\begin{array}{l}\text { Duration of Stay } \\
\text { Victimization } \\
\text { Experience }\end{array}$ & & & & & $\begin{array}{l}1.06 \\
-.56\end{array}$ & $\begin{array}{l}.637 \\
.784\end{array}$ \\
\hline R-Squared & & .35 & & .52 & & .57 \\
\hline
\end{tabular}

\section{Regression Results}

Table 11 presents the results of the three regression models predicting residents' perception of safety. Model 1 -which only estimated the effect of residing location- 
indicated that this variable is significantly related to the outcome variable, in the expected direction. Living in the UT was positively correlated with higher safety perception. In Model 2, four demographic variables (i.e., age, male, freshman, and non-American) were introduced. Location (residing dorm) remained significant in the second model, keeping the same directional relationship. Two of the other four variables-freshman and nonAmerican — were found to be significant determinants of residents' perception of safety, which inversely affected the outcome variable. Finally, Model 3 demonstrated the same results for location and demographic variables in terms of significance and direction, with some slight changes in numbers. However, previous victimization and duration of stay were not significantly related to safety perceptions.

\section{In-Site Observations}

To verify differences in the environmental design of the two sites, a series of participant observations were conducted. As expected, the observations indicated sizeable differences between the two facilities in architectural design, physical landscape, and neighborhood cohesion.

UT is one of the four residence halls situated in the residential district at the central part of the campus housing quad. This dormitory complex enjoys a higher level of natural surveillance compared to UA. The sense of safety in the residential quad is evoked by the presence of well-lit paths and walkways, luminous building exteriors, and large windows and proper visibility in the area enclosing the UT buildings - especially after dark. On the other hand, UA, which is solitarily situated on the eastern periphery of campus, lacked most of the indicators of a standard visible housing district. Weak visibility in the 
surrounding areas (e.g., walkways and nearby parking lots) evoked a feeling of insecurity in the area, particularly after dark.

Comparing indicators of access control in the two facilities, UT apartments are superior. Exterior doors are always locked and could only be opened using individual keys or electronic key cards. Based on informal conversations with UT residents, an active guest policy is implemented by the front desk assistants at UT. This restricts guest-access to specific days of the week and limited hours of the day. Resident-hosts are required to escort their guests to their rooms to reduce the chance of strangers accessing individual rooms. In contrast, UA buildings are weak in access control and easily accessible to outsiders. These courtyard style residences are open and not protected with gates or fences. Although several desk assistants serve this housing complex, they do not have direct supervision over residents/strangers because their office is situated in a separate building. There is no exterior door or hallway for these buildings, so residents enter their individual rooms directly without passing a main entrance or a front desk. Therefore, the implementation of a guest control policy (e.g., limited visitation and escorting) is not feasible.

The observations also revealed that UT area was well-maintained with trimmed vegetation, clean well-kept area, and no noticeable hardware or security equipment failure. On the other hand, UA only had satisfactory well-trimmed vegetation; the presence of litter and broken lights in adjacent parking lots contributed to the feeling that the area was cluttered and unsafe. In terms of territoriality, both housing complexes met the standards by providing signage, pavements, fences, and plantation that drew clear boundaries and conveyed the message that the area is residential. 
Lastly, with regard to activity support, UT had several physical and social features that promoted safety by supporting the intended use of the residential area. These features include: existence of swimming pools, playgrounds, benches, and picnic tables in surrounding areas; holding frequent cultural and entertainment events. The existence of a café/supermarket in the breezeway area located at the entrance of the residential quad is another feature promoting the legitimate use of this area. Although UA had several sport playgrounds and picnic tables, it lacked other activity support features such as entertainment events, stores, and dining places.

\section{Discussion and Conclusion}

To assess the impact of CPTED strategies on improving campus safety, this phase of the study sought to determine and better understand the differences between safety perceptions of the residents of two dormitories at Florida International University. It aimed to examine the influence of CPTED application on residents' perception of safety by comparing two groups of students who lived in two different dorms that varied significantly in environmental design. Although CPTED strategies have been evaluated in several empirical studies since 1970s, the effect of CPTED on campus residents' perception of safety remains an understudied topic. Informed by the defensible space theory, the present study hypothesized that residents of the facility with design features that are more consistent with CPTED principles are likely to have higher perceptions of safety compared to those residing in the dormitory with low level of CPTED.

The t-test results revealed significant differences in perceptions of safety of residents of the two locations overall, as well as in different situations. Residents of University Towers, a high CPTED structure, on average reported higher perceptions of 
safety in their individual rooms, surrounding areas, and shared halls and buildings, and for their personal belongings - compared to inhabitants of University Apartments, a low CPTED building.

To further evaluate these results, three nested models were estimated. All three models supported the main hypothesis of the study, suggesting that location is a significant predictor of on-campus residents' perception of safety. In addition, in-site observations showed clear distinctions in the environmental design of the two facilities. Considerable differences in architectural design, physical landscape, and neighborhood cohesion were distinguished. These findings provide further evidence of the effectiveness of the CPTED approach in promoting safety through reducing fear of crime. Understanding these differences can improve preventive efforts for on-campus residential facilities. CPTED strategies have the potential to improve safety perception in university communities.

Beyond these findings and their implications, several limitations should be taken into account. The first limitation of the study is the possibility of external factors' influences when the situations do not allow to determine if differences are due to CPTED application or other factors. To address this, several key factors that can contribute to safety perceptions were held constant in the two different settings. A second limitation concerns the potential bias that may have arisen from the self-reported data obtained from the survey.

Moreover, it remains unclear whether the findings of this study are generalizable to other universities in the United States. The study setting (FIU) may differ from other universities in terms of social, cultural, community, and economic context. Therefore, this 
study should be replicated at other universities in different areas to determine the extent of design influences on fear of crime and perception of safety.

Despite these limitations, the study provides support for CPTED theory and its application in the university context, highlights the impact of campus environmental design on students' perception of safety, and offers extensive preventive opportunities. Continued inquiry and searches for better data will improve existing understanding of the association between university communities' perception of safety and campus environmental design. There is no doubt that replication of this research, with better quality data, will provide a more detailed understanding of the determinants of campus residents' perception of crime and safety. 


\section{Chapter Five: A Case Study on the Application of CPTED in a College Campus}

\section{Introduction}

In the first two phases of this study, the links between the application of CPTED and campus safety were examined. Two measures of campus safety-official campus crime rates and students' perception of safety-were considered to understand the role CPTED plays in campus security.

This chapter describes the research conducted in the third phase of the dissertation. A case study was crafted in a college campus, and qualitative techniques were employed to gain insight into the strengths and challenges of implementing CPTED in an educational context. The primary data sources of the case study included interviews with administrative officials, staff, and faculty members across the college departments. The interviews were supplemented with a focus group with students, a series of in-site observations, and a review of secondary sources.

The chapter proceeds as follows. The next section explains the process and rationale of the case study selection. This is followed by a detailed description of the methodology and the data collection techniques used to conduct the case study. Then, the findings from the case study are analyzed. Lastly, the chapter closes with a discussion and conclusionincluding policy recommendations.

\section{Purpose of the Case Study}

The third research question of the dissertation (i.e., What are the challenges and strengths of the deployment of CPTED strategies in a university context?) could be best addressed in a natural setting using qualitative methods. This approach would provide a thorough understanding of the implementation processes of CPTED — which was needed to 
identify challenges and strengths. Developing an in-depth understanding of the CPTED procedures could be accomplished by entering the field and talking to the college community to learn about their views and priorities. Explanatory research has the capacity to investigate the nature of social realities, innovative phenomena, and intricate processes. This methodology can also provide insight into the implicit conceptions of local populations - in this case: the college community. Moreover, this approach can be helpful in determining the differences between these perceptions and officials' understanding of the issue (Marshall \& Rossman, 2010).

This phase was conducted on a college campus to understand how the CPTED approach works in an educational setting. The study sought to identify the strengths and challenges of using CPTED and identify the alterations needed to ensure its effectiveness for college campuses. These objectives could be achieved by observing real-life situations and collecting data on various aspects of the environment.

The chosen genre for this research is case study approach—focusing on the use of CPTED measures on college campuses. Case study is a method that entails systematic data collection and analysis of related events in a natural setting to explain the interactions between the phenomena under study (Berg \& Lune, 2011). In this phase, the case study approach was adopted to observe and document interactions between different actors to understand the strengths and challenges of the CPTED program.

\section{Selection of the Case Study}

This case study was conducted in a college campus with a specific focus on the campus community. The aim was to explore the perceptions of individuals in the college community toward campus security issues, their understanding of the CPTED-related 
policies that were already in place, and the modifications that they believed were necessary to improve campus safety.

The site of this case study is Colorado College (CC), a private liberal arts college in Colorado Springs, Colorado. According to the Carnegie Classification of Institutions of Higher Education, $\mathrm{CC}$ is a four-year private not-for-profit college offering baccalaureate degrees. It is located in a predominantly residential area with an enrollment population of 2,067 in the academic year of 2013-14 (Carnegie, 2015). This college was selected as the site of the case study because it has applied CPTED strategies in a systematic manner. The College campus safety department has implemented a CPTED program as part of a broader model of campus safety. The officers have been trained to conduct CPTED evaluations during their daily patrols. They also conduct regular vulnerability assessments based on CPTED standards.

The CC's model of campus safety - which is referred to as The Blended Model of Campus Safety - comprises a variety of security services that are being offered to the College community (CC Annual Security Report, 2014-2015). The safety department initiated this model in 2010 to address serious crime issues affecting the college community. The campus safety officials at the time started to analyze campus crime data to determine the underlying causes of the problem. They realized that the most frequent criminal issues of the College were crimes of opportunity such as theft, vandalism, and sexual assault. Two factors were determined as the major causes explaining the issue: (1) campus location and (2) certain failures in the design and the security elements of the campus. Colorado College is an open campus located in an urban setting, near downtown Colorado Springs. Typically, there are homeless people in the surrounding neighborhoods 
and the openness of the campus attracts transients to the college looking for opportunities to commit crime. Also, the existence of design failures such as dark areas and ambush zones had been exacerbating the problem.

The campus safety department's efforts to address this issue initially focused on correcting campus physical design failures and improving technology systems, including surveillance cameras, emergency blue light phones, and security card swipes. Then, the Blended Model of Campus Safety was developed as a long-term plan. This model is a collaborative effort to achieve a safer campus by utilizing a variety of preventive methods that will be discussed in more detail in the following sections.

\section{Data Collection}

The data for this case study were gathered during two field trips to Colorado Springs, in April and June of 2016. All data collection was conducted in compliance with policies pertaining to human subjects' protection approved by Florida International University. The participants were interviewed under pledges of confidentiality. Campus safety officers, college administrators, staff, and faculty members participated in the interviews. In addition to the interview data, a focus group was conducted with students. Recruitment of participants continued until the point that theoretical saturation was reached. This was the stage in which no new patterns of data were emerging and the components of the theory and their inter-relationships were well-established. In addition, some secondary sources of data were reviewed-including campus maps, newspapers, and safety reports. Moreover, a series of participant observations on campus was conducted.

To obtain access to the $\mathrm{CC}$ site, the institutional review board (IRB) of Colorado College was contacted and the FIU IRB approval, the protocol detailed report, and 
participant consent forms were provided. The Colorado College IRB chair allowed data collection activities at $\mathrm{CC}$ to proceed without restriction-so long as these activities matched those described in the IRB detailed report. Moreover, the campus safety department was contacted via email and phone and provided with descriptions of research objectives and data collection methods. The qualitative data collection methods used in the study are described below.

\section{Semi-Structured Interviews}

Semi-structured questions were used to interview the study participants. The interviews had a predetermined structure, but depending on the participants' responses, modifications were made to the follow-up questions. Four groups of interviewees were identified and invited to participate in the study. These four groups included: campus safety officers, college administrators, faculty members, and staff. For each group, a particular set of interview questions was designed to match their qualifications and expertise. The interview questions for all four groups are listed in the Appendix.

To identify the interviewees, the college website was examined and the relevant administrative offices were determined. The primary focus was on departments that were responsible for campus safety, campus design, and maintenance services. Thus, the campus safety department and the office of facilities services were chosen as the main focus. The supervisors of these two departments were contacted and asked to help with the recruitment of interviewees. Both departments agreed to facilitate face-to-face interviews with their employees. Interviews with campus safety officials were conducted in the office of campus safety and interviews with facilities services staff were conducted in the facilities department's office. 
Additionally, several faculty members were interviewed. To identify faculty interviewees, the college's faculty directory was examined and a list of potential participants was created. Targeted faculty members included those from the social sciences departments (e.g., political science, sociology, psychology, history, education, and philosophy). Also, several faculty members from the inter-disciplinary program of environmental studies were included in the list. The environmental program includes faculty from a wide range of disciplines, but only those with an environmental policy research focus were targeted. The final list of faculty included 37 individuals who were contacted via email. A response rate of $21.6 \%$ was achieved, with eight faculty members agreeing to be interviewed. Of the eight faculty interviews, five were conducted in person and three were conducted via phone/skype.

Moreover, several college administrators from the offices of student life, residential life, sustainability, and Title IX were interviewed. These individuals were selected based on their responsibilities and expertise related to student experiences of campus safety. They were contacted via email and agreed to participate. There were two cases of overlap: two of the interviewed administrators were also faculty members in their academic departments. For these cases, the participants were categorized as administrators; however, both facultyand administrator-related questions were asked. Thus, a total of six administrators were interviewed, two of whom were also faculty members. Among these interviews, two were conducted in the subjects' offices and the other four were conducted via phone/skype.

In total, 34 interviews were conducted, including 12 with campus safety officers, 6 with administrative officials, 6 with faculty members, and 10 with college staff. The length of the interviews ranged from twenty minutes to one hour. Written consent was obtained 
from all the subjects before starting the interviews. In the case of phone/skype interviews, the consent forms were emailed in advance and the participants were asked to sign and return the forms prior to the interview. All the interviews were audio-recorded with the permission of the interviewees. Copious field notes were also taken. After completion, the interviews were transcribed using word-for-word (verbatim) transcription method, and then analyzed using the qualitative data analysis software NVivo 11.4. The software helps organize, analyze, and discover connections in qualitative data to find new insights in unstructured information. Table 12 presents a list of interviewees' demographic information, including their gender, position, department, and average work experience.

Table 12: Interviewee Demographics

\begin{tabular}{llllll}
\hline Position & Total & Department & \multicolumn{2}{c}{ Gender } & Average Years \\
\cline { 3 - 4 } Participants & & F & M & of Experience \\
\hline Safety Official & 12 & Campus Safety & 2 & 10 & 5.9 \\
Administrator & 6 & $\begin{array}{l}\text { Student Life } \\
\text { Residential Life } \\
\text { Sustainability } \\
\text { Title IX }\end{array}$ & 2 & 4 & 9.3 \\
Staff & 10 & Facilities Services & 2 & 8 & 7.9 \\
Faculty & 6 & $\begin{array}{l}\text { Political Science } \\
\text { Sociology }\end{array}$ & 5 & 1 & 9 \\
Psychology & & & \\
Education & & & \\
Total & 34 & Philosophy & 11 & 23 & 8 \\
\hline
\end{tabular}

The questions for campus safety officers mainly focused on their job responsibilities. Officers were asked to describe their daily activities and the security services provided by the safety department. Also, the methods and criteria used in their 
regular security assessments were explored. The questions for college administrative officials related to Colorado College security policies and practices. The administrators were asked questions about the college's safety regulations, the standards that must be met in design and construction, and whether they believe these policies have been translated into practice. The questions for the facilities department's staff explored their ideas about design, landscaping, and maintenance of campus structures, their assessment of the current status of safety on campus, and their thoughts and recommendations for improving security. Lastly, the opinions of faculty members were explored regarding the use of CPTED techniques on campus, their effectiveness, the status of safety on campus, and what they believe should be changed or improved.

\section{Focus Group}

To obtain an in-depth understanding of the status of safety at the $\mathrm{CC}$ campus, a focus group was conducted with six student-participants. It was a guided discussion to explore the topic of "Colorado College Campus Safety." The size of the focus group was intentionally small to ensure effective management of each member's participation (Berg \& Lune, 2011). To recruit participants for the focus group, three methods were used. First, the schedule of summer classes was obtained on the college website. Four professors were contacted and provided with descriptions of the study, its research objectives, and the data collection methods; permission to attend a class session was requested - in order to invite students to participate in the focus group. Of the four professors, one responded and agreed to help. The professor taught a research design course offered through one of the social sciences departments. Subsequently, in a class session during the second field trip to CC, 
the researcher described the study data collection methods to the students - particularly the procedures for the focus group that would be conducted soon thereafter.

Second, a flyer was created and posted on the student center's bulletin boards. On the flyer, students were invited to join a conversation on campus safety at the assigned location, date, and time. Third, the researcher reached out to residential life staff, who were asked to forward the recruitment materials, including the flyer to a number of students that might be willing to participate. They agreed to help by forwarding the information to several student leaders. As an incentive, refreshments (i.e., food, snacks, and non-alcoholic beverages) were provided for the focus group participants.

The focus group was conducted with six students in the student center of the College. Gender was equally represented as three male and three female students attended. The average age of the participants was 20.1 years. The focus group population was also equally distributed in terms of students living on-campus (three) and off-campus (three). For the focus groups attendees, the average length of time spent studying at Colorado College was 2.1 years.

The researcher served as moderator for the focus group. The discussion started by providing background information on the study objectives, its significance, and the data collection methods. Then, the researcher asked questions about campus safety, campus design, participants' perception of safety, and so on. During the session, field notes were taken; the conversation was audio-recorded with the informed consent of the participants. The list of focus group guiding questions can be found in the Appendix. 


\section{Participant Observations}

Participant observations were conducted to directly learn about the environmental design and social dynamics of the campus. Attentive observation is an essential part of ethnographic research that allows researchers to better understand the setting and obtain relevant information. Ethnographers usually start by roaming around in the field to learn about the area. Taking field notes can help the ethnographer describe and map the setting (Berg \& Lune, 2011).

The first field visit to the CC campus was in April 2016. Entering the campus on a Saturday afternoon, the researcher's first impression of the site was that it was an active college campus - a family-oriented event targeting school kids was in progress. The field observations began with activities that included walking around, watching, listening, and interacting with people to obtain an initial understanding of the area. During the next few days, the observations were conducted more systematically by watching, asking questions, and recording events, behaviors, and objects.

To better capture these features, a check-list was created to guide the field observations. The check-list included five major components of the CPTED theory: natural surveillance, access control, territoriality, maintenance, and activity support. Table 13 presents the list of CPTED elements and their indicators. These CPTED indicators were developed and used in another setting to answer the first research question of this dissertation.

To conduct the observations in a more manageable way, the work was divided into three spatial assignments: campus common areas, campus surroundings, and internal parts of campus buildings. The check-list was used while investigating CPTED indicators in 
each spatial field. The observed indicators were check-marked and field notes were taken when needed. This method helped to better examine environmental characteristics of campus aside from the campus design features specified by college officials.

Table 13: Field Observation Check List

\begin{tabular}{|l|l|l|}
\hline CPTED Elements & Indicators & \multirow{2}{*}{ Field Notes } \\
\hline Natural Surveillance & Campus Visibility & \\
\hline & Buildings Visibility & \\
\hline & Regular Control of Lighting & \\
\hline Access Control & Main Entrance Control & \\
\hline & Restricted Access to Residential Buildings & \\
\cline { 1 - 2 } & Restricted Access to Non-Residential Buildings & \\
\hline Territoriality & Defining Campus Boundaries & \\
\hline & Defining Individual Buildings' Boundaries & \\
\cline { 1 - 2 } & $\begin{array}{l}\text { Defining Boundaries between Residential and } \\
\text { Non-Residential Areas }\end{array}$ & \\
\hline Maintenance & Landscaping & \\
\hline & Grounds Keeping & \\
\hline Activity Support & Regular control of broken fixtures & \\
\hline & Holding Events & \\
\hline & Existence of Recreational facilities & \\
\hline & Existence of Gathering Areas & \\
\hline
\end{tabular}

\section{Secondary Sources}

To gain further insight into the college safety policies and practices, secondary sources of data were reviewed. These data included the official college website and the Clery Reports issued by the campus safety department. The campus safety webpage provides an overview of the department's mission and the available safety programs and services. To obtain more in-depth information on campus safety programs as well as on the actual campus safety status, CC's two most recently published Clery Reports were examined. Both reports were available online. The Clery Report for the 2014-2015 academic year provides a brief history on the evolution of the current safety model used by 
the department, as well as a detailed description of the safety services offered. The Clery Report of 2015-2016 adds to the previous information by detailing important physical and environmental features of campus, including lighting, access control, and maintenance. Lastly, campus maps and newspapers were examined, which helped contextualize the collected data.

\section{Data Analysis}

The data collection continued until the point that theoretical saturation was reached. This occurred when collected data repeated previously collected data—and did not provide new information or patterns. At this point, data collection ended and the collected data from the interviews, focus group, observations, and secondary sources were subjected to word-for-word (verbatim) transcription. The data were then analyzed using the qualitative data analysis software NVivo 11.4. The software helps organize, analyze, and discover connections in qualitative data in order to gain new insight into unstructured information.

In light of the third research question of this study, a list of emerging themes was developed and coded accordingly. Then, NVivo software was used to identify and categorize the themes and draw conclusions. Three major themes emerged, which included CPTED implementation, strengths, and challenges. In addition, several sub-themes for each major theme were identified. Then, patterns and clusters in data were explored and analytic memos were written. The next step was to interpret the emerging themes and patterns to draw conclusions. "Interpretation brings meaning and coherence to the themes, patterns, and categories, developing linkages and a story line that makes sense and is engaging to read" (Marshall \& Rossman, 2010, p. 219). Below is a list of major themes and their subthemes: 


\section{Implementation: Inspections and Interventions}

2. Strengths: Educational Value, Diffusion of Benefits, and Cost-Efficiency

3. Challenges: Recommendations Not Acted Upon, Dilemma between Openness and Safety, Historic Building Codes, Human Resource Limitations, and Funding

\section{Limitations}

The analysis and interpretation of the collected data helped to contextualize the CPTED program at Colorado College to determine the program's strengths and challenges. The identification of benefits and drawbacks of the CPTED program, in turn, required familiarity with its implementation processes. Below, some background information on the CC campus safety model is provided. Then, key findings of the case study are presented.

\section{The Blended Model of Campus safety}

The Blended Model comprises a variety of preventive measures that can be classified into seven main groups: educational programs, transportation service, problemand community-oriented policing, situational crime prevention, partnership with the Colorado Springs Police Department (CSPD), and a crime prevention through environmental design (CPTED) program. Each of these seven groups includes several safety programs and services that are either managed and implemented by students or the safety department. The purpose of creating the student-run aspect of the model was to include the college community, particularly students, in their own safety as well as to increase the visibility of campus safety services.

Figure 8 illustrates the seven categories of safety services of the blended model. The description of the seven components of the blended model are discussed below. 
Figure 8: Blended Model of Campus Safety

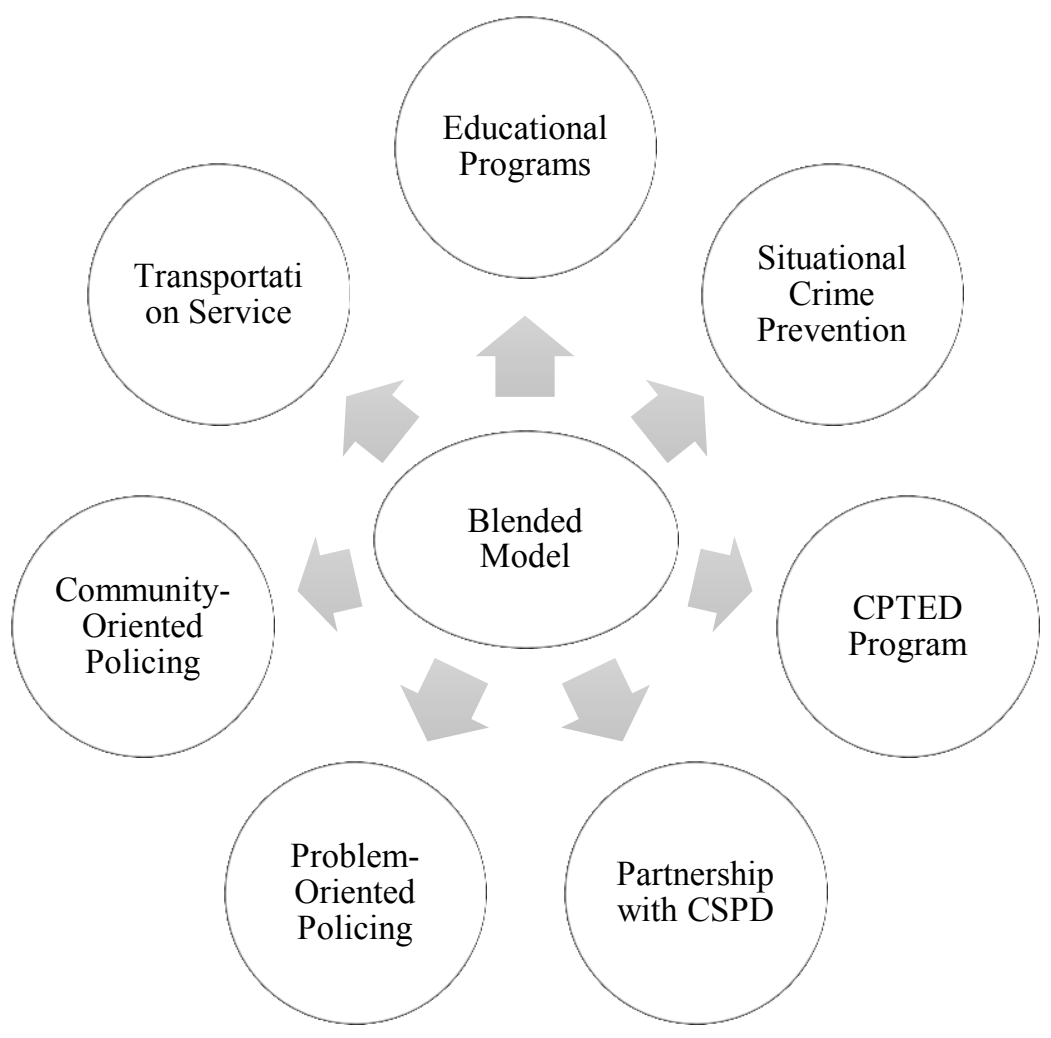

\section{Awareness Programs}

This is the educational aspect of the Blended Model, which comprises several programs to educate the college community on campus safety. This component targets community empowerment and community engagement in crime prevention. For instance, sexual assault prevention programs are offered on a regular basis to cover several topics, including sexual harassment, intimate partner violence, and stalking. Self-defense training and active shooter workshops are other examples of programs that raise community awareness on issues of crime and security.

\section{Transportation Service}

The Colorado College safety department offers a safe ride program and a shuttle service to all members of the community. The safe ride initiative provides escort within 
certain operational boundaries - up to five blocks away from campus - upon request. The shuttle service is available at certain times of the day and week to provide access to the city downtown area.

\section{Community-Oriented Policing}

The other component of the blended model is community-oriented policing programs, which aim to build effective relationships between the College and the college community by engaging them in crime prevention and crime reporting. A neighborhood watch program (Tiger Watch) and a bystander intervention campaign (BADASS) are deployed by the campus safety department and sexual assault response and prevention office, respectively. Program volunteers participate in a training/workshop to officially become involved in campus safety.

\section{Problem-Oriented Policing}

The blended model also entails problem-oriented strategies, which focus on the identification of a problem, and its underlying factors, to design proper responses. In January 2013, the safety department initiated a bike theft prevention campaign: "U-Lock or I Steal." The program included several elements: increasing awareness through information posters, educating people on how to properly lock their bikes, and introducing a new locking method (U-Lock). According to the Clery Report of 2014-2015, one year after the program was launched, bike thefts showed a 60\% decrease (CC Annual Safety Report, 2015).

\section{Situational Crime Prevention}

The college also employs situational crime prevention to reduce the chance of crime. Situational techniques discourage motivated offenders by increasing the risk and 
difficulty of committing crime. The utilization of video surveillance cameras has increased since the initiation of the blended model, and higher technology cameras have been installed to better monitor residential halls, academic buildings, and campus common areas.

\section{Partnership with CSPD}

An important aspect of the blended model is the proactive partnership between the College and the Colorado Springs Police Department (CSPD). Through a written service agreement, a cooperative partnership has been formed between CC and CSPD. This collaboration is beneficial for the campus safety department in terms of responding to their backup needs, providing training opportunities, assigning a campus resource officer as a liaison, and helping with off-campus CPTED inspections.

\section{CPTED Program}

Lastly, the unique component of the blended model is the CPTED program, which has been designed as a vulnerability assessment tool. The CPTED initiative includes a series of interventions and inspections that are implemented by the College on a regular basis to identify deficiencies in design and security elements of the campus. Figure 9 presents two components of the CPTED program: interventions and inspections. The figure also displays the two forms of CPTED inspections that are being conducted in two separate settings—on campus and off campus. 
Figure 9: Colorado College CPTED Program

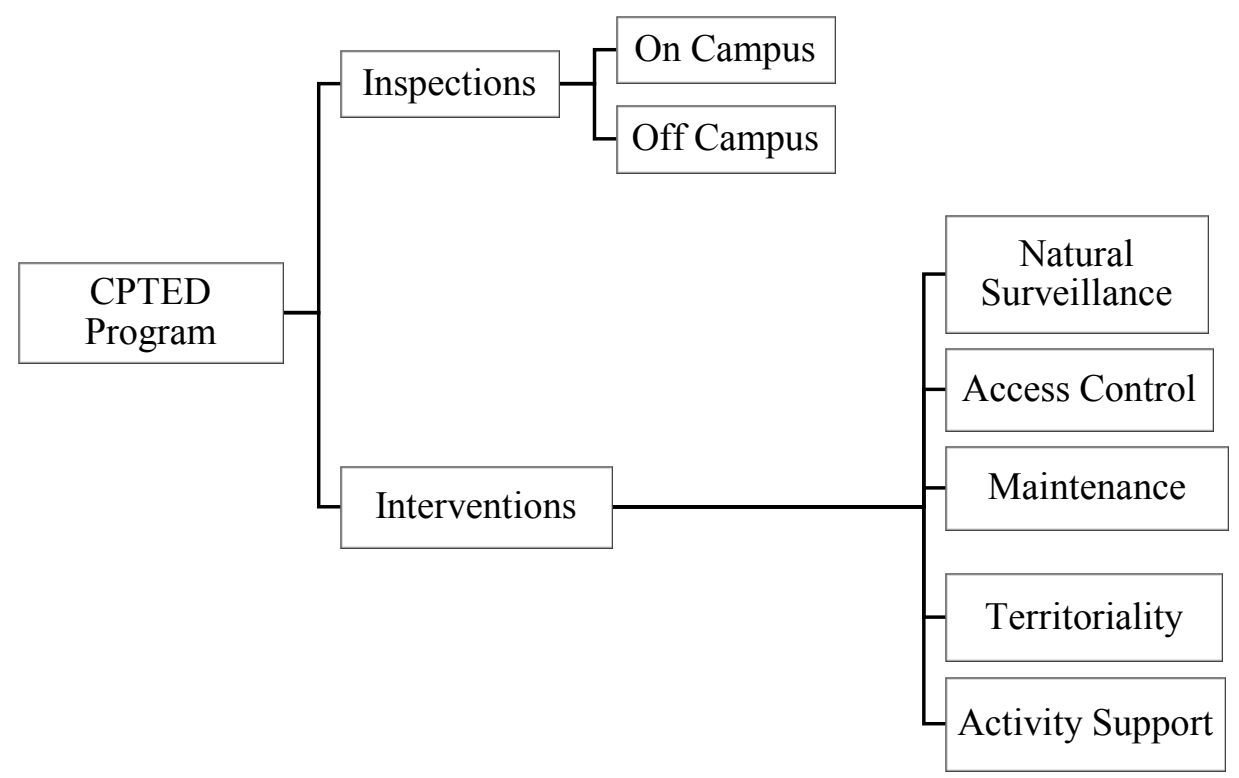

\section{Case Study Findings}

In this section, the key findings of the qualitative case study on the use of CPTED in the Colorado College campus will be discussed. In light of the research question, which asks about the strengths and challenges of the CPTED program in a campus setting, three major themes were identified. The first theme is CPTED implementation, which sets the groundwork for addressing the research question. The identification of strengths and challenges of the CPTED program necessitates a thorough comprehension of the program's implementation. The methods and procedures of the CPTED program are presented first, followed by a detailed description of the strengths and challenges of the program.

\section{Implementation}

Two main areas were targeted in the discussions with college safety officials on CPTED implementation at Colorado College. The primary focus was on the CPTED vulnerability assessment tool at CC. Questions included the administrative processes involved in initiating a CPTED inspection and procedures used in the assessments. Then, 
the attention was shifted to other regular safety activities that are not part of the CPTED program-but are considered to be environmental interventions consistent with CPTED theory.

\section{CPTED Inspections}

Inspections are the core of the CPTED program being implemented by the CC safety department. A former campus resource officer of the College described the CPTED initiative as one of the biggest pushes for crime prevention since the Blended Model was launched (CC Annual Safety Report, 2015). Several campus safety officers attended basic CPTED trainings offered by the Colorado Springs Police Department (CSPD); the campus safety officers earned certification as inspectors. The departments of campus safety and residential life continuously promote the CPTED program in their security-related meetings and in workshops held for the College community.

This service is provided free of charge for both on-campus and off-campus buildings. In the past, on-campus inspections were only conducted at the request of heads of college departments. However, since 2016, the safety department has provided this service for all campus buildings regardless of formal request. Off-campus inspections are offered to all members of the college, including faculty, students, and staff on request. Students who reside on campus, but plan to move off-campus, are highly encouraged to use this service. For off-campus evaluations, a CSPD officer is present and facilitates the process. For instance, the officer can conduct a background check of the property and nearby houses to determine if these areas have been victimized before, which helps the inspectors find the vulnerabilities. 
According to the campus safety website, the four concepts of CPTED that guide campus safety inspections are: natural surveillance, access control, maintenance, and territoriality. This suggests that the program aligns with the first generation of CPTED. Thus, the fifth component of the theory, activity support, is not considered in these CPTED assessments. However, these assessments go beyond what is included in CPTED by definition - they include inspections of fire safety, alarm system, smoke detectors, cameras, etc. Thus, these thorough assessments are augmented by how the safety officers define CPTED. An example of the CPTED inspections is included in the Appendix.

\section{CPTED Interventions}

In addition to the inspections at the center of the CPTED program, the college performs a series of regular activities that help the whole CPTED program move forward. In other words, these activities are not considered as part of the CPTED inspections, but they are conducted to enhance college security through several environmental tactics that are in line with CPTED principles. These strategies can be related to lighting, landscaping, maintaining, and so forth. Thus, this study categorizes these strategies within the quintuple classification of CPTED. Below is a detailed description of Colorado College CPTED interventions, based on the five-fold CPTED taxonomy.

\section{Natural Surveillance}

Providing adequate visibility on campus is a recurring concern of the college- - this is being addressed through a collaboration between the City of Colorado Springs, the city utilities department, and the departments of campus safety and facilities services of the college. One of the safety officials explained this effort: 
Lighting is something that the college is always taking into play, [the] institution and the city work together and on an annual basis we do a combined walk together, we walk around campus and do a communal CPTED inspection just of the lighting. The city might make concessions to fix issues in a particular area, but if we are told that they cannot, all that it does is provide us the requirement to think outside of the box and figure out other ways that we can increase safety in that area.

In addition, a biweekly campus lighting report is produced by the departments of campus safety and facilities services. One of the campus safety officers described the activity: "We do a campus light report with the electric people in the facilities, where we identify lights that are out, broken ones that are not working properly. That, at least, we do two reports every month".

\section{$\underline{\text { Access Control }}$}

Colorado College is an open campus that welcomes visitors and facilitates the organization of athletic and entertainment events. Although this atmosphere provides opportunities for social and cultural connections, it can be hazardous-in the sense that would-be-offenders will be attracted to the potential targets on campus. In the discussions with faculty and students, most of the participants referred to the openness of campus as a potential safety issue that attracts transients to the college and increases the opportunity for them to commit crime. However, the faculty and students acknowledged the need for engagement and communication between the college community and the broader community of Colorado Springs. In other words, in general, the idea of a closed campus is not considered to be acceptable; however, some level of access control is demanded. 
The college implements both physical key access and electronic key card access. The installation of card-swipe security features has rapidly expanded since the blended model was launched. Yet, several buildings still use a physical key control system in which officers are assigned to lock doors every night. The buildings that are equipped with electronic key card readers automatically lock and unlock according to a schedule. One of the campus safety officials described the access control system at residential buildings as follows:

[In residential] buildings, we're able to do a two-level thing, where public would be invited into certain aspects of the building but then to get beyond certain point, you would have to have card access, and that changes at night, where the card access becomes a two-tiered sort of thing.

The access control system at the academic and administrative buildings is described by one of the staff of the facilities department in the following words:

Some of the smaller administrative buildings like our admissions department doesn't have card access, still keys, but any of the academic buildings use cards, [but] on the inside of the buildings there's not much card access, it's mostly keys for student rooms, and keys for the offices.

\section{Maintenance}

To ensure that the campus image remains within certain standards and address the maintenance needs of the area, two techniques are being used. First, officers physically lock the doors of certain buildings every night. If they discover broken fixtures or safety hazards, they submit reports to the facilities office, and request work orders to remedy the situations. Second, campus safety and facilities services work together on a maintenance- 
related initiative. This intervention plan is described by one of the facilities' staff in the following words:

We have a quarterly walk with a member of campus safety to make sure that we don't see any safety hazards, [such as] shrubbery, dark spots, just the little holes that nobody sees around campus, we actually just cut down over thirty trees, that were considered safety hazards, where people could get behind them.

\section{$\underline{\text { Territoriality }}$}

The Colorado College campus has expanded over the past several years. Buildings in the surrounding neighborhood have been absorbed by the College as part of this expansion. Because these buildings do not look structurally different from other buildings in the area, the college needed to define its boundaries - to reduce the risk of trespassing. Walls, fences, or gates do not suit an open academic environment that aims to encourage social communication. Thus, other alternatives were sought to simultaneously secure the community and retain the open-access feature of the campus. Several methods were devised (e.g., signage and rebranding patrol vehicles), as one of safety official explained.

To indicate the institution's boundaries, we added signage for our parking lots and some other buildings. We also created a neighborhood watch sign that we put up on a lot of buildings and onto major pedestrian thoroughfares through campus, so as soon as you cross campus, there is a sign that says you're now on $\mathrm{CC}$ property. We also looked at the concept of rebranding our patrol view vehicles. So we have our officers and students driving around on the vehicles clearly branded as $\mathrm{CC}$, they do patrols along the boundary. So, if somebody doesn't know that this is a College and happens through soon they realize that they are at $\mathrm{CC}$. We've done as much as we 
can without putting up big walls to indicate that when you cross a certain boundary you're on campus, but you need to find creative ways to do it because nobody wants to see fences, or big signs saying you're now entering CC. Everybody gets this weird flashback of a militarized zone, nobody wants that, especially in a liberal arts college.

\section{Activity Support}

Activity support is the non-physical component of CPTED; it was added in the second generation of the approach. Activity support focuses on the social aspects of the environment rather than pure physical design. This strategy includes passive or active methods that encourage the presence of people, and make an area less approachable for would-be-criminals. In the context of campus, this can be achieved by providing gathering areas and holding entertainment events.

As noted earlier, the fifth element of CPTED is not anticipated in the CPTED initiative of the Blended Model. This was determined based on interviews with safety officers and the program description provided on the campus safety webpage. Hence, participant observations and focus group discussions were used to determine the extent of the use of such strategies.

Based on the researcher's in-site observations, Colorado College is a friendly and inviting campus. Within academic buildings, study rooms and furniture encourage students to socialize and study together. Outside the buildings, benches, picnic tables, and playgrounds provide friendly spaces for the college community. Also, several events were observed, in which families, children, and students gathered. The focus group discussions and informal conversations with people confirmed the frequency of such events on campus. 


\section{Strengths}

The strengths of the CPTED program emerged as the second theme in the analysis. The advantages of this initiative were examined through two separate lenses: the viewpoint of the safety officials and those of the administrators. The conversations with safety officers were insightful - these individuals have been trained to implement the program and conduct the assessments. Their real-life experience of conducting CPTED evaluations helped to assess the program. Then, the interviews with college administrators, whose offices had been evaluated by the CPTED team, provided the other side of the story. Listening to their experiences of being safety-checked helped to further understand the CPTED program's benefits.

\section{Educational Value}

Talking to several administrators whose offices were CPTED-evaluated revealed that they most appreciated the educational value of the CPTED assessments. These inspections identified any vulnerabilities in their buildings that might lead to a security problem. The administrators mentioned that awareness of the vulnerabilities allowed them to address particular issues and empowered them by teaching them how easily CPTED interventions are to implement_-particularly in their personal lives. A college administrator explained this process:

My office was evaluated by the CPTED team. It's a great program to get off the ground, especially if the occupants are there during, it makes you aware. It encourages you to open your eyes a little bit, and it could show some of those things that would encourage crime that you might not have thought about before, so it's 
got that educational piece and it's something that's financially pretty easy to do most of the time.

\section{Diffusion of Benefits}

The other advantage of the CPTED program, which was mentioned by several safety officers, is its potential to diffuse benefits to non-treated targets and areas. So, in addition to the direct impact on targeted buildings, the positive outcomes can spread to adjacent campus buildings and the surrounding neighborhoods. One of the safety officials explained:

When you look at the community if you secure one building really well, then it has some spillover effect for other buildings on that area. Having several buildings secured, we can dis-incentivize the campus as being a viable target for crimes of opportunity.

\section{Cost-Efficiency}

Some of CPTED techniques are basic, commonsense measures that ordinary people can easily learn and apply. Given the relative ease and modest cost of implementing some of the recommended fixes, individuals that receive the evaluations are more likely to embrace them. A safety official described the CPTED recommendations in the following words: "It's usually very small fixes that go into place that really cumulatively have a very positive effect on the safety and security of that building."

\section{Challenges}

The data from this study helped explore the major challenges and impediments of using CPTED approach in the Colorado College campus. Despite the promising findings on the program's strengths, the analysis showed that the program faces several important 
challenges in the implementation phase. Further analysis of these obstacles can help to identify the underlying issues and develop solutions.

\section{Recommendations Not Acted Upon}

One common, recurring theme in the interviews with campus safety personnel was a lack of action following the CPTED security evaluations. The security officers of the college emphasized the importance of making changes to address the vulnerabilities that were identified through CPTED inspections. Most of the safety officials expressed disappointment that their reports were often neglected by departments' decision makers. A safety officer explained:

I mean probably the biggest challenge is that after we do it and we present it to whatever department, they automatically think we're going to pay for it, and we're going to go ahead and do it, which is not true, we have our budget, they have their budget, so it's up to them to go and actually make the changes, which don't always get done.

This frustration can intensify when officers' reports are neglected—leading to a crime that could have been prevented. Another safety officer described his frustration in the following words:

We provide the information and things are not acted on, sometimes we saw things, we say we just told you a couple of months ago, and that can be a little frustrating, even though I understand that there's always reasons behind it, but I would say that safety comes first. 


\section{Dilemma between Safety and Openness of a Campus}

Another challenge that emerged as a theme in the findings is caused by the nature of the campus itself. Legitimate users prefer an open and public educational area, but this accessibility can be incongruent with safety. Controlling access to a given area or specifying the boundaries of a property are both essential components of CPTED theory; however, the case of a college campus differs from typical cases (e.g., residential or commercial properties). While controlling entry and exit in typical cases is usually appropriate, closing the whole campus or installing walls or fences around campus would not be desirable - at least in the U.S. context. One safety official explained this dilemma in the following words:

Realistically to make it safe does not make it friendly, and they really want it to be friendly, open and inviting, but with all that open invitation comes a potential danger, so they have to gauge, what is it that they want to do.

This safety officer believes that academics must choose between an open friendly

educational space — that welcomes the broader community of Colorado Springs—and a closed secure environment that exclusively belongs to the smaller college community. 


\section{Historic Buildings Codes}

It is expensive and difficult to modify older buildings. Safety officers believe that most of the campus buildings are old - in the era they were build, safety was not prioritized. Thus, modifying these building using CPTED interventions is challenging. Additionally, many of these old buildings are on the national historic registry, which adds another set of obstacles that may hinder modification-as one safety official described: “There's not a lot of things that we can change about the older ones to implement safety, but we [need to] find ways to do it aesthetically, not messing up the building or anything like that."

\section{Human Resource Limitations}

Shortages in human resources were also raised as an obstacle-particularly a lack of experienced and skilled workers who could focus on the CPTED program. A safety officer mentioned: "Right now it's like we do it while we're working, but if somebody did that particular thing, it would be more specific in origin".

\section{Funding Limitations}

The last challenge that emerged as a theme was funding limitations. The safety department has a limited budget that does not allow it to pay for the changes. On the other hand, report recipients typically expect to have the safety department make the modifications. This conflict usually results in lack of action based on the CPTED recommendations. One safety officer described the situation in the following words:

We can make all these [CPTED] suggestions and give it to the head of the departments but then they have to pay for the changes, so when they see they need to spend money fixing this and nothing bad happened yet, it just gets ignored, so I 
guess if $\mathrm{CC}$ had a fund for making those changes, it would be so much more useful because everything could be updated, I just feel like when we put it in the hands of the departments, they're just going to skip over it.

\section{Discussion and Conclusion}

The third phase of this dissertation examined the application of CPTED in an academic setting. It aimed to provide insight into the strengths and limitations of this approach in college campuses. To achieve this goal, a case study was conducted in Colorado College, as this institution is implementing the method of CPTED systematically. Given the willingness observed in members of the campus safety department-and the supportive administrative efforts at the college-the CPTED program appears to be a promising campus safety initiative. Yet, this program faces several ongoing challenges in the implementation.

The most important challenge was a lack of further action to correct flaws that are indicated on CPTED evaluation reports. The additional challenges are human resource and funding limitations, which are often the consequence of lack of attention to the program from boards of trustees and high ranked administrators. Thus, these three challenges are discussed together.

Interviews with faculty and personnel from the facilities department helped provide better understanding of why these barriers exist. The qualitative analysis sought to determine why action is not taken to address CPTED recommendations and why adequate money and human resources are not dedicated to the program. Four major detrimental factors were found based on the analysis. 
First, the safety department did not have the authority to compel other departments to implement changes. The advisory status of the program is one of the main reasons why CPTED recommendations were not implemented in many cases. There is no follow-up system to investigate to what extent the recommendations have been put into practice. The second detrimental factor was a lack of awareness among the recipients of the CPTED reports about the benefits of the program and how it works. The recipients mistakenly expect that the safety department is responsible for implementing the changes or paying for them. Thus, the recommendations are ignored by the recipients (e.g., an assessed department) as they hold the campus safety department accountable for making the changes.

Third, limited inter-departmental collaboration was another factor contributing to the lack of further action. The analyses revealed insufficient awareness of CPTED inspections among the staff of other departments, especially within the facilities services. Some routine collaborations exist between facilities and campus safety personnelincluding jointly conducted activities such as the annual lighting walk-through, or the quarterly maintenance walk-through. However, the facilities department has no involvement in regular CPTED inspections. Nonetheless, they can be a good partner in performing CPTED vulnerability assessments: the facilities department can promote safety inspections by examining and fixing design and landscaping deficiencies. Finally, safety is typically not prioritized in a college campus. Because many academic and administrative issues must be addressed primarily, novel safety initiatives (e.g., CPTED) often have difficulty gaining resources and funding. 
The program faced two other challenges in the implementation stage. The dilemma between openness and safety stems from a potential conflict in the nature of a college campus, which is simultaneously expected to be open and secure. It is difficult to create a publicly accessible area that is safe from crime. Both safety officers and administrative officials were aware of this challenge and aimed to find creative ways to overcome it. The alternative methods that were discussed included territorial reinforcement efforts (e.g., signage and rebranded patrol vehicles).

The other challenge was that some buildings were subject to historic building preservation requirements - many of Colorado College's buildings appear on the national historic registry. It is difficult and expensive to modify these old buildings, and any modification must comply with the provisions of the historic building codes, which have higher structural and aesthetic requirements in comparison to modern buildings. Despite the complexity of this situation, $\mathrm{CC}$ has been able to systematically implement its CPTED program - implying that these case study results are transferable to other universities. In other words, Colorado College has made initial progress toward this proactive initiative; however, newly built campuses will be more likely to implement a CPTED program successfully.

Identifying the program's challenges can lead to solutions for improvement. As the advisory status of the program was diagnosed as an underlying factor, the college can create mandates on enforcement and follow-up systems. For instance, they can require recommendation recipients to act upon them in a certain amount of time, and then track changes accordingly. They may also post the reports on the college website, so that transparency forces the departments to take action. 
Additionally, the college can offer rewards (e.g., cooperative grants and resources) to departments that act upon the reports. Also, promoting cross-departmental collaborations can facilitate the implementation phase. Providing appropriate training opportunities for departments that work with the CPTED program can eliminate future implementation problems. Furthermore, holding awareness campaigns can bring more resources by drawing attention to the potential benefits of the program. 


\section{Chapter Six: Conclusion}

\section{Introduction}

Much of the previous literature on campus safety has focused on describing the nature and prevalence of campus crime, or testing the theories that explain campus victimization. Although efforts to foster crime prevention began almost three decades ago, following the tragic murder of Jeanne Clery (1986), few studies have evaluated the crime prevention programs used in university campuses. The main objective of this dissertation was to fill this gap in the literature by examining the role of a crime prevention method in campus safety. In this dissertation, it was argued that crime prevention through environmental design (CPTED) — which is regarded as a useful planning tool for creating sustainable and efficient environments - is an appropriate solution for campus crime.

The concept of CPTED is rooted in the notion of Defensible Space (Newman, 1972), which draws a link between environment and residents' capability to defend themselves and their property. The defensible space framework has been used as a practical standard for proper urban design over the past four decades; however, criminologists have criticized the defensible space framework — particularly because it initially did not consider social factors of the environment. Therefore, the framework has redefined its boundaries to embrace the social factors that can play a role in creating defensible spaces. This evolution inspired the enhancement of CPTED — transitioning from first generation, which focused on physical design, into second generation, which added a social component to the initial framework.

This dissertation built on the Defensible Space Theory to examine two hypotheses:

1) Campuses with higher level of CPTED will have lower crime rates. 
2) There is a positive relationship between campus dorm resident students' perception of safety and the extent to which their facilities have adopted the CPTED standards.

\section{Empirical Findings and Conclusions}

To test these hypotheses, a mixed methods approach was used. The first phase included analysis of archival security documents of universities. A thorough content analysis of the Clery Reports of a sample of one hundred Title IV institutions was conducted to understand the extent of the use of CPTED within the schools. The analyses conducted in the first phase revealed two central findings, described below.

First, the descriptive statistics indicated that environmental strategies aligned with CPTED are widely used by the sampled universities. Techniques of access control and activity support were more common than the other three measures within these institutions. It is worth noting here that none of these 100 schools had systematically implemented a CPTED program. The analysis measured the crime prevention methods that were consistent with CPTED principles, which were presumably utilized by the institutions as independent crime control tactics rather than part of a comprehensive CPTED plan. This can explain the extensive use of two CPTED mechanisms while the other three are scarcely used. It might further imply that universities have found access control and activity support measures to be more effective or more suitable for the purpose of safety.

Second, the results of the regression analysis did not support the hypothesized effect. The statistically significant positive relationship between the use of CPTED and campus crime rates was an unexpected finding. Because the Clery Reports do not specify when these CPTED strategies were implemented, the regression analysis could not control 
for the time factor. Additionally, the time-consuming and labor-intensive procedure of reviewing Clery documents made it unfeasible for the researcher to develop a time-series dataset to control for temporal variations in the level of CPTED. Thus, the data of both dependent and independent variables came from the same academic year. On the surface, this unanticipated connection (i.e., significant positive relationship between CPTED and crime rate) might suggest that universities with higher level of CPTED application are likely to experience higher crime rates. However, the lack of control for the time factor in the present study makes it impossible to claim that there is a causal relationship between these two variables. In other words, it is not known if the use of CPTED precedes the high crime rates and, thus, the influence might be in the opposite direction, with crime affecting the use of prevention techniques. Given this, the second set of regression models was run to explore the possible effect of crime rate on the use of CPTED. The results supported the reverse relationship argument and uncovered the effect of campus crime on the use of CPTED strategies. The regression findings indicated that institutions with higher crime rates tend to apply more environmental crime prevention techniques.

In the second phase, the influence of CPTED on students' perception of safety was examined by surveying residents of two campus residential facilities that were substantially different in environmental design. The t-tests results revealed significant differences in the perceptions of safety of the two groups of students. Three nested regression models were estimated to further explore the results. The analyses supported the second hypothesis of the study suggesting that location is a significant determinant of students' perception of safety on campus. On the other hand, in-site observations showed clear distinctions in the environmental design of the two facilities. These findings provide empirical support to the 
effectiveness of environmental prevention approach to enhance campus safety. In light of these findings, suitable crime prevention methods can be devised for on-campus residential facilities.

In the third phase, a case study was carried out in a college campus with an ongoing CPTED initiative as part of a comprehensive campus safety plan. Qualitative methods were used to understand the methods and procedures of implementing the CPTED program. This phase further investigated the program's strengths and challenges. The analysis revealed that although the program is still in its infancy, the awareness among campus safety officials with regard to the program's potential benefits was universal. The long-term advantages of the program-especially in relation to its proactivity, cost-efficiency, and diffusion of benefits to surrounding areas-were noted by most of the safety officers. The educational value of the initiative was stressed by college administrators who had received a vulnerability assessment review for their offices. Simplicity, usefulness, and applicability were raised as the main reasons they found the program beneficial to their personal and professional lives. Although the CPTED program was not well known among other study participants, including students and faculty, findings indicate that they preferred proactive strategies of crime control.

In spite of these promising findings, there were several important challenges with regard to the implementation of the CPTED program. The most concerning problem was the lack of action to address CPTED recommendations provided by the campus safety department. Most suggested fixes were never completed primarily because the program functions in an advisory capacity — without the funds or personnel to address issues. The 
lack of a tracking system to follow-up on the recommended modifications inhibits the program from advancing beyond a consultative effort.

Also, the broader college community is not yet aware of the CPTED program, and/or the way it works. Recipients of the reports expect that the campus safety department will take action to complete modifications/repairs-however, this task is not the responsibility of the department. This lack of awareness is damaging not only because it wastes the time and efforts of the CPTED team, but also creates discouragement among the community toward the CPTED program and the campus safety department.

Moreover, limited cooperation with other college departments is another factor explaining the implementation phase challenges. The department of facilities services, for instance, can contribute to the CPTED program by providing assistance in conducting CPTED evaluations and making modifications to the extent that their budget allows. Lastly, the fact that campus safety is not regarded as a first-ranked priority might explain the limited attention to programs of this kind, which, in turn, results in institutions dedicating fewer resources (e.g., funding, human resources, and training opportunities) to the issue.

Additionally, another challenging situation was caused by the conflict between openness and safety. Although difficult to address, this paradoxical expectation offers opportunities for innovative methods of environmental design, which can respond to both needs. The strategies of access control and territoriality—if tailored to the needs and nature of academic area — will help to overcome this challenge. Finally, the historic buildings on campus, which require that any modification complies with the historic building codes, creates another challenge with regard to the CPTED interventions. However, this suggests 
that other universities can implement similar programs despite challenges that may arise. Newly built universities will likely have fewer challenges of this kind, while older institutions could overcome the challenges by developing creative solutions.

\section{Main Contributions to Literature}

This study uniquely contributes to the literature as it offers operational definitions for the abstract concepts of CPTED. The level of application of CPTED and its impact on campus crime was measured through operationalization of highly subjective qualities of campus design and campus prevention programs. The study further contributed to the literature by empirically testing the argument made by the Defensible Space Theory in an educational context. Two measures of campus safety—campus crime rates and students' perception of safety - were examined to understand the impact of CPTED strategies in universities' safety. Although the hypothesized effect of CPTED on campus crime rate was not supported by the results of the first phase of the study due to the data constraints, the analyses performed in the second phase helped to solve the puzzle through an examination of the other dimension of campus safety: dorm residents' safety perceptions. The qualitative investigation, on the other hand, shed light on the implementation processes of a systematic deployment of CPTED in a college campus, and the program's strengths and challenges. The qualitative case study findings revealed that the CPTED program can be of educational value for the recipients of the vulnerability assessment reports with regard to their personal safety. The program can also be beneficial for the entire campus community due to its cost-efficiency (e.g., relatively inexpensive modifications can produce long term cost-savings in policing). Moreover, the CPTED program has the potential to spread its positive effects to the surrounding areas and neighborhoods. Despite these strengths, any 
university program is likely to face several challenges in the implementation phase due to limited inter-departmental cooperation and funding and human resource limitations. The analyses further offered potential solutions for the program improvement.

\section{Strengths, Limitations and Opportunities for Future Research}

This dissertation comprises three independent study phases and connects them to answer the research questions. Quantitative methods were used to analyze the extent and impact of CPTED on campus crime and students' perception of safety. The content analysis of universities' Clery Reports was conducted to assess the extent of the CPTED use within the institutions. Also, through systematic observations, the level of CPTED use was evaluated in two residential facilities. Then, these understandings were complemented by qualitative methods, including in-depth interviews and a focus group with members of the College community. The triangulation of both methods and data collection strategies helped to control bias and increase the reliability and validity of the study. In addition, the reliability of the content analysis was ensured by adopting an inter-coder reliability technique, using multiple coders and a mutual coding protocol.

Although this dissertation offers a step forward in assessing the CPTED approach for campus safety, it does have several limitations offering opportunities for future research. The time element was not accounted for in the national assessment of the relationship between CPTED and campus crime. This limitation did not allow for the detection of temporal variations in the CPTED strategies. Future studies should consider new data collection methods to obtain time-series data. This can be accomplished by sending surveys to the sampled universities to request more detailed information. 
Another data constraint relates to the potential discrepancies between the actual implementation of the CPTED strategies and the narratives provided by the institutions' Clery Reports. Hence, a second area for future research entails verification of the information provided in the Clery Reports. Qualitative methods can be used to examine several of the sampled schools to assess the differences between the actual and the reported characteristics.

The third area of opportunity for expanding this research is the development of more case studies that investigate the use of CPTED on college campuses. The single qualitative case study did not allow the researcher to examine more programs of this kind in different settings and compare them accordingly. The study identified Colorado College as the only institution in the United States that applies CPTED in an organized way. Given the growing interest in the use of preventive approaches on college campuses, more universities have recently begun to implement the CPTED approach. The comparison of these cases in different settings will provide better understanding of the applicability, strengths, and challenges of the CPTED program.

Lastly, the qualitative case study mainly captured the perspectives of campus safety officials, college administrators, and staff of the facilities office. Another interesting area of future research entails a shift in focus to the experiences of students and faculty, particularly in the context of off-campus CPTED evaluations. Unlike on-campus CPTED recommendations, which address the college departments' chairs, the off-campus ones mainly deal with the owners of the properties, whether it be students/faculty members or their private landlords. 


\section{Policy Implications}

The findings of this research benefit several groups within the campus communities. First, this study offers university safety officials practical information on how to foster campus safety using CPTED approach. Also, the study provides an in-depth understanding of the applicability of this method in the educational context, and elucidates the benefits and drawbacks of the initiative. This research further offers recommendations to overcome challenges and improve the environmental crime prevention techniques.

Second, this research presents recommendations for college administrators on how to provide support for preventive interventions and help safety officials overcome their challenges. Also, the operational definitions developed for the CPTED concepts can be used by university administrators as a benchmark for campus environmental design. Finally, the study can be of important educational value for the whole college community, by informing them on how to use CPTED techniques to create a defensible space in their living and working environments. 


\section{References}

Armitage, R. (2014). Crime Prevention through Environmental Design. In Brinsma, G. \& Weisburd, D. (Eds.), Encyclopedia of Criminology and Criminal Justice (pp. 720731). London: Springer. ISBN 9781461456919

Atlas, R. I. (2008). 21st century security and CPTED: Designing for critical infrastructure protection and crime prevention. Boca Raton: CRC Press.

Banyard, V. L., Moynihan, M. M., \& Plante, E. G. (2007). Sexual violence prevention through bystander education: An experimental evaluation. Journal of Community Psychology, 35(4), 463-481.

Belknap, J., \& Erez, E. (2013). Violence against Women on College Campuses: Rape, Intimate Partner Abuse, and Sexual Harassment. In B. S. Fisher \& J. J. Sloan (Eds.), CAMPUS CRIME: Legal, Social, and Policy Perspectives (pp. 211-235).

Springfield, IL: Charles C Thomas Publisher.

Berg, B. L., \& Lune, H. (2011). Qualitative research methods for the social sciences $\left(8^{\text {th }}\right.$ Edition). Boston: Pearson.

Berke, P., \& Godschalk, D. (2009). Searching for the good plan: A meta-analysis of plan quality studies. CPL bibliography, 23(3), 227-240.

Brantingham, P. L., Brantingham, P. J., \& Taylor, W. (2005). Situational crime prevention as a key component in embedded crime prevention. Canadian Journal of Criminology and Criminal Justice/La Revue canadienne de criminologie et de justice pénale, 47(2), 271-292.

Carnegie Classification of Institutions of Higher Education (n.d.), 2015 edition, Bloomington, IN. Retrieved from http://carnegieclassifications.iu.edu/lookup/lookup.php

Casteel, C., \& Peek-Asa, C. (2000). Effectiveness of crime prevention through environmental design (CPTED) in reducing robberies. American Journal of Preventive Medicine, 18(4), 99-115.

Casteel, C., Peek-Asa, C., Howard, J., \& Kraus, J. F. (2004). Effectiveness of crime prevention through environmental design in reducing criminal activity in liquor stores: A pilot study. Journal of Occupational and Environmental Medicine, 46(5), $450-458$.

Clarke, R. V. (1989). Theoretical background to crime prevention through environmental design (CPTED) and situational crime prevention. In S. Geason \& P. R. Wilson 
(Eds.), Designing out crime: Crime prevention through environmental design (No. 3) (pp. 13-21). Australia: Australian Institute of Criminology.

Clarke, R. V. G. (Ed.). (1997). Situational crime prevention. Monsey, NY: Criminal Justice Press.

Clarke, R. V., \& Cornish, D. B. (1985). Modeling offenders' decisions: A framework for research and policy. Crime and justice, 6, 147-185.

Cohen, L. E., \& Felson, M. (1979). Social change and crime rate trends: A routine activity approach. American sociological review, 44(4), 588-608.

Coker, A. L., Cook-Craig, P. G., Williams, C. M., Fisher, B. S., Clear, E. R., Garcia, L. S., \& Hegge, L. M. (2011). Evaluation of Green Dot: An active bystander intervention to reduce sexual violence on college campuses. Violence against women, 17(6), 777-796. DOI:1077801211410264.

Colorado College Campus Safety Department. (2015). Campus Resource Officer: Annual Report. Colorado Springs CO: Jason Newton. Retrieved from https://www.coloradocollege.edu/offices/campussafety/campus-crimestatistics/annual-security-report.html

Colorado College Campus Safety Department (2016). Campus Safety and Fire Safety Annual Report. Colorado Springs CO: Office of Campus Safety. Retrieved from https://www.coloradocollege.edu/offices/campussafety/campus-crimestatistics/annual-security-report.html

Cozens, P. M., Saville, G., \& Hillier, D. (2005). Crime prevention through environmental design (CPTED): a review and modern bibliography. Property management, 23(5), 328-356.

Cozens, P. (2008). Crime prevention through environmental design in Western Australia: planning for sustainable urban futures. International Journal of Sustainable Development and Planning, 3(3), 272-292.

Crowe, T. D., \& Zahm, D.L. (1994). Crime prevention through environmental design. NAHB Land Development Magazine. National Association of Home Builders.

Crowe, T. D. (2000). Crime prevention through environmental design: Applications of architectural design and space management concepts. National Crime Prevention Institute: Butterworth-Heinemann.

Cullen, F. T., \& Wilcox, P. (Eds.). (2010). Encyclopedia of criminological theory (Vol. 1). Thousand Oaks, CA: Sage. 
Dowdall, G. W. (2013). The Role of Alcohol Abuse in College Student Victimization. In B. S. Fisher \& J. J. Sloan (Eds.), CAMPUS CRIME: Legal, Social, and Policy Perspectives (pp. 184-210). Springfield, IL: Charles C Thomas Publisher.

Eck, J. E. (2002). Preventing crime at places. Evidence-based crime prevention, 241-294.

Eck, J. E., \& Weisburd, D. L. (Eds.) (2015). Crime places in crime theory. In J. E. Eck \& D. L. Weisburd (Eds.), Crime and Place (pp. 1-33). New York: Willow Tree Press.

Ewing, R., Handy, S., Brownson, R. C., Clemente, O., \& Winston, E. (2006). Identifying and measuring urban design qualities related to walkability. Journal of Physical Activity and Health, 3(s1), S223-S240.

Fernandez, M. (2005). Crime prevention and the perception of safety in campus design (Doctoral dissertation). Louisiana State University, Louisiana.

Fisher, B. S., Cullen, F. T., \& Turner, M. G. (2000). The Sexual Victimization of College Women. Washington, D.C.: U.S. Department of Justice, National Institute of Justice, and Bureau of Justice Statistics.

Fisher, B. S., Sloan, J. J., Cullen, F. T., \& Lu, C. (1998). Crime in the ivory tower: The level and sources of student victimization. Criminology, 36(3), 671-710.

Fisher, B. S., \& Nasar, J. L. (1992). Fear of crime in relation to three exterior site features: Prospect, refuge, and escape. Environment and Behavior, 24(1), 35-65.

Fisher, B. S., \& Sloan, J. J. (Eds.) (2013). CAMPUS CRIME: Legal, Social, and Policy Perspectives. Springfield, IL: Charles C Thomas Publisher.

Fox, J. A., \& Savage, J. (2009). Mass murder goes to college an examination of changes on college campuses following Virginia Tech. American Behavioral Scientist, 52(10), 1465-1485.

Freelon, D. G. (2010). ReCal: Intercoder reliability calculation as a web service. International Journal of Internet Science, 5(1), 20-33.

Freelon, D. (2013). ReCal OIR: Ordinal, interval, and ratio intercoder reliability as a web service. International Journal of Internet Science, 8(1), 10-16.

Fritz, A., (2009). Crime Prevention through Environmental Design. Portland, OR: Office of Neighborhood Involvement Crime Prevention Program.

Gardiner, R. A. (1978). Design for safe neighborhoods. Washington, D.C.: Government Printing Office. 
Hanson, R. F., Sawyer, G. K., Begle, A. M., \& Hubel, G. S. (2010). The impact of crime victimization on quality of life. Journal of traumatic stress, 23(2), 189-197.

Hayes, A. F., \& Krippendorff, K. (2007). Answering the call for a standard reliability measure for coding data. Communication methods and measures, 1(1), 77-89.

Heilbrun, K., Dvoskin, J., \& Heilbrun, A. (2009). Toward preventing future tragedies: Mass killings on college campuses, public health, and threat/risk assessment. Psychological Injury and Law, 2(2), 93-99.

Henson, V. A., \& Stone, W. E. (1999). Campus crime: A victimization study. Journal of Criminal Justice, 27(4), 295-307.

Hollander, B., Hartmann, F. X., Brown, R. R., \& Wiles, R. (1979). Reducing Residential Crime and Fear: The Hartford Neighborhood Crime Prevention Program, Washington D.C.: National Institute of Law Enforcement and Criminal Justice.

Janosik, S. M., \& Gregory, D. E. (2003). The Clery Act and its influence on campus law enforcement practices. Naspa Journal, 41(1), 182-199.

Jeffrey, C. (1971). Ray. Crime Prevention Through Environmental Design. Beverly Hills. Sage publications.

Johnson, D., Gibson, V., \& McCabe, M. (2014). Designing in crime prevention, designing out ambiguity: Practice issues with the CPTED knowledge framework available to professionals in the field and its potentially ambiguous nature. Crime Prevention \& Community Safety, 16(3), 147-168.

Jordan, C. E., Combs, J. L., \& Smith, G. T. (2014). An exploration of sexual victimization and academic performance among college women. Trauma, Violence, \& Abuse, 15(3), 191-200.

Kaminski, R. J., Koons-Witt, B. A., Thompson, N. S., \& Weiss, D. (2010). The impacts of the Virginia Tech and Northern Illinois University shootings on fear of crime on campus. Journal of Criminal Justice, 38(1), 88-98.

Kanin, E. J. (1967). An examination of sexual aggression as a response to sexual frustration. Journal of Marriage and the Family, 29(3), 428-433.

Kanin, E. J. (1970). Sex Aggression by College Men. Med Aspects Hum Sexuality, 4(9), $25-40$.

Kanin, E. J., \& Parcell, S. R. (1977). Sexual aggression: A second look at the offended female. Archives of Sexual Behavior, 6(1), 67-76. 
Kaplan, H. M., Palkovitz, L. H., Pesce, E. J., Westinghouse Electric Corporation, \& United States of America. (1978). Crime Prevention Through Environmental Design: Final Report on Residential Demonstration, Minneapolis, Minnesota. Rockville, MD: Westinghouse Electric.

Kilpatrick, D. G., Resnick, H. S., Ruggiero, K. J., Conoscenti, L. M., \& McCauley, J. (2007). Drug-facilitated, incapacitated, and forcible rape: A national study. South Carolina: Medical University of South Carolina National Crime Victims Research and Treatment Center.

Kirkpatrick, C., \& Kanin, E. (1957). Male sex aggression on a university campus. American Sociological Review, 22(1), 52-58.

Koss, M. P., Gidycz, C. A., \& Wisniewski, N. (1987). The scope of rape: incidence and prevalence of sexual aggression and victimization in a national sample of higher education students. Journal of Consulting and Clinical Psychology, 55(2), 162.

Krippendorff, K. (2004). Content analysis: An introduction to its methodology. Thousand Oaks, CA: Sage.

Kushmuk, J., \& Whittemore, S. L. (1981). Re-Evaluation of Crime Prevention Through Environmental Design in Portland, Oregon-Executive Summary. Washington, D.C.: Government Printing Office.

Lab, S. P. (2014). Crime Prevention: Approaches, practices, and evaluations. Waltham, MA: Anderson.

Letch, J., McGlinn, E., Bell, J. F., Downing, E., \& Cook, D. M. (2011). An exploration of 1st and 2nd generation CPTED for end of year school leavers at Rottnest Island. Perth, Western Australia: Security Research Centre, Edith Cowan University.

Marshall, C., \& Rossman, G. B. (2010). Designing qualitative research. Thousand Oaks, CA: Sage.

Marzbali, M. H., Abdullah, A., Razak, N. A., \& Maghsoodi Tilaki, M. J. M. (2012a). The relationship between socio-economic characteristics, victimization and CPTED principles: evidence from the MIMIC model. Crime, Law and Social Change, 58(3), 351-371.

Marzbali, M., Abdullah, A., Razak, N. A., \& Maghsoodi Tilaki, M. J. (2012b). The influence of crime prevention through environmental design on victimisation and fear of crime. Journal of environmental psychology, 32(2), 79-88. 
McCormick, J. G. (2011). National evaluation of crime prevention strategies in urban parks: using rational choice theory to understand decisions of park directors and professors (Doctoral dissertation). University of Florida, Gainesville, FL.

Minnery, J. R., \& Lim, B. (2005). Measuring crime prevention through environmental design. Journal of Architectural and Planning Research, 22(4), 330-341.

Mustaine, E. E., \& Tewksbury, R. (2002). Sexual assault of college women: A feminist interpretation of a routine activities analysis. Criminal Justice Review, 27(1), 89123.

Mustaine, E. E., \& Tewksbury, R. (2013). The Routine Activities and Criminal Victimization of Students: Life Style and Related Factors. In B. S. Fisher \& J. J., Sloan (Eds.), CAMPUS CRIME: Legal, Social, and Policy Perspectives (pp. 158183). Springfield, IL: Charles C Thomas Publisher.

Nasar, J. L., \& Fisher, B. (1993). 'Hot spots' of fear and crime: A multi-method investigation. Journal of environmental psychology, 13(3), 187-206.

Newman, O. (1996). Creating defensible space. New York: Diane Publishing.

Newman, O. (1972). Defensible space. New York: Macmillan.

Nichols, J. W. (2012). Crime Prevention through Environmental Design. Retrieved from http://www.oshkoshpd.com/crime prevention/crime prevention through environm ental design.asp

Pezza, P. E., \& Bellotti, A. (1995). College campus violence: Origins, impacts, and responses. Educational Psychology Review, 7(1), 105-123.

Poyner, B. (1993). What works in crime prevention: An overview of evaluations: Crime prevention studies, 1, 7-34.

Reynald, D. M., \& Elffers, H. (2009). The Future of Newman's Defensible Space Theory Linking Defensible Space and the Routine Activities of Place. European Journal of Criminology, 6(1), 25-46.

Robinson, M. B., \& Mullen, K. L. (2001). Crime on campus: A survey of space users. Crime Prevention \& Community Safety, 3(4), 33-46.

Saville, G., \& Cleveland, G. (1999). 2nd Generation CPTED: An Antidote to the Social Y2K Virus of Urban Design. Unpublished manuscript. Retrieved 04 Apr, 2011, from http://www.edoca.eu/content/docs/CPTED_2ndGeneration.pdf 
Siegel, D. G., \& Raymond, C. H. (1992). An ecological approach to violent crime on campus. Journal of Security Administration, 15(2), 19-29.

Shariati, A., \& Guerette, R. T. (2017). Situational Crime Prevention. In Preventing Crime and Violence (pp. 261-268). Springer International Publishing.

Sloan, J. J., III, Lanier, M. M., \& Beer, D. L. (2000). Policing the contemporary university campus: Challenging traditional organizational models. Journal of Security Administration, 23(1).

Sloan, J. J., III, \& Fisher, B. S. (2011). The dark side of the ivory tower: Campus crime as a social problem. Cambridge: Cambridge University Press.

Smith, M. C. (1989). The ancestry of campus violence. New Directions for Student Services, 47, 5-15.

Smith, M.J., \& Clarke, R.V. (2012) Situational crime prevention: Classifying techniques using good enough theory. In B. C. Welsh, \& D. P. Farrington (Eds.), The Oxford handbook of crime prevention (pp. 291-315). Oxford: Oxford University Press.

Stemler, S. (2001). An overview of content analysis. Practical Assessment, Research \& Evaluation, 7(17), 137-146.

Stewart, M. C. \& Fisher, B. S. (2013). Vulnerabilities and Opportunities 101: The Extent, Nature, and Impact of Stalking and Cyberstalking among College Students and Implication for Campus Policies and Programs. In B. S. Fisher \& J. J. Sloan (Eds.), CAMPUS CRIME: Legal, Social, and Policy Perspectives (pp. 236-269). Location: Charles C Thomas Publisher.

Tewksbury, R. (2013). The dark side of the ivory tower: campus crime as a social problem. Journal of Criminal Justice Education, 25(1), 131-133.

United States Department of Education. (2015a). Federal Student Aid Program, Federal School Code List 2015-2016. Retrieved from ifap.ed.gov/fedschcodelist/attachments/1516FedSchoolCodeList.xlsx

United States Department of Education. (2015b). National Center for Education Statistics, Integrated Postsecondary Education Data System (IPEDS). Retrieved from https://nces.ed.gov/programs/digest/d15/tables/dt15 303.20.asp?current=yes

United States Department of Education. (2016a). Office of Postsecondary Education, Campus Safety and Security Data. Retrieved from https://ope.ed.gov/campussafety/\#/datafile/list 
United States Department of Education. (2016b). Office of Postsecondary Education, The Handbook for Campus Safety and Security Reporting, Washington, D.C. Retrieved from https://www2.ed.gov/admins/lead/safety/handbook.pdf

Wallis, A., Ford, D., Westinghouse Electric Corporation, \& United States of America. (1981). Crime Prevention Through Environmental Design: The School Demonstration in Broward County, Florida: Executive Summary. Washington D.C.: U.S. Department of Justice, National Institute of Justice.

Wallis, A., Ford, D., Westinghouse National Issues Ctr, \& United States of America. (1981). Crime Prevention Through Environmental Design: The Commercial Demonstration in Portland, Oregon: Executive Summary. Washington, D.C.: Government Printing Office.

Welsh, B. C., \& Farrington, D. P. (2012) Crime prevention and public policy. In B. C. Welsh \& D. P. Farrington (Eds.). The Oxford handbook of crime prevention (pp. 319). Oxford: Oxford University Press.

Welsh, B. C., \& Farrington, D. P. (2010). The future of crime prevention: Developmental and situational strategies. National Institute of Justice, 1-65.

Western Australia Planning Commission (WAPC). (2006). Designing Out Crime Planning Guidelines. Perth, WA: Western Australia Planning Commission.

Volkwein, J. F., Szelest, B. P., \& Lizotte, A. J. (1995). The relationship of campus crime to campus and student characteristics. Research in Higher Education, 36(6), 647-670.

Zahm, D. (2007). Using crime prevention through environmental design in problemsolving. Collingdale, PA: DIANE Publishing. 


\section{Appendices}

Appendix A: Crime definitions

\begin{tabular}{|c|c|}
\hline Crime Definition & Inclusion Criteria \\
\hline $\begin{array}{l}\text { Murder and Non-Negligent } \\
\text { Manslaughter is defined as the } \\
\text { willful (non-negligent) killing of one } \\
\text { human being by another. }\end{array}$ & $\begin{array}{l}\text { Include as Murder and Non-Negligent } \\
\text { Manslaughter: } \\
\text { Any death caused by injuries received in a fight, } \\
\text { argument, quarrel, assault or the commission of a } \\
\text { crime. }\end{array}$ \\
\hline $\begin{array}{l}\text { Sexual Assault (Sex Offenses). Any } \\
\text { sexual act directed against another } \\
\text { person, without consent of the } \\
\text { victim, including instances where } \\
\text { the victim is incapable of giving } \\
\text { consent. }\end{array}$ & $\begin{array}{l}\text { Include attempted Sexual Assaults, but do not } \\
\text { include in your Clery Act statistics any Sexual } \\
\text { Assaults other than the four types of Sexual } \\
\text { Assaults described in this chapter: rape, fondling, } \\
\text { incest, statutory rape. }\end{array}$ \\
\hline $\begin{array}{l}\text { Robbery is the taking or attempting } \\
\text { to take anything of value from the } \\
\text { care, custody, or control of a person } \\
\text { or persons by force or threat of force } \\
\text { or violence and/or by putting the } \\
\text { victim in fear. }\end{array}$ & $\begin{array}{l}\text { Essential Elements of a Robbery: } \\
\text { - Committed in the presence of a victim (usually the } \\
\text { owner or person having custody of the property). } \\
\text { - Victim is directly confronted by the perpetrator. } \\
\text { - Victim is threatened with force or put in fear that } \\
\text { force will be used. } \\
\text { - Involves a Theft or Larceny. }\end{array}$ \\
\hline $\begin{array}{l}\text { Aggravated Assault is an unlawful } \\
\text { attack by one person upon another } \\
\text { for the purpose of inflicting severe } \\
\text { or aggravated bodily injury. This } \\
\text { type of assault usually is } \\
\text { accompanied by the use of a weapon } \\
\text { or by means likely to produce death } \\
\text { or great bodily harm. }\end{array}$ & $\begin{array}{l}\text { Include as Aggravated Assaults: } \\
\text { - Assaults or attempts to kill or Murder } \\
\text { - Poisoning (including the use of date rape drugs) } \\
\text { - Assault with a dangerous or deadly weapon } \\
\text { - Maiming } \\
\text { - Mayhem } \\
\text { - Assault with explosives } \\
\text { - Assault with disease }\end{array}$ \\
\hline $\begin{array}{l}\text { Burglary is the unlawful entry of a } \\
\text { structure to commit a felony or a } \\
\text { theft. Count one offense per each } \\
\text { distinct operation. }\end{array}$ & $\begin{array}{l}\text { Classify as Burglary: } \\
\text { - Offenses that are classified by local law } \\
\text { enforcement agencies as Burglary (any degree) } \\
\text { - Forcible Entry } \\
\text { - Unlawful Entry-No Force } \\
\text { - Attempted Forcible Entry } \\
\end{array}$ \\
\hline $\begin{array}{l}\text { Motor Vehicle The } \\
\text { attempted theft of a }\end{array}$ & $\begin{array}{l}\text { Classify as Motor Vehicle Theft: } \\
\text { - Theft of any self-propelled vehicle that runs on } \\
\text { land surface and not on rails. } \\
\text { - All incidents where automobiles are taken by } \\
\text { persons not having lawful access even though the } \\
\text { vehicles are later abandoned. Include joyriding in } \\
\text { this category. }\end{array}$ \\
\hline
\end{tabular}




\begin{tabular}{|l|l|}
\hline & \\
\hline $\begin{array}{l}\text { Arson is any willful or malicious } \\
\text { burning or attempt to burn, with or } \\
\text { without intent to defraud, a dwelling } \\
\text { house, public building, motor } \\
\text { vehicle or aircraft, personal property } \\
\text { of another, etc. }\end{array}$ & $\begin{array}{l}\text { Classify as Arson: } \\
\text { - Only fires determined to have been willfully or } \\
\text { maliciously set. }\end{array}$ \\
- Any fire that investigation determines to meet the \\
UCR definition of Arson regardless of the value of \\
any property damage. \\
- Incidents where an individual willfully or \\
maliciously burns his or her own property.
\end{tabular}

Adopted from: The Handbook for Campus Safety and Security Reporting (2016) 
Appendix B: Survey Questionnaire

Students' Perception of Safety in the FIU On-Campus Housing Facilities (2015)

This survey is about the perception of safety of the residents of on-campus housing facilities at FIU. It's been developed so you can express how you feel in and around your dorms and how you assess the environmental design of your dormitories.

\section{Instructions:}

- DO NOT write your name on this survey. Your answers will be kept private.

- Completing this survey is voluntary.

- The questions that ask about your background will be used only to describe the types of students completing this survey.

- Answering this survey is expected to take 15 minutes.

\section{Thank you very much for your participation}

\section{Biographic Information}

1. How old are you? .....

2. What is your gender?

Male

3. In what educational level are you?

$\square$ Freshman

Sophomore

Junior

4. Are you Hispanic/Latino?

Yes
Female

Senior

Graduate

No 
5. What is your race?

American Indian or Alaska

Native

Asian

Black or African American
Hawaiian or Other Pacific

Islander

White

\section{Dorm Info and Duration of Stay}

6. Which dormitory are you living in?

\section{$\square$ University Apartments}

$\square \quad$ University Towers

7. How long have you been living there? ......

\section{Victimization Experience}

8. Have you ever been victim of a crime in or around your dorm?

$\square$ Yes

$\square \quad$ No

9. If your answer to the above question is positive, then what was the type of that crime?

$\square$ Theft

Burglary

Robbery

10. Where was the location in which you were victimized?

$\square \quad$ Inside my room

In the dorm's halls $\square$ Sexual Assault

$\square$ Other (Please Specify) $\square \quad$ In the courtyard

Graduate

11. Have you ever heard of a friend or acquaintance being victim of a crime in their dorms? 
12. If your answer to the above question is positive, then what was the type of that crime?

$\square$ Theft

Burglary

Robbery $\square$ Sexual Assault

$\square$ Other (Please Specify)

$\square$ Not Sure

13. Where was the location in which they were victimized?

$\square \quad$ Inside their room

In their dorm's halls $\square \quad$ In the courtyard

$\square \quad$ Not Sure

\section{Structural Features of the Housing Facilities}

\section{Visibility}

14. Are there enough well-lit paths/walkways which you can take to commute to your educational department at night?
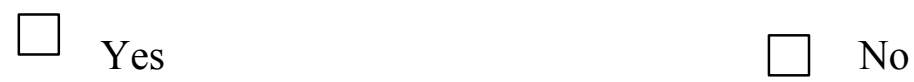

15. Do you consider the area enclosing your dorm as a well-lit area?

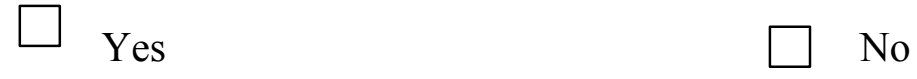

16. Do you consider the outward structure of your dorm as a luminous/visible building exterior?

Yes

$\square \quad$ No

17. Does the building of your dorm have enough windows giving you the opportunity to watch the surrounding area?
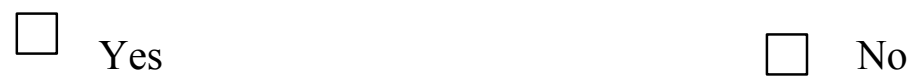

\section{Access Control}


18. Are the exterior doors of your residential hall locked 24 hours a day?
$\square$ Yes
$\square$ No

19. Do you have access to your assigned building with your own identification card/individual key?
Yes
$\square \quad$ No

1. Do you have access to your room with your own identification card /individual key?

$\square$ Yes

$\square \quad$ No

2. Is there limited visitation rule allowing your guests to visit you in your residential halls/rooms only during specific hours a day or specific days a week?

$\square$ Yes

$\square \quad$ No

3. Is there standard visitation rule allowing your guests to visit you in your residential halls/rooms anytime with your permission?
$\square$ Yes
$\square \quad$ No

$\square$ Not Sure

4. Are you notified by phone when your guests are seeking access to the dorm to visit you?

$\square$ Yes

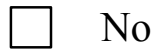

5. Are you required to escort your guests while visiting the residence hall?

Yes

No

\section{Maintenance}

7. Is trimming vegetation around your dorm building conducted on a regular basis? 


\section{I don't know}

8. Are security hardware (doors, locks, etc.) failures in your dorm inspected and fixed periodically?

$\square$ Yes

$\square$ I don't know

9. Are lighting failures in and around your dorm inspected and fixed regularly?
$\square$ Yes
$\square \quad$ No

\section{I don’t know}

10. How are the typical security calls for reporting not functioning of lights, doors, etc. responded?

$\square$ During the same day (even if a $\quad \square \quad$ In the next business day weekend)

It's usually postponed to the $\quad \square \quad$ I don't know following days

\section{Territoriality}

12. Are there any signs which define the entrances of your dorm?

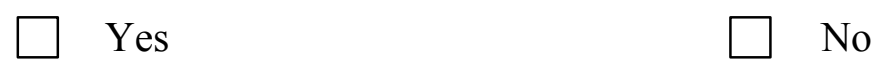

13. Are there fences, pavements, curbs, or other landscaping features which demarcate the borders of the residential area?

$\square$ Yes

$\square$ No 
14. In the aggregate, do you consider your dormitory and the area enclosing it as having specified borders?
$\square$ Yes
$\square \quad$ No

\section{Activity Support}

16. Are there pools, playgrounds, or sports courts around your dorm which encourage the use and promote the safety of the area?
$\square$ Yes
$\square$ No

17. Are there picnic tables, benches, fountains, or other gathering areas which provide visibility for secluded areas around the dorm?

$\square$ Yes $\square$ No

18. How often entertaining/cultural events or activities are held around your residential area?
$\square$ Very Often
$\square$ Rarely
Often
$\square$ Never

\section{Sometimes}

19. Is there any shop or marketplace around the dorm?

$\square$ Yes

\section{Perception of Safety and Security}

20. Do you feel safe to go out of your residential building late at night alone?

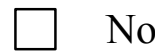

21. Do feel safe to walk around your dorm during the day light hours? 
22. Are you fearful of leaving your personal belongings at your individual room being stolen by others?

$\square$ Yes

$\square \quad$ No

23. Are you scared of being burglarized, robbed, or attacked when you are at your personal room?

$\square$ Yes

$\square \quad$ No

24. On a scale of 1-10 (one considered as the lowest), how do you rate your own perception of safety in your residential area?
1. $\square 2 . \square$
3.
4. $\square 5$.
6. $\square 7$
7. $\square 8$
8. $\square 9$.
9. $\square \quad 10 . \square$ 
Appendix C: Interview Questions

Crime Prevention Strategies and Campus Safety

SEMI-STRUCTURED INTERVIEW GUIDE

\begin{tabular}{|l|l|}
\hline Interviewer: & \\
\hline Date: & \\
\hline Place: & \\
\hline Starting Time: & \\
\hline Interviewee/ Pseudonym: & \\
\hline
\end{tabular}

\section{SECTION A. INTERVIEW WITH CAMPUS SAFETY OFFICERS}

In this interview, I will ask you questions about your experiences as a campus safety officer at CC College.

A1. Could you please tell me a little bit about the safety programs and services provided by Colorado College (CC) Campus Safety Department?

A2. May I ask how each of these programs/services work? I would like to have a brief description of each of these services, please.

A3. What would you think is the main safety issue of CC campus?

A4. Would you please explain how security officers of CC campus are trained?

A5. I am curious to know about the administrative processes, people/departments involved in applying crime prevention methods, particularly CPTED, and how they work together to accomplish this program.

A6. I know that you implement CPTED on CC campus, through providing CPTED assessments, upon request, for campus community. Would you please explain how these assessments are conducted?

A7. What does "crime prevention through environmental design" (CPTED) mean to you? How would you define it? 
A8. What are some of the strengths of the CPTED program you implement?

A9. Are there any gaps/limitations in terms of the implementation of CPTED on CC

Campus?

A10. What do you think can be done to improve the process and fill the gaps?

A11. Have you ever faced with any challenges/problems in implementing CPTED-related services?

\section{SECTION B. INTERVIEW WITH COLLEGE ADMINISTRATORS}

I will now ask you some questions about your administrative involvement in policy-making for safety as well as in implementing the existing policies.

B1. What does your department do to secure CC campus? In what ways did it help to improve safety of this campus?

B2. What is your role in these administrative processes, if any, in helping CC community feel safer?

B3. Have you been involved in policy-making for safety-related issues of CC Campus?

B4. Have you been involved in implementing already existent policies related to safety of CC Campus? If so, how do you assess these policies/regulations?

B5. Are there any areas that you believe are in need of legal/administrative changes for the purpose of improving safety of CC campus?

B6. What would you think is the main safety issue of CC campus?

\section{SECTION C. INTERVIEW WITH BUIDING PLANNERS}

I will be asking you questions about your role and experience in building and design of campus. 
C1. What are/were your responsibilities in the planning/design of CC campus?

C2. What are/were the security-related criteria/standards that you consider while planning/landscaping?

C3. How would you define CPTED? Do you consider CPTED strategies while designing/building campus buildings?

C4. In your opinion, what are the factors that affect the security of a college campus?

C5. In your opinion, what are the factors that affect the practicability of CPTED strategies?

C6. What have been the challenges that you faced while planning/designing/building campus constructions?

C7. What have been the strengths of your team/group that helped while designing/building campus structures? [Probes: experiences and skills of team members, strong leadership, and community engagement]

C8. What were some of the lessons you learned from these processes of planning/designing/building?

\section{SECTION D. INTERVIEW WITH FACULTY/STAFF}

I would like to ask you questions about the status of safety in CC College.

D1. Please tell me how you perceive of your college campus security? Would you consider it as a safe campus?

D2. In what ways/aspects do you think your campus is vulnerable/unsafe?

D3. What would you think is the main safety issue of CC campus?

D4. In your opinion, what should be done to improve the security of your college campus? 
D5. Please tell me what crime prevention means to you. What do you understand from this term?

D6. Do you think your campus safety officials are addressing the problems?

D7. In your opinion, what should be done to enhance the security status of your campus [Probes: employ more reactive methods, improve the quality of college structures, provide better preventive services, consult people]

D8. Have you heard of the "Crime Prevention through Environmental Design" (CPTED) Program? Do you know that it's implemented in your college?

D9. If your answer to the above question is positive, how do you estimate the public awareness of this program?

D10. To what extent you are familiar with CPTED program?

D11. Do you think CPTED is a good strategy for improving safety of your campus?

\section{YOUR NAME:}

YOUR POSITION:

\section{SECTION F. DEMOGRAPHICS}

For analysis purposes, please fill out the following section about your background.

F1. How old are you?

$18-25$

26-30

$31-35$

$36-40$

$41-45$
$46-50$

$51-55$

$56-60$

61-65

Above 65 
F2. What is the highest degree of level of school you have completed? If you are currently enrolled, please mark the previous grade or highest degree received.

Less than $12^{\text {th }}$ grade

$12^{\text {th }}$ grade, no diploma

High school graduate- high school

diploma or the equivalent (for

example: GED)

Some college credit, no degree

Other (please specify)
Associate degree (e.g., AA, AS)

Bachelor's degree

Graduate degree

Professional degree (e.g., MD, JD)

F3. What is your ethnicity?

Hispanic or Latino

Not Hispanic or Latino

F4. Could you please specify your race?

American Indian or Alaska Native

Black or African American

Asian

Native Hawaiian or Other Pacific

Islander

White

Do not know

Other (please specify)

F5. Please mark your gender below.

Male

Female

F6. Which department do you work for?

F7. How long have you been working in your current work place?

Less than 1 year

More than 1 year but less than 3

years
More than 6 years but less than 9

years

More than 9 years but less than

12 years 
More than 3 years but less than 6

12 years or more

years

\section{CONTACT INFORMATION}

Please provide your contact information below for follow up purposes.

Address:

Phone:

Email:

\section{REFERRAL}

If it is OK with you, I would like you to suggest a few individuals for me to contact. These individuals could be college administrators, safety personnel, faculty members, staff, and students who have been actively involved in the safety related issues of CC campus or might be interested to participate in this study.

\begin{tabular}{|l|l|l|}
\hline Name & Position/Department & $\begin{array}{l}\text { Contact Information } \\
\text { (Address, Tel., Email) }\end{array}$ \\
\hline & & \\
\hline & & \\
\hline & & \\
\hline
\end{tabular}


Appendix D: Focus Group Guide

CRIME PREVENTION AND CAMPUS SAFETY

FOCUS GROUP GUIDE

\begin{tabular}{|l|l|}
\hline Moderator: & \\
\hline Note Taker: & \\
\hline Date: & \\
\hline Place: & \\
\hline Starting Time: & \\
\hline
\end{tabular}

Before we start, let's go over a few things and agree on the rules of our meeting. [Ex: We will not cut each other off, we will wait for the recorder to reach before we speak, etc.] Now that we have fixed the rules of our meeting, can we proceed with our discussion? DISCUSSION QUESTIONS

A1. Please tell me a little bit about the safety status of your college campus? How safe is your campus?

A2. What does safety mean to you? How would you define a safe campus?

A3. Do you think the campus safety department is doing a good job to make college community feel safe?

A4. Please tell me how vulnerable is your college community to crime?

A4. In your opinion, what are the factors that affect the safety of a college campus?

A5. How would you define crime prevention?

A6. In your opinion, what are the factors that affect the practicability/appropriateness of preventive programs on a college campus?

A7. What do you think are the challenges of implementing crime prevention programs on campus? [Probes: insufficient resources, coordination/collaboration issues, lack of appropriate planning] 
A8. What have been the strengths and weaknesses of CC college safety department?

A10. In your opinion, what should be done to reduce crime rates of your campus? [Probes: improve policing, increase public awareness, provide better preventive service, improve neighborhood conditions]

A11. Please tell me what crime prevention through environmental design mean to you?

A12. In your opinion, what should be done to enhance the security of your college campus?

Is there anything else you would like to share that we have not yet touched upon?

Let me summarize the key points of our discussion. Does this summary sound complete? Is there anything you would like us to revise?

YOUR NAME:

FOCUS GROUP:

FOCUS GROUP LOCATION:

SECTION B. DEMOGRAPHICS

For analysis purposes, please fill out the following section about your background.

B1. How old are you?

$18-25$

26-30

$31-35$

$36-40$

$41-45$
46-50

$51-55$

$56-60$

$61-65$

Above 65

B2. What is the highest degree of level of school you have completed? If you are currently enrolled, please mark the previous grade or highest degree received.

Less than $12^{\text {th }}$ grade

$12^{\text {th }}$ grade, no diploma

High school graduate- high school
Associate degree (e.g., AA, AS)

Bachelor's degree

Graduate degree 
diploma or the equivalent (for

example: GED)

Some college credit, no degree

Professional degree (e.g., MD, JD)

Other (please specify)

B3. What is your ethnicity?

Hispanic or Latino Not Hispanic or Latino

B4. Could you please specify your race?

$\begin{array}{ll}\text { American Indian or Alaska Native } & \text { Black or African American } \\ \text { Asian } & \text { Native Hawaiian or Other Pacific } \\ & \text { Islander } \\ \text { White } & \text { Do not know } \\ \text { Other (please specify) } & \end{array}$

B5. Please mark your gender below.
Male
Female

B6. How long have you been studying at Colorado College?

$\begin{array}{ll}\text { Less than } 1 \text { year } & \text { More than } 6 \text { years but less than } 9 \\ & \text { years } \\ \text { More than } 1 \text { year but less than } 3 & \text { More than } 9 \text { years but less than } \\ \text { years } & 12 \text { years } \\ \text { More than } 3 \text { years but less than } 6 & 12 \text { years or more } \\ \text { years } & \end{array}$

B7. Do you work?

Yes No

B8. If you work, how long have you been working? 
Less than 1 year

More than 1 year but less than 3

years

More than 3 years but less than 6 years
More than 6 years but less than 9 years

More than 9 years but less than

12 years

12 years or more

\section{CONTACT INFORMATION}

Please provide your contact information below for follow up purposes.

Address:

Phone:

Email:

\section{REFERRAL}

If it is $O K$ with you, I would like you to suggest a few individuals for me to contact. These individuals could be college administrators, safety personnel, faculty members, staff, and students who have been actively involved in the safety related issues of CC campus or might be interested to participate in this study.

\begin{tabular}{|l|l|l|}
\hline Name & Position/Department & $\begin{array}{l}\text { Contact Information } \\
\text { (Address, Tel., Email) }\end{array}$ \\
\hline & & \\
\hline & & \\
\hline & & \\
\hline
\end{tabular}


Appendix E: CPTED Assessment Sheet

\section{Campus Safety}

CPTED Inspection

Time: 11:42 AM

Date: $11 / 19 / 2015$

Certified Inspector: Campus Safety Officer

Definition: CPTED: (Crime Prevention Through Environmental Design) The proper design and effective use of the built environment can lead to a reduction in the fear of crime and the incidence of crime, and to an improvement in the quality of life. Through using both soft principles (such as trimming trees and bushes) to hard principles (such as changing lights and locks) CPTED strives for safer communities.

Reason for Inspection: To provide options to consider to alleviate safety concerns with this building.

\section{The Building:}

With that being said, there are still vuinerabilities to this building that can be improved.

Exterior: The exterior of the building is primarily brick, glass blocks, windows, and stucco.

- Doors:

- The main entrance is located on the west side of the building and the door is unlocked all of the time. The main entrance leads into the lobby. One option to consider would be to make the main entrance ADA compliant and add an ADA button to the exterior of the building and inside the lobby. There has been a complaint about the lack of ADA accessibility.
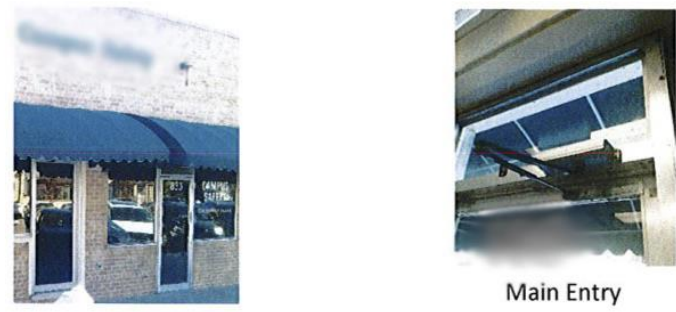

Main Entry

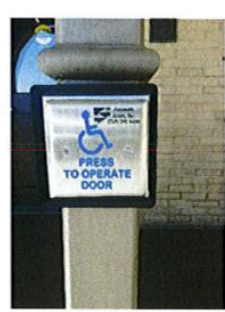


- The secondary entrance is located on the east side of the building and it is meant for authorized personnel only. The door is accessed by a card reader and has an intercom to communicate with whomever is outside of the door. On the interior side of this door, there are hand rails for ADA accessibility but there is a step instead of a ramp. Option to consider would be to add a ramp to increase the accessibility. The secondary entrance door features a window that would be vulnerable for forced entry into the building. By breaking the glass, a person could reach through to open the door from the handle on the inside. An option to consider would be to replace the window in the door with a wire mesh window for added security, or a solid metal door with door viewer.
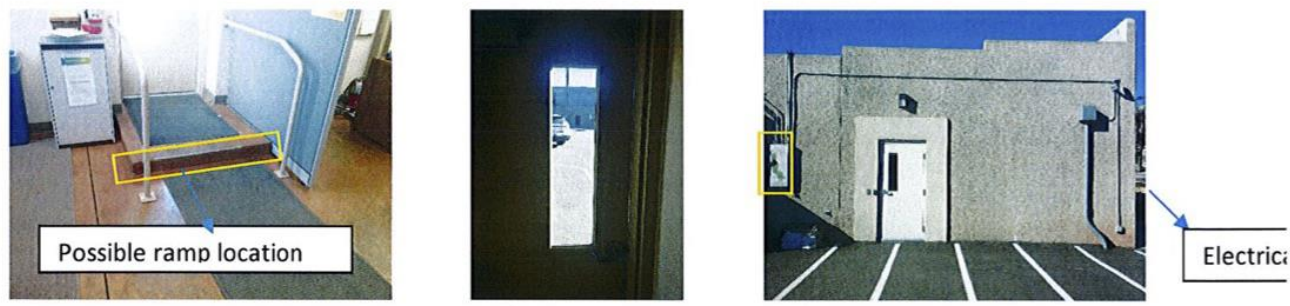

- Windows

o only has windows on the north and west sides of the building if you don't count the window on the east door. All exterior windows are either translucent glass blocks or regular glass windows with reflective metallic tinting for privacy. The reflective tinting works very well during daytime hours, but at night it is very transparent from the outside looking in. An option to consider would be to add blinds to the interior of the window for increased privacy. Also, the windows could be upgraded to a laminated or wire mesh for increased security against forced entry.

- Lighting

- Lighting on the exterior of the building relies mostly on lighting from street lights. There is one exterior light on each of the west, north and east sides of the building. The light on the west side of the building is partly obstructed by a green awning. Also noticed as a partial safety concern is the electrical safety switch located just south of the east entry door. The safety switch is in the on position without a padlock. However, a motivated person with a pair of bolt cutters could turn off electricity to the building, subsequently shutting down computers and lights inside the 
- There are two cameras located on the exterior of the covering both points of entry. Adjustment of viewing angle would be an option to consider.

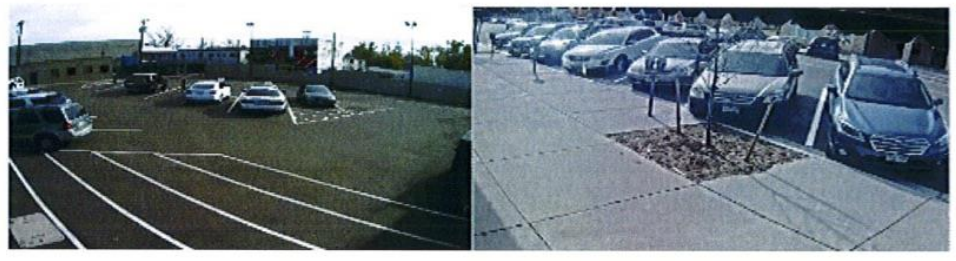

\section{Interior:}

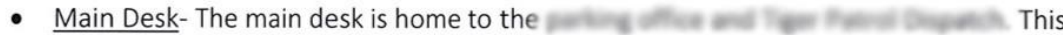
desk is not occupied at all times. Just behind the front counter is a door release button to allow patrons or personnel in the lobby to enter the area behind the main desk. When the desk is not occupied, this button is visible and able to be reached by anyone who is standing at the main desk in the lobby. An option to consider would be to install a pull down gate or window to add security to the main desk. Access to secure areas are controlled by card access systems. The door leading into the "back office" includes a window near the door handle. This could be vulnerable to forced entry.
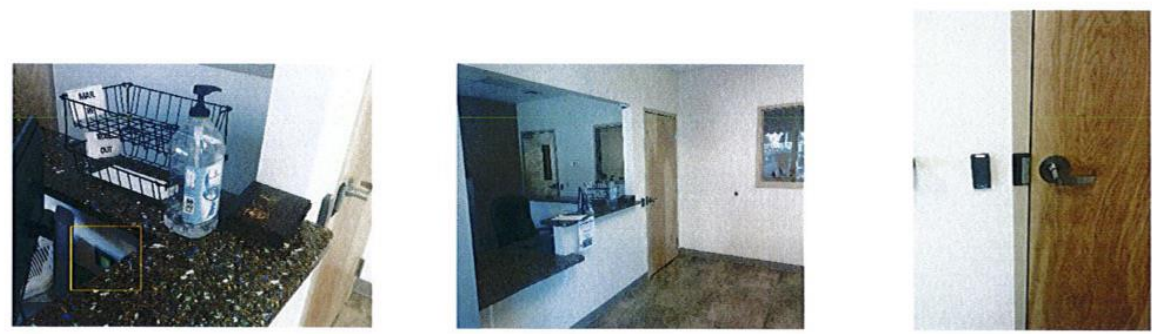
- CCTV-There are two cameras located on the interior of the covering the two points of entry. An option to consider would be to move the camera on the interior side of the east entry. Currently the camera views the squad room table and whomever is leaving out of the east door. This camera would be more useful if it were located perhaps on an interior wall facing the east door to see who is entering the space.
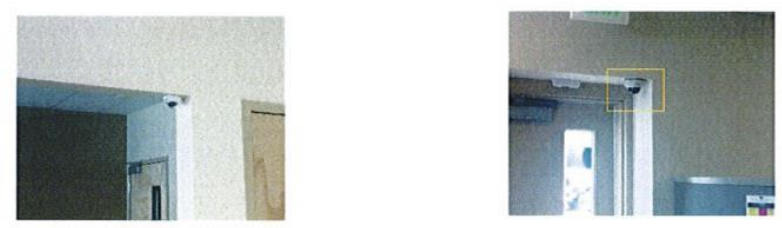

- $\quad$ at ane complained that the window tint on the front (west side) exterior windows do not provide any privacy during the dusk and dark hours of the day and night. The windows looking into the lobby and main desk area are regular glass windows and could be vulnerable to forced entry. An option to consider would be to upgrade the windows to a wire mesh window. A door viewer could be installed for increased security.
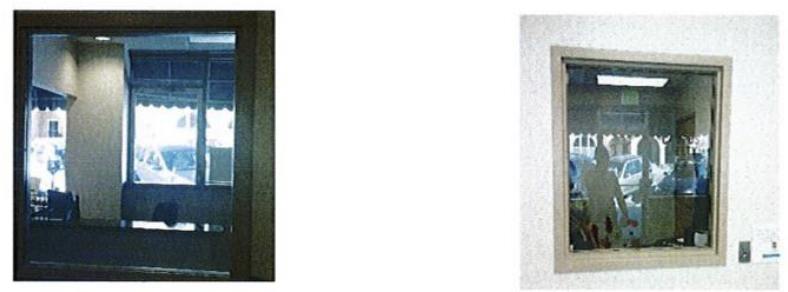

- Locker Rooms- There have been many requests that locks be installed on the locker doors.

- Fire Safety- The contains fire extinguishers, but does not have any smoke detectors. An option to consider would be to install a few smoke detectors for added safety. 
Appendix F: Focus Group Flyer

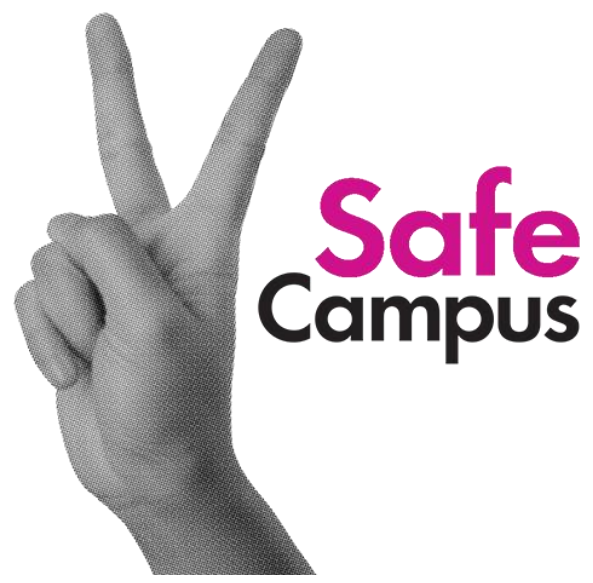

\title{
FOCUS GROUP - STUDENTS NEEDED! Your Voice Matters!
}

\section{Come join the conversation about your college campus safety}

\author{
DATE: Thursday, June 23rd \\ LOCATION: Worner 218 \\ TIME: 12:30 p.m. -2 p.m. \\ Food and Snacks will be provided \\ For More Information, Contact: \\ Auzeen Shariati \\ ashar028@fiu.edu \\ Phone: 305-397-9988
}

Auzeen Shariati is a $\mathrm{PhD}$ candidate of Criminal Justice at Florida International University who is conducting a qualitative field study in Colorado College. Discussion will focus on experiences and/or perceptions as it relates to safety and environmental design of CC campus.

Dissertation topic is: "the role of crime prevention through environmental design (CPTED) in improving campus safety". 
Appendix G: List of Sampled Institutions

\begin{tabular}{|c|c|c|c|c|c|c|}
\hline $\begin{array}{l}\text { School } \\
\text { Code }\end{array}$ & School Name & City & State & ZIP Code & Region & Division \\
\hline E00961 & Trinity Law School & Santa Ana & $\mathrm{CA}$ & 92705 & West & West-pacific \\
\hline G22249 & Stanford University & Stanford & $\mathrm{CA}$ & 94305 & West & West-pacific \\
\hline 001172 & Pitzer College & Claremont & $\mathrm{CA}$ & 91711 & West & West-pacific \\
\hline 001243 & $\begin{array}{l}\text { Mount St Mary's } \\
\text { University }\end{array}$ & Los Angeles & $\mathrm{CA}$ & 90049 & West & West-pacific \\
\hline 001325 & $\begin{array}{l}\text { University Of San } \\
\text { Francisco }\end{array}$ & $\begin{array}{l}\text { San } \\
\text { Francisco }\end{array}$ & $\mathrm{CA}$ & 94117 & West & West-pacific \\
\hline 010111 & \begin{tabular}{|l|} 
Cerro-Coso \\
Community College \\
\end{tabular} & Ridgecrest & $\mathrm{CA}$ & 93555 & West & West-pacific \\
\hline 015732 & $\begin{array}{l}\text { Life Chiropractic } \\
\text { College West } \\
\end{array}$ & Hayward & $\mathrm{CA}$ & 94545 & West & West-pacific \\
\hline 030113 & $\begin{array}{l}\text { Calif State } \\
\text { University, San } \\
\text { Marcos }\end{array}$ & San Marcos & $\mathrm{CA}$ & 92096 & West & West-pacific \\
\hline 035163 & $\begin{array}{l}\text { King's University } \\
\text { (The) }\end{array}$ & Van Nuys & $\mathrm{CA}$ & 91405 & West & West-pacific \\
\hline 041331 & $\begin{array}{l}\text { California University } \\
\text { Of Management And }\end{array}$ & Anaheim & $\mathrm{CA}$ & 92801 & West & West-pacific \\
\hline 042058 & $\begin{array}{l}\text { Sae Institute Of } \\
\text { Technology, Los } \\
\text { Angeles }\end{array}$ & Los Angeles & $\mathrm{CA}$ & 90028 & West & West-pacific \\
\hline 003203 & \begin{tabular}{|l|} 
Mount Angel \\
Seminary \\
\end{tabular} & St Benedict & OR & 97373 & West & West-Pacific \\
\hline G34664 & $\begin{array}{l}\text { Seattle School Of } \\
\text { Theology And } \\
\text { Psychology }\end{array}$ & Seattle & WA & 98121 & West & West-Pacific \\
\hline 12259 & $\begin{array}{l}\text { Bates Technical } \\
\text { College }\end{array}$ & Tacoma & WA & 98405 & West & West-Pacific \\
\hline 003681 & Westminster College & $\begin{array}{l}\text { Salt Lake } \\
\text { City }\end{array}$ & UT & 84105 & West & West-Mountain \\
\hline 041710 & $\begin{array}{l}\text { Advanced Training } \\
\text { Institute }\end{array}$ & Las Vegas & $\mathrm{NV}$ & 89115 & West & West-Mountain \\
\hline 015681 & Brookline College & Phoenix & $\mathrm{AZ}$ & 85021 & West & West-Mountain \\
\hline 042118 & $\begin{array}{l}\text { College Of Western } \\
\text { Idaho }\end{array}$ & Nampa & ID & 83687 & West & West-Mountain \\
\hline 001355 & $\begin{array}{l}\text { Lamar Community } \\
\text { College }\end{array}$ & Lamar & $\mathrm{CO}$ & 81052 & West & West-Mountain \\
\hline 041277 & \begin{tabular}{|l|} 
American Sentinel \\
University \\
\end{tabular} & Aurora & $\mathrm{CO}$ & 80014 & West & West-Mountain \\
\hline 002991 & \begin{tabular}{|l|} 
Lake Region State \\
College \\
\end{tabular} & Devils Lake & ND & 58301 & $\begin{array}{l}\text { Mid- } \\
\text { West }\end{array}$ & $\begin{array}{l}\text { West-North- } \\
\text { Central }\end{array}$ \\
\hline 002551 & \begin{tabular}{|l} 
University Of \\
Nebraska At Kearney
\end{tabular} & Kearney & $\mathrm{NE}$ & 68849 & $\begin{array}{l}\text { Mid- } \\
\text { West }\end{array}$ & $\begin{array}{l}\text { West-North- } \\
\text { Central }\end{array}$ \\
\hline 002343 & College Of St & Duluth & $\mathrm{MN}$ & 55811 & Mid- & West-North- \\
\hline
\end{tabular}




\begin{tabular}{|c|c|c|c|c|c|c|}
\hline & Scholastica & & & & West & Central \\
\hline 10248 & $\begin{array}{l}\text { Art Institutes Intl } \\
\text { Minnesota }\end{array}$ & Minneapolis & $\mathrm{MN}$ & 55402 & $\begin{array}{l}\text { Mid- } \\
\text { West }\end{array}$ & $\begin{array}{l}\text { West-North- } \\
\text { Central }\end{array}$ \\
\hline 001928 & $\begin{array}{l}\text { Kansas State } \\
\text { University }\end{array}$ & Manhattan & $\mathrm{KS}$ & 66506 & $\begin{array}{l}\text { Mid- } \\
\text { West }\end{array}$ & $\begin{array}{l}\text { West-North- } \\
\text { Central }\end{array}$ \\
\hline 001859 & Dordt College & $\begin{array}{l}\text { Sioux } \\
\text { Center }\end{array}$ & IA & 51250 & $\begin{array}{l}\text { Mid- } \\
\text { West }\end{array}$ & $\begin{array}{l}\text { West-North- } \\
\text { Central }\end{array}$ \\
\hline 015616 & $\begin{array}{l}\text { Des Moines } \\
\text { University } \\
\text { Osteopathic Med } \\
\text { Center }\end{array}$ & Des Moines & IA & 50312 & $\begin{array}{l}\text { Mid- } \\
\text { West }\end{array}$ & $\begin{array}{l}\text { West-North- } \\
\text { Central }\end{array}$ \\
\hline 002479 & Lincoln University & $\begin{array}{l}\text { Jefferson } \\
\text { City }\end{array}$ & MO & 65101 & $\begin{array}{l}\text { Mid- } \\
\text { West }\end{array}$ & $\begin{array}{l}\text { West-North- } \\
\text { Central }\end{array}$ \\
\hline 013208 & Baptist Bible College & Springfield & $\mathrm{MO}$ & 65803 & $\begin{array}{l}\text { Mid- } \\
\text { West }\end{array}$ & $\begin{array}{l}\text { West-North- } \\
\text { Central }\end{array}$ \\
\hline G01712 & $\begin{array}{l}\text { Lutheran School Of } \\
\text { Theology At Chicago }\end{array}$ & Chicago & IL & 60615 & $\begin{array}{l}\text { Mid- } \\
\text { West }\end{array}$ & $\begin{array}{l}\text { East-North- } \\
\text { Central }\end{array}$ \\
\hline 001704 & Knox College & Galesburg & IL & 61401 & $\begin{array}{l}\text { Mid- } \\
\text { West }\end{array}$ & $\begin{array}{l}\text { East-North- } \\
\text { Central }\end{array}$ \\
\hline 006385 & $\begin{array}{l}\text { Chamberlain College } \\
\text { Of Nursing }\end{array}$ & Addison & IL & 60101 & $\begin{array}{l}\text { Mid- } \\
\text { West }\end{array}$ & $\begin{array}{l}\text { East-North- } \\
\text { Central }\end{array}$ \\
\hline 022141 & $\begin{array}{l}\text { Resurrection } \\
\text { University }\end{array}$ & Chicago & IL & 60302 & $\begin{array}{l}\text { Mid- } \\
\text { West }\end{array}$ & $\begin{array}{l}\text { East-North- } \\
\text { Central }\end{array}$ \\
\hline G20876 & $\begin{array}{l}\text { Concordia } \\
\text { Theological } \\
\text { Seminary }\end{array}$ & Fort Wayne & IN & 46825 & $\begin{array}{l}\text { Mid- } \\
\text { West }\end{array}$ & $\begin{array}{l}\text { East-North- } \\
\text { Central }\end{array}$ \\
\hline 010489 & $\begin{array}{l}\text { American National } \\
\text { University }\end{array}$ & Indianapolis & IN & 46250 & $\begin{array}{l}\text { Mid- } \\
\text { West }\end{array}$ & $\begin{array}{l}\text { East-North- } \\
\text { Central }\end{array}$ \\
\hline E02104 & $\begin{array}{l}\text { Career Quest } \\
\text { Learning Center - } \\
\text { Kalamazoo } \\
\end{array}$ & Kalamazoo & MI & 49002 & $\begin{array}{l}\text { Mid- } \\
\text { West }\end{array}$ & $\begin{array}{l}\text { East-North- } \\
\text { Central }\end{array}$ \\
\hline 002304 & $\begin{array}{l}\text { Oakland Community } \\
\text { College - Auburn } \\
\text { Hills }\end{array}$ & $\begin{array}{l}\text { Auburn } \\
\text { Hills }\end{array}$ & MI & 48323 & $\begin{array}{l}\text { Mid- } \\
\text { West }\end{array}$ & $\begin{array}{l}\text { East-North- } \\
\text { Central }\end{array}$ \\
\hline 035883 & $\begin{array}{l}\text { Irene's } \\
\text { Myomassology } \\
\text { Institute } \\
\end{array}$ & Southfield & MI & 48033 & $\begin{array}{l}\text { Mid- } \\
\text { West }\end{array}$ & $\begin{array}{l}\text { East-North- } \\
\text { Central }\end{array}$ \\
\hline 003026 & $\begin{array}{l}\text { Central State } \\
\text { University }\end{array}$ & Wilberforce & $\mathrm{OH}$ & 45384 & $\begin{array}{l}\text { Mid- } \\
\text { West }\end{array}$ & $\begin{array}{l}\text { East-North- } \\
\text { Central }\end{array}$ \\
\hline 003127 & $\begin{array}{l}\text { University Of } \\
\text { Dayton }\end{array}$ & Dayton & $\mathrm{OH}$ & 45469 & $\begin{array}{l}\text { Mid- } \\
\text { West }\end{array}$ & $\begin{array}{l}\text { East-North- } \\
\text { Central }\end{array}$ \\
\hline 012891 & Antonelli College & Cincinnati & $\mathrm{OH}$ & 45202 & $\begin{array}{l}\text { Mid- } \\
\text { West }\end{array}$ & $\begin{array}{l}\text { East-North- } \\
\text { Central }\end{array}$ \\
\hline 026038 & $\begin{array}{l}\text { Lorain County Jvs } \\
\text { Adult Career Center }\end{array}$ & Oberlin & $\mathrm{OH}$ & 44074 & $\begin{array}{l}\text { Mid- } \\
\text { West }\end{array}$ & $\begin{array}{l}\text { East-North- } \\
\text { Central }\end{array}$ \\
\hline 003832 & Alverno College & Milwaukee & WI & 53234 & $\begin{array}{l}\text { Mid- } \\
\text { West }\end{array}$ & $\begin{array}{l}\text { East-North- } \\
\text { Central }\end{array}$ \\
\hline 005387 & Northcentral & Wausau & WI & 54401 & Mid- & East-North- \\
\hline
\end{tabular}




\begin{tabular}{|c|c|c|c|c|c|c|}
\hline & Technical College & & & & West & Central \\
\hline G02783 & $\begin{array}{l}\text { New York Law } \\
\text { School }\end{array}$ & New York & NY & 10013 & $\begin{array}{l}\text { North- } \\
\text { East }\end{array}$ & Middle-Atlantic \\
\hline 002728 & Hamilton College & Clinton & NY & 13323 & $\begin{array}{l}\text { North- } \\
\text { East }\end{array}$ & Middle-Atlantic \\
\hline 002841 & Suny Brockport & Brockport & NY & 14420 & $\begin{array}{l}\text { North- } \\
\text { East }\end{array}$ & Middle-Atlantic \\
\hline 004765 & $\begin{array}{l}\text { Cuny Graduate } \\
\text { School \& University } \\
\text { Center }\end{array}$ & New York & NY & 10016 & $\begin{array}{l}\text { North- } \\
\text { East }\end{array}$ & Middle-Atlantic \\
\hline 010286 & Empire State College & $\begin{array}{l}\text { Saratoga } \\
\text { Springs }\end{array}$ & NY & 12866 & $\begin{array}{l}\text { North- } \\
\text { East }\end{array}$ & Middle-Atlantic \\
\hline 014662 & Bramson Ort College & Forest Hills & NY & 11375 & $\begin{array}{l}\text { North- } \\
\text { East }\end{array}$ & Middle-Atlantic \\
\hline 031207 & $\begin{array}{l}\text { New York } \\
\text { Conservatory For } \\
\text { Dramatic Arts }\end{array}$ & New York & NY & 10011 & $\begin{array}{l}\text { North- } \\
\text { East }\end{array}$ & Middle-Atlantic \\
\hline 042134 & Access Careers & Hempstead & NY & 11550 & $\begin{array}{l}\text { North- } \\
\text { East }\end{array}$ & Middle-Atlantic \\
\hline 004736 & $\begin{array}{l}\text { Bergen Community } \\
\text { College }\end{array}$ & Paramus & NJ & 07652 & $\begin{array}{l}\text { North- } \\
\text { East }\end{array}$ & Middle-Atlantic \\
\hline 038033 & $\begin{array}{l}\text { Healthcare Training } \\
\text { Institute }\end{array}$ & Union & NJ & 07083 & $\begin{array}{l}\text { North- } \\
\text { East }\end{array}$ & Middle-Atlantic \\
\hline G30908 & $\begin{array}{l}\text { Lake Erie College Of } \\
\text { Osteopathic Med }\end{array}$ & Erie & PA & 16509 & $\begin{array}{l}\text { North- } \\
\text { East }\end{array}$ & Middle-Atlantic \\
\hline 003298 & Messiah College & $\begin{array}{l}\text { Mechanicsb } \\
\text { urg }\end{array}$ & PA & 17055 & $\begin{array}{l}\text { North- } \\
\text { East }\end{array}$ & Middle-Atlantic \\
\hline 004890 & Central Penn College & Summerdale & PA & 17093 & $\begin{array}{l}\text { North- } \\
\text { East }\end{array}$ & Middle-Atlantic \\
\hline 013263 & $\begin{array}{l}\text { South Hills School } \\
\text { Of Business \& } \\
\text { Technology }\end{array}$ & $\begin{array}{l}\text { State } \\
\text { College }\end{array}$ & PA & 16801 & $\begin{array}{l}\text { North- } \\
\text { East }\end{array}$ & Middle-Atlantic \\
\hline 017034 & $\begin{array}{l}\text { Commonwealth Tech } \\
\text { Institute at Hiram G }\end{array}$ & Johnstown & PA & 15905 & $\begin{array}{l}\text { North- } \\
\text { East }\end{array}$ & Middle-Atlantic \\
\hline 008038 & $\begin{array}{l}\text { Middlesex } \\
\text { Community College }\end{array}$ & Middletown & $\mathrm{CT}$ & 06457 & $\begin{array}{l}\text { North- } \\
\text { East }\end{array}$ & New-England \\
\hline G09756 & $\begin{array}{l}\text { University Of Mass } \\
\text { Medical Center }\end{array}$ & Worcester & MA & 01655 & $\begin{array}{l}\text { North- } \\
\text { East }\end{array}$ & New-England \\
\hline 002188 & $\begin{array}{l}\text { Salem State } \\
\text { University }\end{array}$ & Salem & MA & 01970 & $\begin{array}{l}\text { North- } \\
\text { East }\end{array}$ & New-England \\
\hline 015648 & $\begin{array}{l}\text { Hallmark Institute Of } \\
\text { Photography }\end{array}$ & $\begin{array}{l}\text { Turners } \\
\text { Falls }\end{array}$ & MA & 01376 & $\begin{array}{l}\text { North- } \\
\text { East }\end{array}$ & New-England \\
\hline 031229 & $\begin{array}{l}\text { York County } \\
\text { Community College }\end{array}$ & Wells & $\mathrm{ME}$ & 04090 & $\begin{array}{l}\text { North- } \\
\text { East }\end{array}$ & New-England \\
\hline 003690 & Marlboro College & Marlboro & VT & 05344 & $\begin{array}{l}\text { North- } \\
\text { East }\end{array}$ & New-England \\
\hline 011727 & $\begin{array}{l}\text { Delaware Technical } \\
\text { Community College }\end{array}$ & Dover & $\mathrm{DE}$ & 19901 & South & South-Atlantic \\
\hline
\end{tabular}




\begin{tabular}{|c|c|c|c|c|c|c|}
\hline E02088 & $\begin{array}{l}\text { Ata College-Ata } \\
\text { Career Education }\end{array}$ & Spring Hill & FL & 34606 & South & South-Atlantic \\
\hline 001519 & Santa Fe College & Gainesville & FL & 32606 & South & South-Atlantic \\
\hline 014016 & $\begin{array}{l}\text { Concorde Career } \\
\text { Institute }\end{array}$ & Jacksonville & FL & 32211 & South & South-Atlantic \\
\hline 030358 & Heritage Institute & Jacksonville & $\mathrm{FL}$ & 32216 & South & South-Atlantic \\
\hline 039035 & $\begin{array}{l}\text { Southern Technical } \\
\text { College }\end{array}$ & Orlando & FL & 32809 & South & South-Atlantic \\
\hline E00947 & $\begin{array}{l}\text { (United Education } \\
\text { Institute) - Uei Morro }\end{array}$ & Morrow & GA & 30260 & South & South-Atlantic \\
\hline 001586 & $\begin{array}{l}\text { Oglethorpe } \\
\text { University }\end{array}$ & Atlanta & GA & 30319 & South & South-Atlantic \\
\hline 016139 & $\begin{array}{l}\text { Gwinnett Technical } \\
\text { College }\end{array}$ & $\begin{array}{l}\text { Lawrencevil } \\
\text { le }\end{array}$ & GA & 30043 & South & South-Atlantic \\
\hline 002073 & Goucher College & Baltimore & MD & 21204 & South & South-Atlantic \\
\hline E00160 & Duke University & Durham & $\mathrm{NC}$ & 27708 & South & South-Atlantic \\
\hline 002936 & $\begin{array}{l}\text { Johnson C Smith } \\
\text { University }\end{array}$ & Charlotte & $\mathrm{NC}$ & 28216 & South & South-Atlantic \\
\hline 005463 & $\begin{array}{l}\text { Alamance } \\
\text { Community College }\end{array}$ & Graham & $\mathrm{NC}$ & 27253 & South & South-Atlantic \\
\hline 041435 & $\begin{array}{l}\text { Charlotte School Of } \\
\text { Law }\end{array}$ & Charlotte & $\mathrm{NC}$ & 28208 & South & South-Atlantic \\
\hline 003456 & Winthrop University & Rock Hill & $\mathrm{SC}$ & 29733 & South & South-Atlantic \\
\hline G42186 & $\begin{array}{l}\text { Virginia Tech } \\
\text { Carilion School Of } \\
\text { Medicine }\end{array}$ & Roanoke & VA & 24016 & South & South-Atlantic \\
\hline 006819 & $\begin{array}{l}\text { Blue Ridge } \\
\text { Community College }\end{array}$ & $\begin{array}{l}\text { Weyers } \\
\text { Cave }\end{array}$ & VA & 24486 & South & South-Atlantic \\
\hline 042210 & $\begin{array}{l}\text { Standard Healthcare } \\
\text { Services, College Of }\end{array}$ & Falls Church & VA & 22046 & South & South-Atlantic \\
\hline 026094 & Valley College & Martinsburg & WV & 25404 & South & South-Atlantic \\
\hline E00956 & $\begin{array}{l}\text { Vatterott College - } \\
\text { Memphis }\end{array}$ & Memphis & $\mathrm{TN}$ & 38132 & South & $\begin{array}{l}\text { East-South- } \\
\text { Central }\end{array}$ \\
\hline 003999 & $\begin{array}{l}\text { Cleveland State } \\
\text { Community College }\end{array}$ & Cleveland & $\mathrm{TN}$ & 37312 & South & $\begin{array}{l}\text { East-South- } \\
\text { Central }\end{array}$ \\
\hline 015575 & $\begin{array}{l}\text { Chattanooga College } \\
\text { - Medical, Dental An }\end{array}$ & Chattanooga & $\mathrm{TN}$ & 37411 & South & $\begin{array}{l}\text { East-South- } \\
\text { Central }\end{array}$ \\
\hline 002447 & $\begin{array}{l}\text { William Carey } \\
\text { University }\end{array}$ & Hattiesburg & MS & 39401 & South & $\begin{array}{l}\text { East-South- } \\
\text { Central }\end{array}$ \\
\hline 001996 & $\begin{array}{l}\text { Big Sandy } \\
\text { Community And } \\
\text { Technical College }\end{array}$ & $\begin{array}{l}\text { Prestonsbur } \\
\mathrm{g}\end{array}$ & KY & 41653 & South & $\begin{array}{l}\text { East-South- } \\
\text { Central }\end{array}$ \\
\hline 001022 & $\begin{array}{l}\text { Jefferson State } \\
\text { Community College }\end{array}$ & Birmingham & $\mathrm{AL}$ & 35215 & South & $\begin{array}{l}\text { East-South- } \\
\text { Central }\end{array}$ \\
\hline 001108 & $\begin{array}{l}\text { University of } \\
\text { Arkansas Fayetteville }\end{array}$ & Fayetteville & AR & 72701 & South & $\begin{array}{l}\text { West-South- } \\
\text { Central }\end{array}$ \\
\hline 002021 & $\begin{array}{l}\text { Northwestern State } \\
\text { University }\end{array}$ & $\begin{array}{l}\text { Natchitoche } \\
\mathrm{s}\end{array}$ & LA & 71457 & South & $\begin{array}{l}\text { West-South- } \\
\text { Central }\end{array}$ \\
\hline
\end{tabular}




\begin{tabular}{|c|c|c|c|c|c|c|}
\hline 037303 & $\begin{array}{l}\text { Baton Rouge } \\
\text { Community College }\end{array}$ & $\begin{array}{l}\text { Baton } \\
\text { Rouge }\end{array}$ & LA & 70806 & South & $\begin{array}{l}\text { West-South- } \\
\text { Central }\end{array}$ \\
\hline 005889 & $\begin{array}{l}\text { University Of } \\
\text { Oklahoma-Health } \\
\text { Science Center }\end{array}$ & $\begin{array}{l}\text { Oklahoma } \\
\text { City }\end{array}$ & $\mathrm{OK}$ & 73190 & South & $\begin{array}{l}\text { West-South- } \\
\text { Central }\end{array}$ \\
\hline B42154 & $\begin{array}{l}\text { Grace School Of } \\
\text { Theology }\end{array}$ & Woodlands & $\mathrm{TX}$ & 77384 & South & $\begin{array}{l}\text { West-South- } \\
\text { Central }\end{array}$ \\
\hline G04977 & $\begin{array}{l}\text { South Texas College } \\
\text { Of Law }\end{array}$ & Houston & TX & 77002 & South & $\begin{array}{l}\text { West-South- } \\
\text { Central }\end{array}$ \\
\hline 003607 & $\begin{array}{l}\text { Alamo Community } \\
\text { College District } \\
\text { Program }\end{array}$ & San Antonio & $\mathrm{TX}$ & 78207 & South & $\begin{array}{l}\text { West-South- } \\
\text { Central }\end{array}$ \\
\hline 008353 & $\begin{array}{l}\text { Lincoln College Of } \\
\text { Technology - Grand } \\
\text { Program }\end{array}$ & $\begin{array}{l}\text { Grand } \\
\text { Prairie }\end{array}$ & $\mathrm{TX}$ & 75052 & South & $\begin{array}{l}\text { West-South- } \\
\text { Central }\end{array}$ \\
\hline 016396 & $\begin{array}{l}\text { Northeast Texas } \\
\text { Community College }\end{array}$ & $\begin{array}{l}\text { Mount } \\
\text { Pleasant }\end{array}$ & $\mathrm{TX}$ & 75455 & South & $\begin{array}{l}\text { West-South- } \\
\text { Central }\end{array}$ \\
\hline 036124 & $\begin{array}{l}\text { Valley Grande } \\
\text { Institute For } \\
\text { Academic Studies }\end{array}$ & Weslaco & $\mathrm{TX}$ & 78596 & South & $\begin{array}{l}\text { West-South- } \\
\text { Central }\end{array}$ \\
\hline
\end{tabular}


VITA

\section{AUZEEN SHARIATI}

Born, Tehran, Iran

2006

BA Judicial Law

University of Tehran

Tehran, Iran

2010

MA Criminal Law and Criminology

Allameh Tabataba'I University

Tehran, Iran

2015

ACJS Doctoral Student Scholarship

2016

GSAW (FIU) Best Paper Award

2016

Dissertation Evidence Acquisition Fellowship

2016

Morris and Anita Board Fellowship

2017

Dissertation Year Fellowship

2017

Ph.D. Public Affairs

Criminal Justice Track

Florida International University

Miami, Florida

\section{PUBLICATIONS}

Guerette, R.T., Pires, S. F., Shariati, A. (2016), A Case Control Study of Kidnapping for Ransom Epidemics, Studies in Conflict and Terrorism.

Guerette, R.T., Pires, S. F., Shariati, A. (2017), Further Evidence on Rational Choice and Reasoning in Offending: Determinants and Trajectories of Death among Ransom Kidnappings, Journal of Quantitative Criminology.

Shariati, A., Guerette, R.T. (2017), Situational Crime Prevention, Advances in Crime Prevention Sciences Series, Springer Press. 